\title{
Smoking prevention and cessation among adolescents in South Africa
}

Citation for published version (APA):

Panday, S. (2005). Smoking prevention and cessation among adolescents in South Africa. [Doctoral Thesis, Maastricht University]. Maastricht University. https://doi.org/10.26481/dis.20050414sp

Document status and date:

Published: 01/01/2005

DOI:

10.26481/dis.20050414sp

Document Version:

Publisher's PDF, also known as Version of record

\section{Please check the document version of this publication:}

- A submitted manuscript is the version of the article upon submission and before peer-review. There can be important differences between the submitted version and the official published version of record.

People interested in the research are advised to contact the author for the final version of the publication, or visit the DOI to the publisher's website.

- The final author version and the galley proof are versions of the publication after peer review.

- The final published version features the final layout of the paper including the volume, issue and page numbers.

Link to publication

\footnotetext{
General rights rights.

- You may freely distribute the URL identifying the publication in the public portal. please follow below link for the End User Agreement:

www.umlib.nl/taverne-license

Take down policy

If you believe that this document breaches copyright please contact us at:

repository@maastrichtuniversity.nl

providing details and we will investigate your claim.
}

Copyright and moral rights for the publications made accessible in the public portal are retained by the authors and/or other copyright owners and it is a condition of accessing publications that users recognise and abide by the legal requirements associated with these

- Users may download and print one copy of any publication from the public portal for the purpose of private study or research.

- You may not further distribute the material or use it for any profit-making activity or commercial gain

If the publication is distributed under the terms of Article $25 \mathrm{fa}$ of the Dutch Copyright Act, indicated by the "Taverne" license above, 
Smoking prevention \& cessation among adolescents in South Africa 


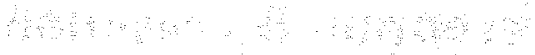

$$
\begin{aligned}
& \text { a d a } \\
& \text { 2. }
\end{aligned}
$$




\section{Smoking prevention \& cessation among adolescents in South Africa}

\section{DISSERTATION}

To obtain the degree of Doctor at the Universiteit Maastricht, on the authority of the Rector Magnificus,

Prof.dr. G.P.M.F. Mols,

in accordance with the decision of the Board of Deans,

to be defended in public on

Thursday 14 April 2005 ,

at 14 h00 hours

by 


\section{Promotores:}

Prof dr. H. de Vries

Prof. dr. S. P. Reddy, Medical Research Council, South Africa

\section{Co-promotors:}

Dr. E. Bergström, Umeå University, Sweden

\section{Beoordelingscommissie:}

Prof. dr. N. K. de Vries (chairman)

Prof. dr. H. W. van den Borne

Prof. dr. R. Engels (Radboud Uniwersiteit Nijmegen)

Prof. dr. G. J, Kok

Dr. S. P. J. Kremers

ISBN: $0-620-33911-x$

Printed by: The Active Group Layout and cover design by: Muhdni Grimwood Cover linages: Cedric Numn and Guy Stubbs / africapictures.net

The studies presented in this thesis were conducted at and funded by the National Health Promotion Research and Development Group, Medicall Research Council, South Africa. 


\section{Contents}

Chapter 1

General Introduction

Chapter 2 page 31

A qualitative study on the determinants of smoking behaviour among adolescents in South Africa.

Chapter 3 page 43

The determinants of smoking among adolescents in South Africa.

Chapter 4 page 61

The determinants of smoking cessation among adolescents in South Africa.

Chapter 5 page 77

Nicotine dependence and withdrawal symptoms among adolescents in South Africa.

Chapter 6 page 91

Access point analysis. What do adolescents in South Africa say about tobacco control programmes?

Chapter 7 page 107

General Discussion

References page 124

Summary page 136

Samenvatting page 139

Acknowledgements page 141 


\section{Chapter 1}

General Introduction 


\section{Overview of South Africa}

South Africa (SA) is situated at the southern most tip of Africa. The country is divided into nine provinces namely Eastern Cape, Free State, Gauteng, KwaZuluNatal, Limpopo Province, Mpumalanga, Northern Cape, North West Province and Western Cape and has 11 official languages (see Figure 1.1). According to the population census of $2001,57.5 \%$ of South Africans live in urban areas while 42.5\% live in rural areas (Statistics South Africa and Census 2001, 2003). SA consists of a population of approximately 46.6 million citizens of whom $51 \%$ or 23.6 million are female (Statistics South Africa, 2004b). Children and adolescents (0-19 years of age) make up $43.5 \%$ or just over 20 million of the population (Statistics South Africa, 2004b). The majority of the population are Black African' (79.3\% or 37 million), 4.4 million (9.5\%) are White, 4.1 million $(8.8 \%)$ are Coloured and 1.11 million $(2.4 \%)$ are Indian (Statistics South Africa, 2004b). Classification according to race groups was used as an instrument of apartheid and its separatist policies and does not find its origin in science.

The history of race across the world is a painful one. America and SA are two poignant examples of the battle against racial injustice. The classification and differential treatment of people according to externally visible traits such as skin colour and hair type have been in the past re-inforced by science (Freeman, 2003). The research community at large has been slow and indecisive in providing guidance on studies of race or ethnic differences (Yee et al., 1993). In 1996, the American Association of Physical. Anthropologist stated that the biological concept of race has no place in anthropological or biological sciences (AAPA, 1996). In 1999. The Institutes of Medicine recommended that the National Institutes of Health make the conceptual shift from race, which focused on biological differences, to ethnic groups (Oppenheimer, 2001). While the switch from race to ethnicity is advocated, caution is advised not to lose the focus on poverty, social, economic, cultural and spatial differences as well as social injustices that have become synonymous with race and racism (Oppenheimer, 2001).

Race was used by the South African apartheid regime to discriminate and subjugate Black African, Coloured and Indian people. Despite the transition to a democratic political system in 1994, the effects of decades of highly skewed distribution of wealth, steep earning inequalities, low access to basic services and unemployment and underemployment are still prevalent (UNDPSA, 2003). In 2002 , it was estimated that $48.5 \%$ or 21.9 million of the $5 A$ population fell below the national poverty line (R354 per month) and that poverty and inequality continued to exhibit strong spatiall and racial biases (UNDPSA, 2003). For example, a labour force survey in March 2004 showed that the unemployment rate was highest among the Black African group (29.2\%) and lowest among the White group (3.8\%) (Statistics South Africa, 2004a). In July 2003, 99,6\% of the White

During the Apartheid years, all South Africans were classified into race groups in accordance with the Population Registration Act of 1950 namely. Black African (people of African descent), Coloured (people of mixed descent), Indian (people of Indian descent) and White (people of European descent). The authors in no way subscribe to this classification. 


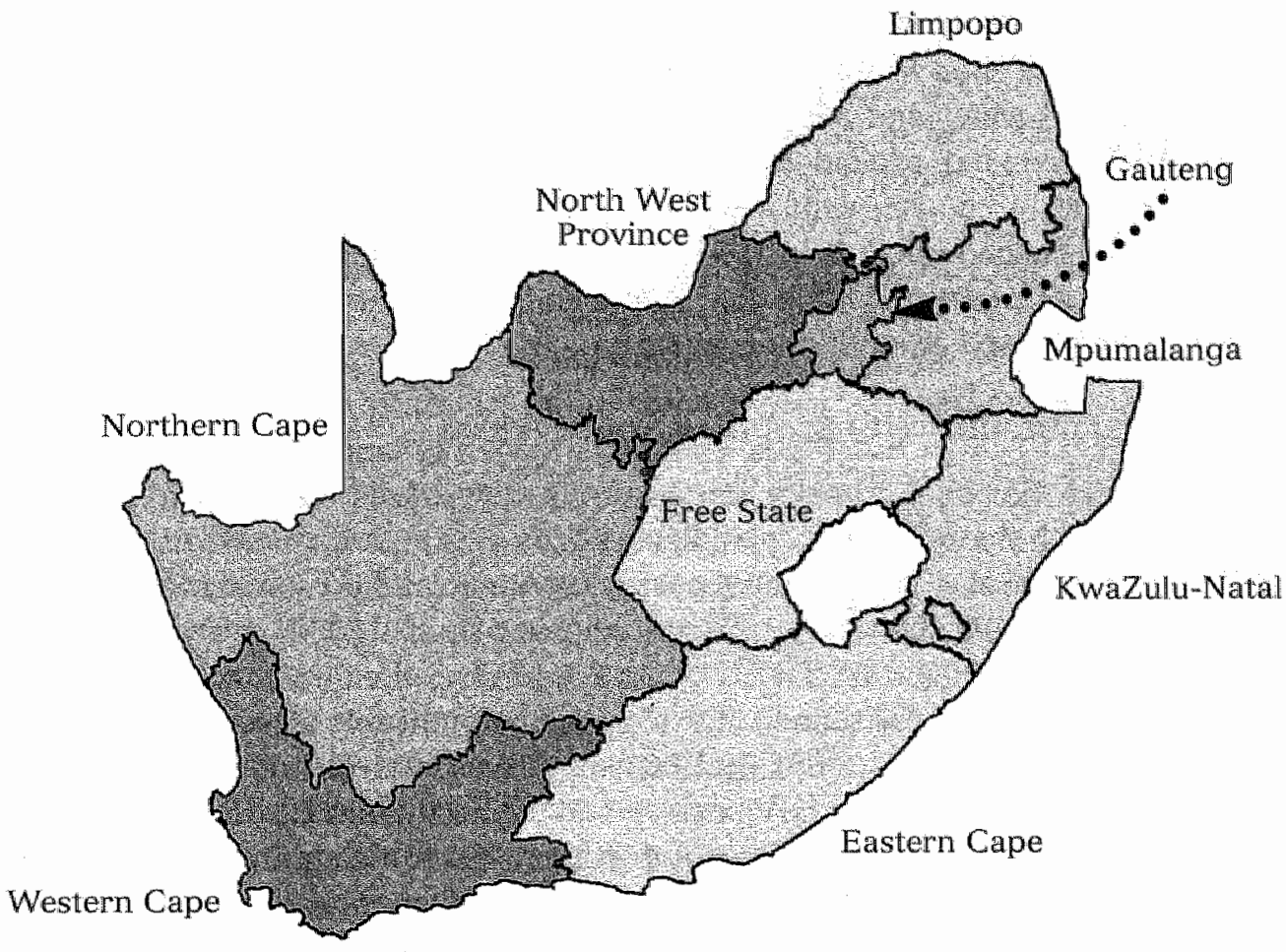

Figure 1.1 Map of South Africa

group lived in formal dwellings as opposed to $67.4 \%$ of the Black African group; $98.7 \%$ of households headed by other populations groups had access to clean water as opposed to $83.2 \%$ of Black African-headed households; $99.8 \%$ of Whiteheaded households had access to a hygienic toilet facility as opposed to $54.0 \%$ of Black African headed-households; $93.2 \%$ of other population groups had access to electricity for cooking as opposed to $48.9 \%$ of Black African-headed households; $93.3 \%$ of White-headed households had access to a telephone in their home as opposed to $37.3 \%$ of Black African-headed households and $65.2 \%$ of White-headed households had access to private health insurance as opposed to $8.0 \%$ of Black African-headed households (Statistics South Africa, 2003). Until such time that these disparities and injustices are addressed, the impact of ethnicity must be factored into research in SA, perhaps the only valid justification for studying such differences (Freeman, 2003).

Despite the persisting inequalities, tremendous change and progress has encompassed the lives of South Africans over the past 10 years. President Thabo Mbeki in his State of the Nation address of 2004 caplured some of these achievements (Mbeki, 2004). In 1994, five to seven million people were living in shacks or informal dwellings. By 2004, 1.9 million housing subsidies had been granted and 1.6 million houses had been built for the poor. In 1994, 60\% of households did not have access to electricity. By 2004, more than $70 \%$ of households had been electrified. Ten years ago, over half of the population did not 
have access to clean water ( 16 million) or adequate sanitation (22 million). Ten years later, more than 9 million additional people and $63 \%$ of households have access to clean water and adequate sanitation respectively. Over a period of 10 years, 19 fragmented education departments have given birth to an integrated education system coupled with a school nutrition programme. Secondary school enrolment has risen from $70 \%$ in 1994 to $85 \%$ in 2004 . Inflation has tumed around from twenty one years of double digit figures to 4 percent and the negative growth rate has been turned around to a positive growth rate.

\section{Morbidity and mortality profile of South Africa}

Historically in $S A$, public health interventions were based on mortality rates in accordance with the biomedical paradigm (Reddy et al., 2003). However, countries like SA that are in the midst of rapid social, economic and demographic transition have witnessed radical shifts in the mortality profile. In 2000 , thirty percent of deaths were attributed to HIV/AIDS, $21 \%$ to other communicable, maternal, perinatal and nutritional diseases, $37 \%$ to non-communicable diseases and $12 \%$ to injuries (Bradshaw et al., 2003). In 2004, it was estimated that 3.83 million or $15.2 \%$ of South Africans were HIV-positive and the accumulated AIDS deaths were reported at 1.49 million (Statistics South Africa, 2004b). Cardiovascular disease (16.6\%) and malignant neoplasms $(7.5 \%)$, for which a causal relationship with tobacco use is known (USDHHS, 2004), were among the leading causes of death (Bradshaw et al., 2003). Furthermore, low birth weight, respiratory infections, stroke, ischaemic heart disease, hypertensive heart disease, COPD and specifically lung cancer for males and cervical cancer for females, for which causal relationships also exist with tobacco use (USDHHS, 2004), featured in the top 20 specific causes of premature mortality (Bradshaw et al., 2003).

The contribution of both communicable and non-communicable diseases towards premature mortality in SA (Bradshaw et al., 2003) necessitated a paradigm shift in the public health approach. An understanding of the determinants of behaviour that result in morbidity, which often precedes mortality by several decades, will allow for timely intervention and perhaps circumvent premature mortality. Tobacco use provides an apt example of the 15-25 year time lag between smoking and the manifestation of morbidity such as lung cancer and cardiovascular disease.

The adoption of risk behaviours can be often traced to the period of adolescence. The first National Youth Risk Behaviour Survey of 2002 is a reflection of the mortality pattern in SA (Reddy et al., 2003). Students reported being bullied (41\%), carrying weapons (17\%), forced to have sex (10\%), attempting suicide (17\%), using alcohol $(32 \%)$, tobacco ( $21 \%)$ and marijuana $(13 \%)$, having sex $(41 \%)$, low rates of condom use (29\%) under nutrition (stunting (11\%), underweight (9\%) and wasting $(4 \%)$ ), over nutrition (overweight (17\%) and obesity (4\%)) and being physically inactive $(37.5 \%$ ) (Reddy et al., 2003). The data speaks to the need for timely interventions. 


\section{A global perspective on tobacco use}

The adoption of the Framework Convention on Tobacco Control (FCTC) by the World Health Assembly in 2003 is a landmark event in the history of tobacco control. It recognised the sheer magnitude of the health impact of tobacco use and unequivocally declared its commitment to drastically reduce the harmful effects of the single most preventable cause of morbidity and mortality. Countries that ratify this first international treaty on tobacco control will be legally bound to restrict tobacco advertising. sponsorship and promotion, establish new packaging and labelling of tobacco products, institute clean indoor air policies, and strengthen legislation to reduce tobacco smuggling (WHO, 2003).

In 2002, the World Health Organisation rated tobacco use after under-nutrition as the second most important cause of the Global Burden of Disease (WHO, 2002). Tobacco use is responsible for 4.9 million deaths each year and is expected to kill 10 million people by 2030 to become the single largest health problem (Murray and Lopez, 1997). In the EU alone tobacco use kills 540000 people each year while in the US tobacco kills 461000 people each year (Peto et al., 1994). It is estimated that $8 \%$ or 21500 of all deaths each year in SA are attributable to tobacco use (Sitas et al., 2004).

The 2004 US Surgeon General's Report focused on the health effects of active smoking and concluded that (1) smoking damages almost every organ of the body, causing multiple diseases and reducing the overall health of smokers; (2) quitting smoking has immediate as well as long-term benefits by reducing risks for diseases caused by smoking and improves health in general; (3) smoking cigarettes with lower tar and nicotine content provide no clear benefit to health and (4) the list of diseases for which a causal relationship with smoking has been expanded to include abdominal aortic aneurysm, acute myeloid leukemia, cataract, cervical cancer, kidney cancer, pancreatic cancer, pneumonia, periodontitis and stomach cancer (USDHHS, 2004).

On average, lifelong smokers loose between twenty and twenty five years of life (World Bank, 1999) and die at the peak of their economically productive years (35-69 years). The economic consequences of tobacco use are at minimum twofold, namely lost productivity due to morbidity and premature mortality and the cost of treatment. In 1994, it was estimated that tobacco use caused a net loss of LS $\$ 200$ billion to the global economy. In that same year in SA, the direct cost of hospitalisation and outpatient treatment for smoking-related diseases in the public sector alone was 1,5 billion Rand or US\$251 million (Yach, 1995). The triple burden of disease in SA (Bradshaw et al., 2003) coupled with a substantial and growing HIV/AIDS epidemic places significant constraints on the health system. The need to curb tobacco-related morbidity and mortality is indisputable.

Globalisation that is credited for rapid economic transformation, the collapse of time and space through electronic communication, the development of a global cosmopolitan culture and transnational social and political movements has also proliferated the liberalisation and penetration of negative influences such as 
tobacco use (Yach and Bettcher, 2000). The migration of smoking in developed countries from men to women was accompanied by concomitant gender-specific tobacco marketing campaigns (Pierce and Gilpin, 1995). However, public awareness of the health effects of smoking, and increased lobbying and legislative control against tobacco use resulted in a decline in smoking in the US and Western Europe (Mackay, 1994; Peto et al., 1992; Yach, 1986). To compensate for the dwindling revenue from western markets, the tobacco industry turned to developing countries where lack of legislative control on tobacco use and existing trade agreements were used to access these foreign markets and grow tobacco sales (Honjo and Kawachi, 2000; Mackay, 1997). Approximately 800 million people in developing countries smoke and this number is increasing. Furthermore, it is projected that $70 \%$ of future deaths from tobacco will occur in developing countries (Murray and Lopez, 1997).

\section{History of tobacco control legislation in South Africa}

South Africa's history of tobacco control legislation dates back to the 1970 s when tobacco use was banned in cinemas and domestic flights (Swart and Reddy, 1998). However, the cordial relationship between the apartheid government and the tobacco industry tempered the introduction of tobacco control legislation in SA (van Walbeek, 2003). The formation of the Tobacco Action Group in 1991, whose partners included the National Council Against Smoking, the Cancer Association of South Africa and the Heart Foundation of Southern Africa, raised awareness on the health effects of smoking but their efforts were limited in their reach (Reddy, 1999b; Reddy, 2001). As time passed, more groups such as the South African Medical Research Council joined the coalition (Reddy, 1999b; Reddy, 2001). With the change in government imminent, Nelson Mandela issued a statement on World No Tobacco Day, in 1992, declaring the future government's commitment to tobacco control legislation in SA for which he was awarded a WHO Medal in 1995 (Reddy, 1999b; Reddy, 2001).

\section{Tobacco Products Control Act of 1993}

As the apartheid regime reached its end, in 1993, it passed the first Tobacco Products Control Act (1993) that was eventually implemented in 1995. The Act regulated smoking in public places, prohibited the sale of cigarettes to children below 16 years of age and regulated some aspects of tobacco products' advertising. However, the act was no where close to comprehensive as a complete ban of smoking in public places was not instituted, the definition of public places did not include the workplace, the definition of advertising did not include radio advertising which was the medium that was used by majority of the population, and mechanisms were not established to enforce the legislation (Reddy, 1999b; Reddy, 2001). As a trade-off the government made provisions for the introduction of health warnings which came into effect in 1995. However, the tobacco industry used various techniques to thwart the intent of health warnings by among others failing to meet regulations regarding the size of the warnings (Reddy, 2001). 


\section{Tobacco Products Control Amendment Act of 1999}

The 1990 s saw a concerted effort by the research community in SA to highlight the extent of tobacco use in the country and weigh the public's support for such legislation. The tobacco industry, supported by the hospitality industry, was equally vocal about the public's right to freedom of choice. What ensued was a public debate in the media on the pros and cons of introducing comprehensive tobacco control legislation. The positive spin offs were inevitable in creating both awareness of the detrimental effects of smoking and, more importantly, in shifting social norms against smoking. Studies conducted in 1995 (Reddy et al., 1996) and 1996 (Reddy et al. 1998) reported that $34 \%$ of adult South Aricans smoked. By 1998 this number had dropped to 25\% (DOH et al., 2002; Meyer Weitz et al., 2000).

The comprehensive Tobacco Products Control Amendment Act that was promulgated in 1999 (1999) banned all advertising and promotion of tobacco products including sponsorship and free distribution, restricted smoking in public places including work places and public transport, stipulated penalties for transgression of the law and specified the maximum permissible levels of tar and nicotine. The regulations of the Act were implemented in 2001 ("Tobacco Products Amendment Act, 1999 Regulations", 1999).

\section{Excise taxes}

The government's plan to tackle tobacco use was multi-faceted, for concomitantly with introducing tougher legislative control, it consistently increased the tax on tobacco products. As early as June 1994, the Minister of Finance announced his intention to increase the tax on tobacco products to $50 \%$ of the retail price (van Walbeek, 2003). This target was achieved in 1997 . The result was a $40 \%$ decrease in cigarette consumption as people gave up smoking. It is also estimated that the average cigarette consumption per smoker has decreased by 20 percent in the last decade (van Walbeek, 2003). The reduction in cigarette consumption has been greatest among the poor, namely low-income earners, the Black African population, males and the youth in particular (van Walbeek, 2003). This was achieved despite tobacco advertising campaigns directed at the emerging Black African middle class in the mid 1990s (van Walbeek, 2003).

\section{Tobacco Products Control Amendment Bill 2003}

Consequently, SA is regarded as a world leader on tobacco control. In recognition of their sterling efforts to introduce comprehensive tobacco control legislation, the South African government was awarded a medal of honour at the 11 th World Conference on Tobacco or Health held in Chicago in 2000. In fact, examples of their efforts to control tobacco use were used as supporting material at the World Health Assembly in 2003 during the adoption of the FCTC (Swart and Panday, 2003; van Walbeek, 2003).

As a signatory to the FCTC, SA is in the process of further strengthening its tobacco control legislation. These changes include restrictions on smoking in outdoor public places where persons congregate within close proximity to one 
another, emphasis on the prohibition of indirect advertising including the sponsorship of programmes, projects, bursaries and scholarships, removal of tobacco products from the general view of the public at the point of sale, prohibition on the use of words such as 'light' and 'low tar", increase in the age of sale to minors from 16 to 18 years of age and increases in the penalties for transgressing the law ("Tobacco Products Control Amendment Bill", 2003).

\section{Smoking among adolescents}

The tobacco industry has not only targeted developing countries to grow their market sales but has also focused on the youth as an 'untouched market'. Despite their denial thereof, the use of cartoon characters for advertising, free entrance to disco's in exchange for empty cigarette packets, increased cinema advertising and aggressive sponsorship of sporting and cultural events spoke volumes of their new target market (Davis, 1986; Reddy, 1997). Advertising has glamourised tobacco use to represent success, independence and a Western value system whose allure has been hard to resist for adolescents during their search for identity. In fact, studies have shown that tobacco advertising and promotion makes adolescents vulnerable to start smoking (Lovato et al., 2003) and progress onto regular smoking (Choi et al, 2002). With the advent of global control measures such as the FCTC, the tobacco industry is finding alternative ways to overcome bans on advertising and promotion. Movie stars who smoke have been shown to encourage female adolescents to start to smoke (Distefan et al., 2004). Despite a comprehensive advertising ban, 50\% of Norwegian adolescents (Braverman and Aaro, 2004) and over two thirds of South African adolescents (Swart et al., 2004) reported exposure to tobacco marketing. What is more, minors seem to have easy access to cigarettes purchased via the Internet (Ribisl et al, 2003).

The global increase in adolescent smoking rates in the 1990s and the Surgeon General's Report on Preventing Tobacco Use among Young People in 1994 (LISDHHS, 1994) provided impetus to the international focus on adolescent smoking and resulted in smoking being labelled a paediatric disease or epidemic (Kessler, 1995; Perry et al., 1994). In SA, the findings of the first Global Youth Tobacco Survey (GYTS) (Swart et al., 2003) were used by the National Department of Education to include tobacco as an addictive drug in their policy on the management of drug abuse in schools (National Drug Policy, 2002). If left unchecked, tobacco use will be responsible for the deaths of 250 million young people alive, the majority of whom live in developing countries (Peto et al., 1994).

The GYTS estimated that worldwide, ever smoking and current or monthly smoking averaged at $33.0 \%$ and $18.7 \%$ respectively and peaked at $79.8 \%$ and $39.6 \%$ respectively (The GYTS Collaborative Group, 2002). The study also reported that on average $23.9 \%$ of ever smokers had their first cigarette before the age of 10 (The GYTS Collaborative Group, 2002). In the US, smoking rates among adolescents in grades 9-11 rose from $27.5 \%$ in 1991 to $36.4 \%$ in 1997 but declined steadily to $21.9 \%$ by 2003 (MMWR, 2004). In SA, ever smoking among adolescents 
in grades 8-10 decreased significantly from $47.6 \%$ in 1999 to $37.6 \%$ in 2002 while current smoking decreased from $23.0 \%$ in 1999 to $18.5 \%$ in 2002 (Swart et al., 2004). Current frequent smoking (smoked on 20 or more days in the past 30 days) also declined significantly from $10.1 \%$ in 1999 to $5.8 \%$ in 2002 . Age at initiation among ever smokers below the age of 10 also showed a slight decrease in SA from $18.5 \%$ in 1999 to $16.2 \%$ in 2002 . The decline in the smoking rates in SA was attributed to changing social norms towards smoking as a result of the strengthening of the Tobacco Products Control Amendment Act in 2001 (Swart et al., 2004; van Wallbeek, 2003). SA is in the process of further strengthening its tobacco control policies in order to ratify the FCTC. One of the anticipated benefits of these policy changes, is that the youth's interest in quitting will grow (Lantz et al., 2000). Evidence-based tobacco control programmes will be timely to sustain the decrease in smoking uptake and to promote cessation among young people.

\section{Planning models}

The development of effective health promotion programmes is dependent on the extent to which a systematic process is adopted to plan ahead and make sound decisions (De Vries, 1998). This process may prevent the development of ineffective programmes (Green and Kreuter, 1991; Kok and De Vries, 1989). The health promotion matrix (Reddy, 1999a; Reddy et al., 2003) (see Figure 1.2) as well as the integrated planning model (I-Plan Model) (De Vries, 1998) (see Figure 1.3), are complementary models that support comprehensive approaches to improve the effectiveness of anti-smoking strategies.

\section{The Health Promotion Matrix.}

In view of the triple burden of disease profile in $S A$, battling both communicable and non-communicable diseases, health promotion needed to adopt a multifaceted strategy that intervened at the political, economic, environmental as well as the social and cultural levels (Reddy, 1999a; Reddy et al., 2003). To gamer adequate support and resources for the implementation of programmes, intersectoral collaboration is also required. The Health Promotion Matrix recognises that behaviour change ranges from the primary prevention level before behaviour is adopted, to the early detection leve] where new behaviours are adopted and mastered, to the patient care level where morbidity associated with the behaviour starts to manifest.

Health Promotion strategies that operate across the three levels include the provision of health education and information e.g. at the primary prevention level, health education and refusal skills will be taught to adolescents before the onset of smoking while at the early detection level adolescent smokers will be encouraged to engage in smoking cessation programmes. Health Promotion Strategies also need to ensure the provision of facilities appropriate to the three levels of care e.g., adolescent smokers who are highly dependent on nicotine may require access to nicotine replacement therapy (NRT). 


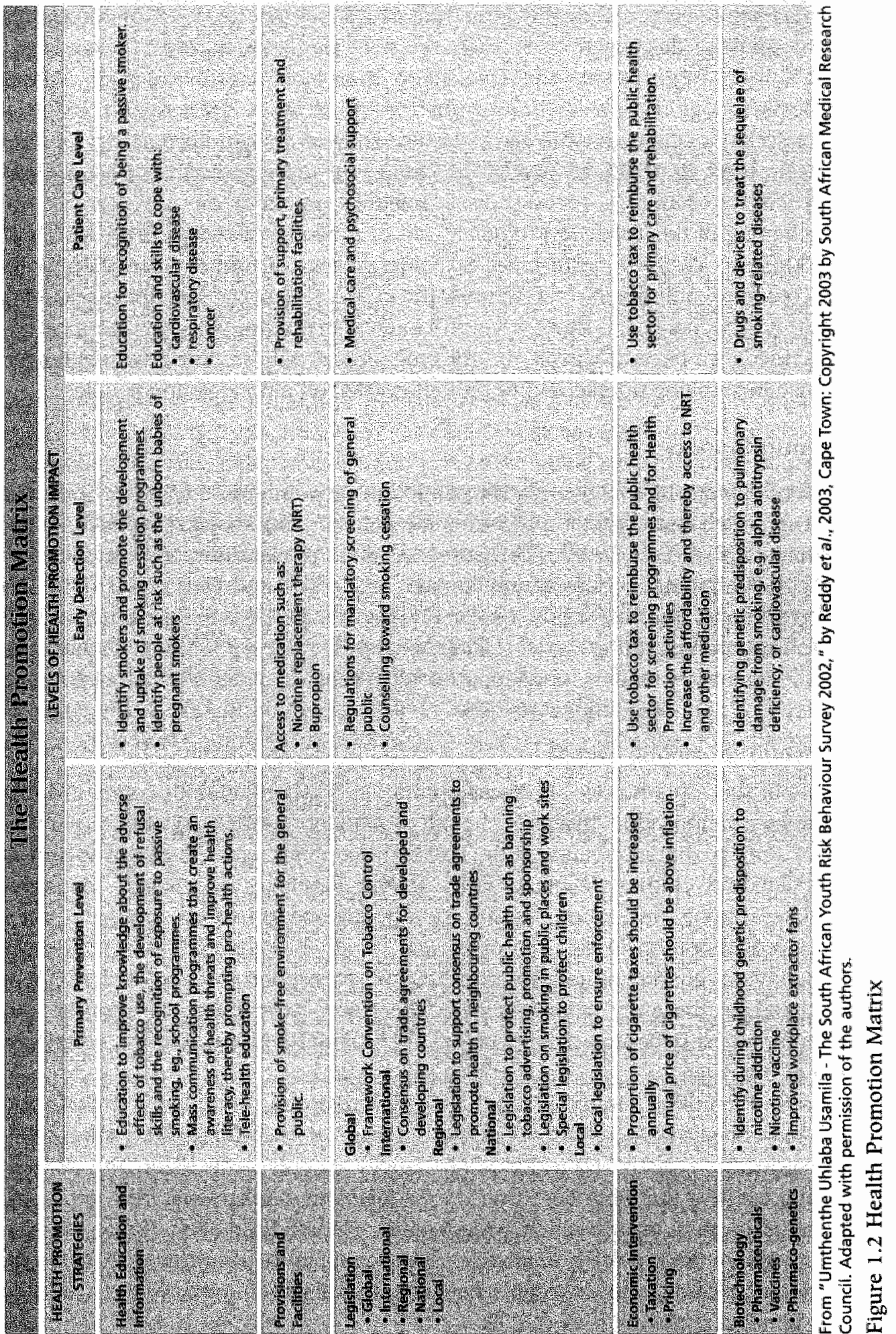


Interventions at the individual or community level must be supported by enabling legislation at the local national, regional and international levels e.g; smoking prevention or cessation programmes must be supported at the local level through enforcement of the ban of the sale of cigarettes to minors. Economic interventions such as increases in excise taxes on tobacco products can be used to encourage the youth to quit smoking. Tobacco taxation can be then re-directed to subsidise NRT for highly dependent adolescent smokers. Biotechnology as a health promotion strategy involves the use of pharmacogenetics and pharmacotherapy to identify individuals vulnerable to nicotine addiction and to deliver therapy appropriate to the level of care required.

This thesis focused on the primary prevention and early detection levels using health education and information strategies for adolescent smokers.

\section{The I-Plan Model}

The I-Plan Model, previously known as the ABC Planning Model, incorporates insights from the PRECEDE-PROCEED Model (Green and Kreuter, 1991), the Community Change Model (Bracht, 1990) and the Diffusion of Innovations Model (Rogers, 1983). It consists of three phases namely, Analysis, Behavioural Intention and Continuation.

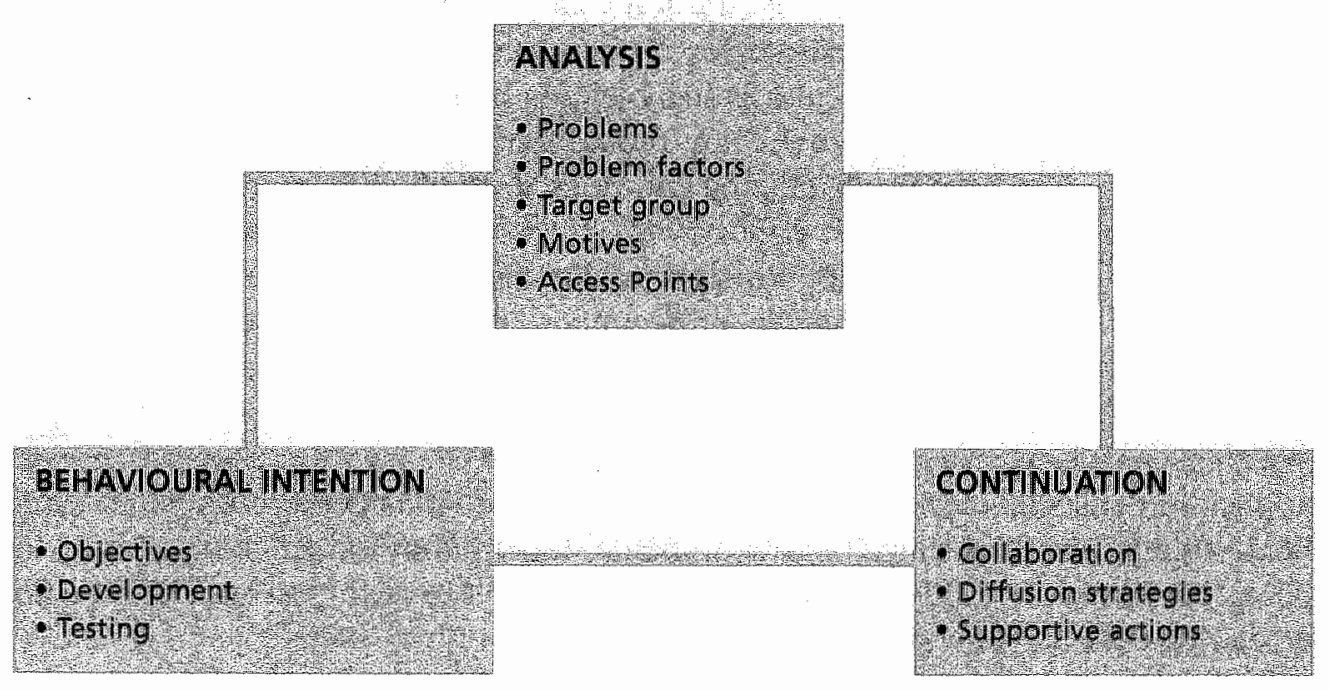

Figure 1.3 The I-Plan Model

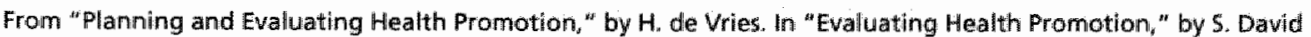
and R. Weston, 1998, Cheltenham: Stanley Thornes. Copyright 1998 by Stanley Thornes (Publishers) Ltd. Adapted with permission of the author. 
In the Analysis Phase, factors that lower the quality of life of a community including physical, mental and social problems are identified using participatory approaches. This is followed by a study of the individual and external factors related to a health problem. Individual factors refer to biological factors (e.g., gender and age), behavioural (e.g., previous experience with smoking) and psychological factors (e.g., knowledge and depression) while external factors refer to physical and social cultural factors (e.g., school climate and national policies). Once the target group is selected, behaviour can be studied at the micro or individual level, at the meso or organisational level, and at the macro or sociocultural and political level. The micro level refers to one individual or groups of individuals such as adolescents. The meso level refers to social systems or social settings in which individuals live while the macro level refers to institutions that directly or indirectly impact on health through the implementation of policies. The motivational cleterminants that underpin the educational objectives of smoking programmes are subsequently identified using the I-Change Model (De Vries, et al., 2003c) (see Figure 1.4).

The Analysis Phase also includes an exploration of the needs of and the channels through which the target audience can be accessed, known as an Access Point Analysis. Access point analyses are similar in principle to social marketing that segments the audience according to four basic marketing decisions, namely product (e.g., smoking programmes), price (e.g., cost or effort to participate in the programme), place (channels of distribution e.g., programme provider and delivery format), and promotion (e.g., strategies to recruit and retain the target audience) (Walsh et al., 1993). Public health is increasingly borrowing concepts from social marketing to develop effective health promotion interventions. In fact, social marketing was first used in developing countries to promote immunisation, family planning and nutrition (Walsh et al., 1993). Subsequently the concept has been used, among others "to develop cardiovascular disease prevention programmes, smoking prevention and cessation programmes, substance abuse programmes, HIV/AIDS programmes and breast cancer awareness programmes (Black et al., 1993; Futterman et al., 2001; Kennedy et al., 2000; Lefebvre and Rochlin, 1997; Walsh et al., 1993; Worden et al., 1988). Caution is, however, advised in the application of social marketing to public health, in that it has been criticised for not being cognisant of the range of environmental factors that influence behaviour, in being economically motivated and in being a means to and end sometimes with deleterious effects (Buchanan et al., 1994).

In the Behavioural Intervention Phase of the I-Plan Model, the results of the Analysis Phase are used to formulate goals for the programme such as smoking cessation at the individual level, non-smoking school policies at the meso level and enforcement of the ban on underage sales at the macro level. These goals are then translated into programme objectives. Three types of programme objectives are developed namely health, behaviour and motivational objectives. Examples of these three types of objectives include the following: the health objectives of a smoking programme may be to reduce lung cancer mortality by 15 percent after 10 
years, the behavioural objectives may be to increase quit rates by $25 \%$ after one year, and the motivational objectives may be to increase self-efficacy to stop smoking by $20 \%$. Thereafter, the programme is developed by combining theoretical methods such as learning assertiveness skills with practical methods of delivery such as posters, videos and group discussions. This is followed by pilot testing to refine the programme, programme implementation and an evaluation of its effectiveness. Several levels of evaluation can be undertaken namely process evaluation to ascertain the extent to which the programme was implemented and programme evaluation by the target group and the programme providers; effect evaluation on the outcome variables and behavioural evaluation such as improvement in self-efficacy; and an evaluation of the cost effectiveness of the programme.

The Continuation Phase of the I-Plan Model involves the use of an intersectoral collaborative group, who represent the various stakeholders who may have an interest in the utilisation of the programme, to develop diffusion strategies and supportive mechanisms to ensure wide-scale use of the programme.

The Health Promotion Matrix and the I-Plan Model provide the guiding framework for the development of tobacco control programmes for adolescents in SA. With the analysis of the problem and the epidemiological diagnosis complete, this thesis focused on an assessment of the motivational factors related to smoking onset and smoking cessation as well as the channels through which adolescents can be accessed for tobacco control programmes.

\section{The Integrated Model for Change}

Health behaviours are increasingly viewed from a psychosocial perspective to account for the personal variables that influence such behaviour (Torres, 1995). This approach is particularly germane among adolescents as they experiment with behaviours as part of their search for identity (Bonaguro and Bonaguro, 1987). Earlier, public health efforts to prevent smoking were developed along healthrelated and demographic profiles, but the ineffectiveness of such programmes to reduce smoking rates has seen a shift in research towards the psychosocial theories of adolescent smoking behaviour (USDHHS, 1994).

The choice of theories underpinning research is a complex one. Theories are constantly evolving, undergoing adaptation and refinement, as they are applied to research that is practiced in reality. One approach to improve the effectiveness of anti-smoking strategies would be to target the cognitions specified by psychological models such as the integrated model of change (I-Change Model) (De Vries et al., 2003c). The model incorporates insights from the Theory of Reasoned Action (Fishbein and Ajzen, 1975), Social Cognitive Theory (Bandura, 1986) and the Transtheoretical Model (Prochaska and DiClemente, 1983). The model as well as its previous versions (referred to as the Attitude-Social influence-Self-efficacy Model) have been used to assess the determinants of smoking and to develop and evaluate smoking prevention programmes in several European countries (De Vries et al., 


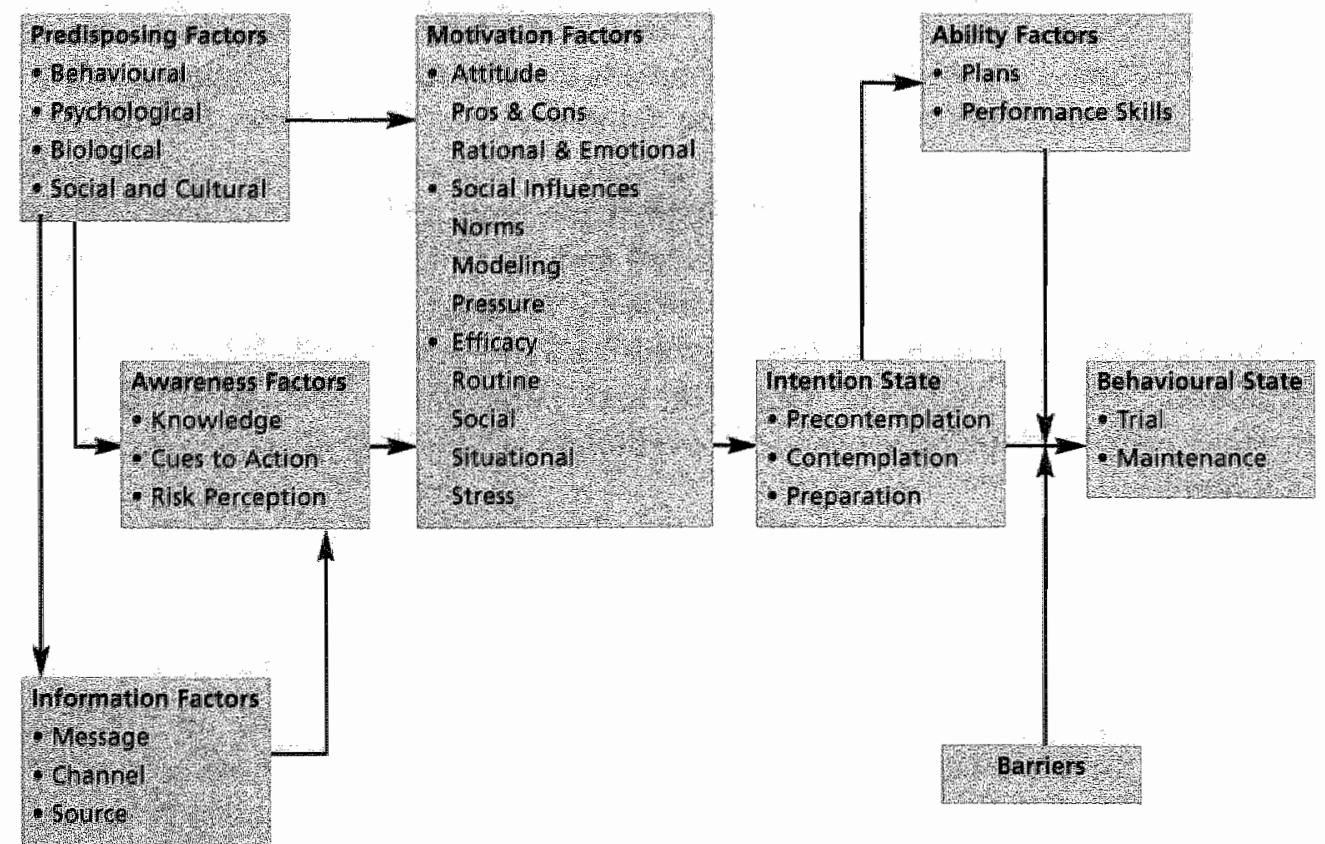

Figure 1.4 An Integrated Model for Change

From "The European Smoking Prevention Framework Approach (ESFA): an example of integral prevention" by H. de Vries, M. P. Clemente, H. Storm, A. G. Gonzallez, M. Nebot, T. Prins and S. Kremers, 2003, Health Education Research, 18, p.612. Copyright 2003 by Oxford University Press. Reprinted with permission of the author.

1994; De Vries et al., 1995; De Vries et al., 1988; Dijkstra et al., 1999), determinants of STD's (Meyer Weitz et al., 2000a; Meyer Weitz et al., 1999; Reddy et al., 2000) and HIV/AIDs prevention activities in SA (Taylor et al.,2003) as well as several other health behaviours in adults (De Vries and Mudde, 1998). The model assumes that the most important determinant of behaviour is behavioural intention which, in turn, is influenced by three proximal factors namely one's overall evaluation of the behaviour (attitude), one's beliefs concerning the beliefs and behaviours of significant others (social influences) and the control that people perceive themselves to have over performing a behaviour (self-efficacy) (see Figure 1.4).

While similar in format to the Theory of Planned Behaviour, the I-Change Model differs in several ways. Firstly, attitudes and social norms are not measured by multiplicative functions but are entered separately into regression equations (Evans, 1991). Secondly, the model assesses attitudes by measuring both the pros and cons of behaviour. Thirdly, it distinguishes three types of social influences namely social norms, direct pressure or support and the perceived behaviour of others. Fourthly, self-efficacy expectations are measured rather than perceived control, as described in the Social Learning Theory (Bandura, 1977), by measuring 
confidence to perform the desired behaviour in various situations. Fifthly, the model includes the stage of change concept that describes behavioural change as a process as elaborated by Prochaska's Transtheoretical Model (1994). Sixthly, the model recognises four types of distal or pre-disposing factors that influence behavioural intention through the proximal factors namely behavioural (previous experience with the same and related behaviour e.g., alcohol and use of other substances), psychological (e.g., depression, risk behaviour), biological (e.g., gender, age) and social and cultural factors (e.g., social climate, socio-economic status) (De Vries and Mudde, 1998). Seventhly, unlike the Theory of Planned Behaviour, the model explicitly distinguishes awareness factors and a goal setting phase.

In this thesis, the I-Change Model was used as a theoretical framework to study the motivational factors (attitude, social influences and self efficacy as proximal factors and depressive mood, risk behaviour, nicotine dependence and withdrawal symptoms as pre-disposing factors) related to smoking onset and smoking cessation among adolescents in SA.

\section{Associations with smoking}

The US Surgeon General's Report on Smoking among Young People (1994), building on the work of Flay (1993) and others, summarised the process of smoking onset. During the preparatory phase, adolescents formulate beliefs and attitudes about smoking. Some adolescents make the decision to remain as never smokers (never smoked even one puff) while others proceed to try smoking a few cigarettes. Depending on their physiological response to smoking and the social reinforcement that they receive from their environment, adolescents may advance to the experimental phase where they smoke repeatedly but on an irregular basis frequently referred to in the literature as monthly or current smoking. With adequate social support from their peers and lower self-efficacy to refuse cigarettes, adolescents may then progress onto regular smoking, where smoking occurs on at least a weekly basis. This is followed by nicotine addiction characterised by a physiological need for nicotine. Adolescents in this phase are thought to develop a tolerance for nicotine and experience withdrawal symptoms if they try to quit. The model also proposed that the time interval from initial trying smoking to regular use takes two to three years. However, this may show individual variation. The model provides exit points at each phase labelled as "no longer smokes" until the regular: use phase where those who stop smoking are labelled as quitters. Recently Kremers and colleagues $(2004 ; 2001 \mathrm{a})$ cognitively disentangled these former smokers into two distinct groups namely those who try smoking but do not in fact progress onto regular smoking, known as non-smoking deciders, and ex-regular smokers, known as quitters. They showed that non-smoking deciders displayed more risk for future smoking than never smokers but less risk for future smoking than quitters. However, when taken together, both non-smoking deciders and quitters, showed less risk for future smoking than experimenters and regular smokers. 
Three major reviews, namely by Conrad and partners (1992), the US Surgeon General (1994) and Tyas and colleagues (1998), documented the factors associated with smoking onset. Demographic factors such as age at initiation, gender, ethnicity and school performance were linked to smoking onset. Smoking initiation and the prevalence of smoking have been shown to increase with age such that those adolescents who initiate smoking at a younger age were more likely to become regular smokers. Smoking and gender showed some cultural patterns with higher levels of smoking reported among females in Western cultures and males in Eastern cultures. Black students displayed lower levels of smoking initiation and current smoking than White students. Students who do well at school and report higher academic aspirations were also less likely to smoke.

The three reviews also referred to the association between cognitive factors such as attitude towards smoking, social influences such as parental, sibling and peer smoking, self-efficacy and intention to smoke. Studies have found a significantly increased risk of adolescent smoking with increased parental smoking. Parental attitudes towards smoking, specifically their children's smoking, were also related to adolescent smoking. There was support for the relationship between sibling smoking and increased adolescent smoking. By far the most consistent finding was the relationship between peer smoking and adolescent smoking irrespective of the definition of peer used (e.g., best friend, classmates, friends, girlfriends, and boyfriends). In fact, the reviews report on studies where controlling for peer influence rendered the effect of parental smoking non-significant. It is, however, unclear whether peer influence resulted in smoking or if adolescents who smoke selected other smoking peers as friends. Contrarily, a recent study by De Vries and colleagues (2003a) demonstrated that peer influence in smoking onset may have been overestimated while parental influences may have been underestimated and that the peer selection mechanism may be a more plausible explanation of smoking onset than peer pressure. The three reviews also reported that difficulty in refusing offers of cigarettes or self-efficacy was a strong predictor of smoking onset as was intention to smoke.

Other behavioural factors such as alcohol and other substance use as well as risk behaviour were consistently linked to adolescent smoking onset in several studies included in the three reviews. Additionally, psychological factors such as depression or stress were important factors motivating smoking initiation.

Since the 1970s, the social influences approach (Evans, 1976) has been adopted in adolescent smoking prevention programmes and has achieved positive, though modest, short-term effects (Rooney and Murray, 1996; Tobler et al., 2000). A Cochrane Review of school-based smoking prevention programmes concluded that, of 15 rigorous social influences smoking prevention programmes identified, only eight showed positive effects on smoking prevalence with seven failing to detect any effect (Thomas, 2004). The Hutchinson Smoking Prevention Project that included an eight-year intensive programme, did not show positive long-term effects. Thus the long-term effectiveness of stand-alone school-based tobacco control programmes has been questioned (Backinger et al., 2003; Skara and Sussman, 2003). 
Recommendations have been therefore made for comprehensive approaches that address multiple determinants at the individual, community and policy levels (Bracht, 1999; De Vries et al., 2003c; Glynn, 1989; Klepp et al. 1993; Lantz et al., 2000; Reddy, 1999a; Tones and Tilford, 1994; USDHHS, 1994). Yach and Ferguson (1999) recognised that there is no 'magic bullet' for tobacco control and advocated comprehensive approaches that incorporate the following key elements: policies to increase the price of cigarettes, bans on all forms of advertising and promotion of tobacco products, counter advertising, availability of cessation methods that augment and support improved and sustained education and skills-building efforts for both in-school and out-of-school youth and restricted availability of tobacco to youth.

\section{Smoking cessation among adolescents}

While the thrust of traditional smoking interventions has been prevention for teenagers and cessation for adults, increasing adolescent smoking rates in the 1990s sparked interest in the need for adolescent smoking cessation programmes. What is more, as many as $80 \%$ of adults initiate smoking as adolescents and if adolescents do not use tobacco before the age of 20 , they are unlikely to initiate smoking as adults (MMWR, 1998). Smoking cessation interventions for adolescents are therefore ideally placed to stunt the growth of the tobacco epidemic, before adolescents make the transition into adult smokers. Almost two thirds of current smokers want to stop smoking and actually make quit attempts (Warren et al., 2000). The SA GYTS showed that the percentage of monthly smokers who expressed a desire to stop smoking and actually made quit attempts remained high in both $1999(73.9 \%$ and $76.6 \%)$ and $2002(72.6 \%$ and $74.4 \%)$ respectively (Swart et al., 2004). As far back as 1999, SA advocated smoking cessation programmes for adolescents as part of a comprehensive strategy towards tobacco control (Reddy and Panday, 1999). Most teenagers prefer to quit on their own; success is limited (Gillespie et al., 1995) with the average quit attempt lasting no more than a week (Burt and Peterson, 1998). Success rates have been also modest in youth cessation programmes. A review of 66 youth smoking cessation programmes reported a mean overall cessation rate of $12 \%$ across active treatment groups compared to $7 \%$ in the control groups (Sussman, 2002).

One of the possible reasons for the limited efficacy of cognitive-behavioural smoking cessation programmes is the faillure to address nicotine dependence. This may be the result of the belief that prolonged use of nicotine is required before signs of dependence emerge (USDHHS, 1994). However, recent studies have reported signs of dependence early in the trajectory of tobacco use before adolescents progress onto regular smoking (DiFranza et al., 2000; Difranza et al., 2002a; O'Loughlin et al., 2003). DiFranza and colleagues (2000) showed that $22 \%$ of monthly smokers reported symptoms of nicotine dependence within two weeks of the onset of monthly smoking. Despite the fact that when compared to adults, adolescents smoke fewer cigarettes and with less regularity, $20-68 \%$ of adolescent 
smokers are actually considered dependent and at minimum $66 \%$ experience some form of withdrawal symptoms when they quit or cut down (Backinger et al., 2003b; Colby et al., 2000a). The infancy of smoking cessation research and particularly of nicotine dependence among adolescents has limited the availability of theoretical literature and validated measure of nicotine dependence among adolescents (Colby et al., 2000b; Shadel et al., 2000). In the interim adult measure of nicotine dependence and withdrawal have been adapted for adolescents such as the Fagerström Tolerance Questionnaire (Prokhorov et al., 2000; Prokhorov et al., 1996) and the Diagnostic and Statistical Manual of Mental Disorders (DSM IV criteria) (1994) (Prokhorov et al., 2001; Rojas et al., 1998) respectively. These measures have demonstrated that substantial numbers of adolescents smokers experience nicotine dependence (almost 20\%) and withdrawal symptoms (Prokhorov et al., 2001; Prokhorov et al., 1996; Rojas et al., 1998; Stanton et al., 1996). While nicotine replacement therapy (Silagy et al, 2004) and bupropion (Hurt et al., 1997) have become the gold-standard of treatment among adults, the dearth of trials on nicotine replacement therapy among adolescents and its general ineffectiveness in the few existing trials (Hurt et al., 2000; Killen et al., 2004; Smith et al., 1996), together with the belief that smoking among adolescents is more socially oriented, have tempered recommendations for the use of nicotine replacement therapy among adolescents.

\section{Associations with smoking cessation}

The design of effective smoking cessation programmes for adolescents is currently being informed by the documentation of factors related to smoking cessation. Similar to smoking prevention, adolescent quitting behaviour has been linked to demographic factors such as age at initiation, gender, ethnicity, school performance; cognitive factors including attitude towards quitting, social influences such as parental, peer and sibling smoking, self-efficacy, intention to smoke and psychological factors such as depression (e.g., see Arisa and Nebot, 2002; Breslau and Peterson, 1996; Burt and Peterson, 1998; Chassin et al., 1984; Engels et al., 1998; Ershler et al., 1989; Redmond, 2002; Rose et al., 1996; Sargent et al., 1998; Siqueira et al., 2001; Stanton et al., 1999; Sussman et al., 1998; Zhu et al., 1999).

Sussman and colleagues (1998) summarised the findings of several studies on self-initlated quitting among adolescent smokers. They reported that those who start smoking at a younger age are less likely to quit. The literature lacks clarity on the influence of gender on quit rates. While some studies have reported lower quit rates among females, others have not. This may be attributable to gender differentials in nicotine dependence as some studies have reported higher nicotine dependence among females (DiFranza et al., 2000; DiFranza et al., 2002a; DiFranza, et al., 2002b; O'Loughlin et al., 2003) although the limited the number of studies in this area makes findings inconclusive (Colby et al., 2000a). The lower quit rates among White adolescents have been attributed to younger age of initiation in this group. 
The summary by Sussman et al (1998) on the cognitive factors associated with quitting reported that negative attitudes towards continued smoking and negative beliefs about the health effects of smoking were consistent predictors of quitting among adolescents. Quit rates were lower among adolescents who reported smoking among their friends and approval of smoking by their peers. Parental disapproval of smoking was predictive of quitting while family use of cigarettes was associated with lower quit rates. Intention to smoke in future has been found to be inversely related to quitting.

The summary paper also reported that psychological factors such as lower levels of emotional distress and greater coping and social skills were consonant with higher quit rates (Sussman et al, 1998). Depression was also inversely related to quitting. Quitters were less likely to use alcohol and engage in risk behaviour.

A review of 20 smoking cessation programmes for youth with moderate internal validity concluded that effective methods to help adolescents quit smoking do exist but are rare and underutilised (McDonald et al., 2003). Furthermore, they identified that cognitive-behavioural models are an effective theoretical basis for such programmes. Although the majority of studies that were effective were delivered in the classroom setting by teachers and school personnel, the number of studies with sufficient validity supporting the classroom as the preferred setting and teachers as the preferred providers were inadequate. What was definitively concluded in the review was that much more quality research is required on adolescent tobacco cessation.

To the best of our knowledge, data is not available in SA on either the proximal (attitude, social influences, self-efficacy) or distal (nicotine dependence, withdrawal symptoms, depressive mood, risk behaviouri) factors related to smoking onset or smoking cessation among adolescents. This information is required for the formulation of the educational objectives of tobacco control programmes for adolescents.

\section{Ethnic factors related to smoking}

Several studies have reported lower levels of smoking initiation and current smoking among Black adolescents than among White adolescents (Epstein et al., 1998; Griesler and Kandel, 1998; Kandel et al., 2004; Kelder et al., 2003; Markham et al., 2004; Riedel et al., 2003; USDHHS, 1994). Black African adolescents in SA also consistently report lower prevalence of current smoking (15.7\%) than White $(21.7 \%)$ and Coloured (38.7\%) adolescents (Swart et al., 2004; Swart et al., 2003). However, few studies have attempted to unravel the aetiology of these ethnic differences and test whether smoking programmes developed primarily for White adolescents are applicable to other ethnic groups (Skara and Sussman, 2003). The US Surgeon General's Report on Tobacco Use Among Racial/Ethnic Minority Groups (1998) referred to the paucity and methodological weaknesses of studies on the factors related to adolescent smoking among minority groups.

The ethnic differences in the prevalence of smoking may intimate towards the 
differing roles that smoking plays for adolescents from differing backgrounds (Markham et al., 2004; Tyas and Pederson, 1998). Studies have shown that White adolescents start smoking earlier, are more likely to continue smoking, are more influenced by peer smoking, display higher levels of nicotine dependence and lower quit rates than other ethnic groups (Griesler and Kandel, 1998; Redmond, 2002; Siqueira et al., 2001; Sussman et al., 1987; Sussman et al., 1998; Unger et al., 2001; USDHHS, 1994, 1998). Other studies have shown that social norms and modelling may be largely responsible for ethnic differences in smoking (Ellickson et al., 2003; Markham et al., 2004). The consistently high smoking rates among Coloured adults (Reddy et al., 1996) in SA have filtered through to Coloured adolescents (Swart et al., 2004) suggesting that smoking may have become normative and socially acceptable in these communities.

While some studies have identified ethnic-specific predictors of smoking, other studies have concluded that there are more common than unique predictors of smoking across ethnic groups (Griesler et al., 2002; Kandel et al., 2004). An understanding of the differences in the determinants of smoking would allow programmes to be tailored to the needs of the ethnic subgroups. The history of racial discrimination and segregation in $\mathrm{SA}$ as well as the increasing racial integration of schools makes ethnic-specific school-based programmes undesirable. Programme development; however, must account for the nuances specific to each group even if tobacco control programmes are presented to ethnically diverse audiences. The need for culturally sensitive tobacco control programmes for adolescents (Markham et al., 2004; Skara and Sussman, 2003; Swart et al., 2004; USDHHS, 1998), therefore motivated for an investigation of ethnic differences in the factors associated with smoking in this thesis.

\section{Outline of the project}

\section{Study area}

This research project was initiated by the South African Medical Research Council in 1998 following an invitation for research on adolescent health behaviours by the Department of Health in the Southern Cape-Karoo Region (see Figure 1.5). The study area is one of four health regions in the Western Cape Province. The 1999 population estimates for the Southern Cape-Karoo Region was 462414 with 90901 of the population between 10 and 19 years of age (Mehtar, 1999). The average age of mortality was 56 years and ranged between 44.4 years among Black African adults and 69.5 years among White adults (Mehtar, 1999). Cardiovascular disease was the number one cause of mortality with cancer and respiratory illnesses, for which causal relationships with tobacco use are also known (USDHHS, 2004), rated as fourth and sixth respectively on this list (Mehtar, 1999).

The focus on smoking behaviour was further supported by the high adult daily smoking rates in this province ( $44.0 \%$ for men and $27 \%$ for women) (DOH et al., 2002). The province is home to the Coloured population who have reported the highest daily smoking rates ( $54.9 \%$ for men and $37.3 \%$ for women) compared to the 
national average ( $36.7 \%$ for men and $36.7 \%$ for women) (DOH et al., 2002). At the inception of the project, data was not available on the prevalence or the determinants of smoking among adolescents. This study represents the first formative research on the associations of smoking and smoking cessation that is critical for the development of empirically-based tobacco control programmes.

\section{Study setting}

The school was chosen as the study setting due to the access it offers to large groups of adolescents for a sustained period and the opportunity to address socially motivated behaviours such as tobacco use. Furthermore, schools in SA provide a relatively stable environment that can influence a wide array of people namely students, teachers, parents and the community at large.

The education system in SA has undergone tremendous transformation since 1994. The democratic order was tasked with integrating 19 racially and ethnically divided departments involving more than 10 million students and teachers without a break in service delivery (SA NDOE, 2001b). The right to education is now entrenched in the SA Constitution and supported by several pieces of legislation

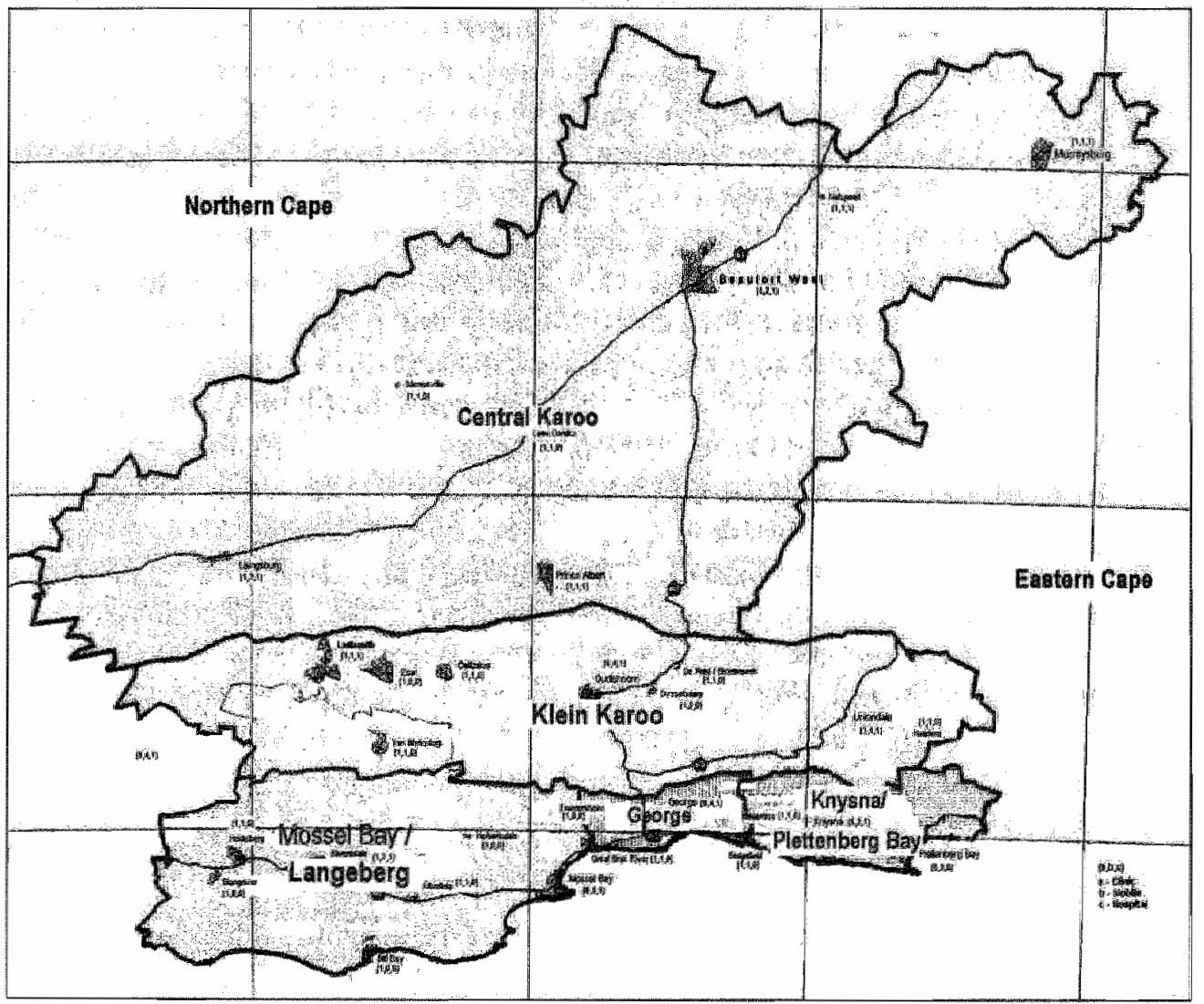

Figure 1.5 Map of the Southern Cape-Karoo Region 
that were passed in the last 10 years such as the National Education Policy Act (1996) and The South African Schools Act (1996) (SA NDOE, 2001b). The latter act made schooling compulsory for all 7-14 year old children. Currently the South African schooling system consists of more than 12.3 million students $(50.5 \%$ female) who are accommodated in 29386 primary and secondary schools (SA NDOE, 2001b).

Formall education in South Africa is divided into three bands namely the General Education and Training band (Grade 0-9), the Further Education and Training band (Grade 10-12) and the Higher Education band (diplomas and degrees). These three levels of education are integrated into a National Qualification Framework that is underpinned by the South African Qualification Authority Act of 1996.

In 1999, the Minister of Education implemented Tirisano (working together) as a call to action to reform education in SA. The pillars of this plan included among others, reducing illiteracy among adults and youth in five years, ensuring that schools are the centres of community life, ending the physical degradation of schools, ensuring active learning through outcomes based education and coping with HIV/AIDS in the education and training system.

The School Register of Needs studies documented some of the achievements of education in SA (SA NDOE, 2001a). In 2000, there were 27148 schools compared to 26734 schools in 1996. There was a decline in the number of platoon schools (sharing of school building facilities) from 1198 in 1996 to 1023 in 2000. In 2000, 30793 more classrooms were provided for students in SA which significantly reduced overcrowding in schools. In 1996,55\% of students ( 6.6 million) did not have sanitation facilities and 35\% of schools did not have access to water. In 2000 , these numbers decreased to $16.6 \%$ ( 1.9 million) and $28 \%$ respectively. The percentage of schools that were electrified rose from $41.8 \%$ in 1996 to $57.1 \%$ in 2000 and the lack of access to telephones in schools declined from $59.5 \%$ in 1996 to $35.5 \%$ in 2000 .

Curriculum 2005, the tool for the delivery of education in South African schools, is considered one of the most progressive policies in the world. Its guiding principles are outcomes based education and learner-centred education (SA NDOE, $2001 \mathrm{~b}$ ). It shifts the balance away from rote learning to involving students as active participants in their education and responds to their life experiences and needs. One of the learning areas is Life Orientation that teaches students practical skills to cope with everyday life including enhancing refusal skills to resist influences such as drugs, alcohol and tobacco use. An opportunity therefore exists to integrate evidence-based tobacco control programmes into the Life Orientation learning area in the school setting.

\section{Objectives}

In 1998, focus group discussions were conducted on the factors related to smoking amongst grade 6,7 and 8 (12 to 14 years) adolescents. This study showed substantial reports of craving and difficulty to stop smoking. The need for a study on the motivational factors related to smoking cessation and the channels through 
which adolescents can be accessed for the development of empirically-based and culturally sensitive tobacco control programmes was identified. This smoking cessation study was conducted in tandem with a smoking prevention study in the same study area. In order to achieve the overall goal, the project adopted the following objectives:

1) To investigate the motivational factors related to smoking.

2) To investigate the motivational factors related to smoking cessation.

3) To investigate the prevalence of nicotine dependence and withdrawal symptoms.

4) To conduct an access point analysis that elaborates adolescent preferences for the setting, timing, provider and delivery format for tobacco control programmes.

5) To investigate the need for ethnic and gender sensitivity in the design of tobacco control programmes for adolescents.

\section{Design}

The I-Plan Model and the Health Promotion Matrix provide the overarching framework for the development of tobacco control programmes. This study focused on the Analysis Phase of the I-Plan Model and the primary prevention and early detection levels of the Health Promotion Matrix. The I-Change Model provided the theoretical underpinning for the study of the motivational factors related to smoking prevention and cessation. The objectives of the project were achieved through two phases namely a qualitative phase and a quantitative phase.

In the first phase, nine focus group discussions were conducted in March 2000 with grade 8 and 9 school-going smokers and ex-smokers (see Figure 1.6). Themes explored included knowledge, attitude and social influence towards smoking onset and cessation, quit attempts, self-efficacy to stop smoking and maintain abstinence, knowledge of and methods used to stop smoking and other forms of tobacco use, awareness of and participation in tobacco control programmes as well as the preferred setting, timing, provider and delivery format for tobacco control programmes. Furthermore, key elements of tobacco control programmes were explored. The findings of the smoking cessation and smoking prevention access point analyses were compared.

In the second phase, a cross-sectional survey was conducted in February/March 2002 among 4768 Grade 9-11 students The questionnaire assessed smoking behaviour, attitude, social influence, self-efficacy expectations, intention not to smoke in the next year, risk behaviour, nicotine dependence, withdrawal symptoms, depressive mood and several demographic items.

\section{Outline of thesis}

Chapters 2 and 6 emanate from the qualitative study that explored the factors related to smoking behaviour among adolescents while Chapters 3,4 and 5 use sub-samples of the cross-sectional survey conducted among 4768 Grade 9-11 students. Chapter 2 explores the factors related to smoking behaviour among Grade 8 and 9 smokers and ex-smokers. Chapter 3 outlines the ethnic associations of smoking, depressive mood and risk behaviour in a sample of Grade 9-11 monthly 
and non-monthly smokers. Chapter 4 discusses the ethnic associations of smoking cessation among Grade 9-11 monthly smokers and former smokers. Chapter 5 reports on the prevalence and gender differences in nicotine dependence, withdrawall symptoms, depressive mood and risk behaviour between weekly and monthly smokers. Chapter 6 describes the adolescents' preferences for the channels through which they can be accessed for tobacco control programmes. Key elements of tobacco control programmes are also discussed. Chapter 7 summarises and discusses the main findings, the implications for tobacco control programmes among adolescents in $\mathrm{SA}$ as well as recommendations for future research.

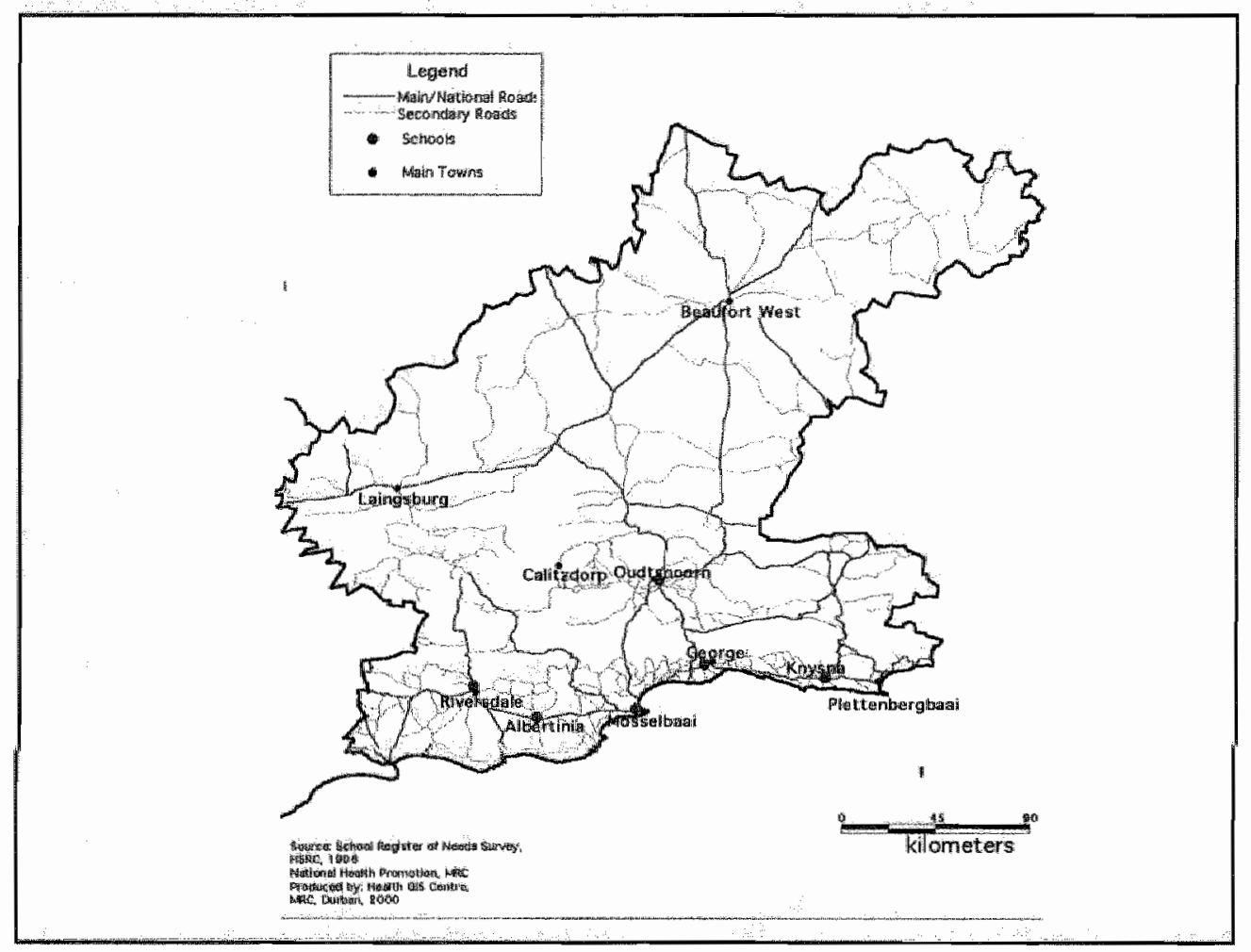

Figure 1.6 Schools in which smoking cessation focus group discussions were conducted in the Southern Cape-Karoo Region 


\section{Chapter 2}

\section{A qualitative study on the determinants of smoking behaviour among adolescents in South Africa}




\section{Abstract}

Increasing adolescent smoking rates have highlighted the need for smoking cessation programmes for adolescents.

Aim: To explore adolescent opinions ${ }^{7}$ on the determinants of smoking, with a focus on smoking cessation.

Methods: Nine focus group discussions were conducted with grade 8 and 9 schoolgoing smokers and ex-smokers in the Southern Cape Karoo Region, South Africa. Six schools were purposively selected based on their locality (urban or rural) and ethnicity ("black", "white", and "coloured"). The groups were homogenous in terms of gender and ethnicity. Data was analysed thematically.

Results: The majority of the participants declared their intention to stop smoking in the future. They reported multiple quit attempts of short duration. They perceived quitting as a difficuit process and that only a few of their friends wanted to stop smoking. Participants believed that they were not addicted to nicotine even though they reported nicotine withdrawal symptoms. While "coloured" and "black" participants reported their smoking peers as obstacles to quitting, their "white" counterparts, emphasised that they smoked by choice and that they would support friends who wanted to stop smoking.

Conclusion: This study shows that the psychosocial determinants of tobacco use may vary substantially between ethnic groups and cultural contexts. A long-term strategy of poverty reduction that would create greater perceived future prospects is an important consideration for interventions in developing countries. The manifestation of withdrawal symptoms, indicative of nicotine addiction, is a common and significant hindrance for smoking cessation among these adolescents. 


\section{Background}

The steady increase in adolescent smoking rates in developed countries in the last decade (USDHHS, 1994; Hill et al., 1995) has been one of the fundamental motivating factors for increasing the profile of smoking cessation efforts for adolescents. South Africa (SA), a middle income developing country, where concerted efforts are being made to control the explosion of the anticipated tobacco epidemic, shows strong parallels between adult and adolescent smoking rates, $24 \%$ (DOH and MRC, 1998) and 23\% (Swart et al., 2000) respectively. Adolescence, the period during which almost $80 \%$ of adult smokers initiate the habit (USDHHS, 1994), provides a window of opportunity to rescue thousands of potential smokers from many years of tobacco-related addiction, morbidity and premature mortality:

In SA, the Tobacco Products Control Amendment Act of 1999 restricts tobacco use in public places. Enforcement of the law requires regulation as well as encouragement and support for the public to stop smoking. The Global Youth Tobacco Survey in SA reported that $74 \%$ of grade 8-10 school smokers expressed a desire to stop smoking and $77 \%$ had made a quit attempt (Swart et al., 2000). Several other international studies among high school smokers have documented similar evidence (Burt and Peterson, 1998; Sussman et al., 1998; MMWR, 1998).

The link between socio-economic status (SES) (World Bank, 1999), ethnicity (USDHHS, 1998) and smoking among adults in high-income countries, as well as low and middle-income countries (World Bank, 1999) is well known. For adolescents the uptake of cigarette usage has been also marked by differences in socio-economic status (USDHHS, 1994) and ethnicity (USDHHS, 1998). A similar link between the likelihood of stopping smoking and SES and ethnicity (Sussman et al., 1998) has been reported. In SA, as apartheid created a divide with the majority of "white" people enjoying affluence and the majority of "black" and "coloured" people living in poverty, ethnicity can be used as a proxy for socioeconomic status. Vast differences can be seen in the smoking rates for adults among the ethnic groups namely, 19.3\% among "Blacks", 46.7\% among "Coloureds", 32.6\% among "Whites" and 26.9\% among "Indians" (DOH and MRC, 1998). However, the impact of SES and ethnicity on adolescent smoking cessation in SA has not been investigated.

Smoking cessation for adults has made significant advancements. The Cochrane Collaboration has profiled the various techniques for adult cessation and rated their effectiveness in bringing about cessation (Lancaster et al., 2000). Smoking cessation interventions for adolescents on the other hand lacks consistency. It has been an under-researched field (Stanton et al., 1996) with few evaluated interventions (Lamkin et al., 1998). With increasing recognition for its place in tobacco control, smoking cessation research for adolescents is becoming an international priority.

Smoking interventions for adolescents have moved away from "Just say no" campaigns with a focus on knowledge of the health effects of tobacco use for prevention programmes. Addressing the psychosocial and contextual determinants 
of behaviour now forms the hallmark of intervention development. The theoretical constructs of a combination of theories including the Theory of Planned Behaviour (Ajzen, 1991), Social Cognitive Theory (Bandura, 1962) and the Transtheoretical Model (Prochaska, 1984) provide the basis for exploring and analysing these determinants in our study. In addition, the opinions of adolescents on the process of quitting; the preferred methods for quitting and their experiences during quitting have not been taken into account in the design of smoking cessation interventions (Gillespie et al, 1995).

\section{Aim}

This study aimed to explore adolescent opinions" on the determinants of smoking and smoking cessation as a precursor towards intervention development.

\section{Methods}

The findings described in this chapter emanate from the nine focus group discussions conducted among school-going smokers and ex-smokers in the Southern Cape-Karoo Region, one of four health regions in the Western Cape Province. For the purposes of this study, a current smoker was defined as an individual who had smoked a cigarette or a part thereof in the previous thirty days. An ex-smoker was defined as an individual who had stopped smoking and had been smoke-free for at least the previous six months.

The Group Areas Act of 1950, designated areas where people could reside such that people of the same race or ethnic group lived together. Schools were also divided by ethnicity such that "black" children attended school in their area, "whites" in their area and so forth. Despite the abolition of apartheid in 1994, most people still reside in previously defined group areas and schools in the majority of cases, are ethnically homogenous.

\section{Selection of participants}

Six schools were purposively selected based on their locality namely. urban or rural and their ethnicity viz., "black", "white" or "coloured". School selection was also based on the recommendations of the school nurses for this region and verified by the chief medical officer. One class of grade 8 students and one class of grade 9 students (13-14 years old) were randomly selected from each school. Where the prevalence of smoking was low in a class, more than one class was sampled per grade. All the students in the selected classes provided demographic information (age, sex and grade) and their smoking status on a form that was administered by the researchers, independent of the class teacher. Students who reported that they were current or ex-smokers were invited to participate in the discussions.

Students were selected using criterion purposive sampling. The groups combined grade 8 and 9 students of the same gender and in most cases, ethnicity. A total of 74 students ( 24 females and 50 males) were invited to participate. Sixty students 
(20 females and 40 males) participated in the discussions. They were informed that participation was voluntary and were briefed on the nature of the study.

\section{Data collection procedures}

A structured discussion guide was developed using theoretical constructs from the Theory of Planned Behaviour (Ajzen, 1991), Social Cognitive Theory (Bandura, 1962) and Transtheoretical Model of Change (Prochaska, 1984) together with an extensive literature review. The discussion guide was translated from English to Afrikaans and Xhosa and then back translated to English. It was also adjusted according to the local dialect in the study area. Themes explored in the discussion included: knowledge, attitude and social influence towards smoking behaviour, quit attempts, self-efficacy to stop smoking and maintain abstinence, knowledge of and methods used to stop smoking and other forms of tobacco use. The study was piloted amongst learners in Cape Town.

The focus group discussions were 90 minutes in duration and were moderated by the researcher and two research assistants who were as far as possible, of the same ethnic group as the participants. After each discussion, a debriefing session was held to discuss lessons learned, new questions identified and to refine procedures for the next discussion.

The discussions were conducted in English, Afrikaans and Xhosa and were tape recorded with the consent of the participants. Discussions were transcribed and translated into English. Sections of the Xhosa and Afrikaans transcriptions were translated by a second person. Both versions were then compared for accuracy. Discrepancies were discussed with both translators. Research assistants were given explicit guidelines for transcription and translation to ensure uniformity of procedure.

\section{Data analysis}

Data was coded using the software management tool QSR Nudist version 4. The discussion guide was used as a means to create a tree of themes. The data was analysed thematically. New themes were assigned to data that fell outside the possible alternatives. Data was analysed at the first level to synthesise the findings across the discussion groups for each code. At the second level, urban/rural differences as well as gender and ethnic differences were elicited.

\section{Consent}

Ethical approval for the study was obtained from the Ethics Committee of the Faculty of Medicine and Dentistry, Umea University. Permission to conduct the study was also obtained from the South African Department of Education as well as from principals of selected schools. Parents and students were informed verbally and in writing of the purpose of the study and informed consent was obtained. 


\section{Results}

\section{The "journey of quitting"}

\section{Attitude to stop smoking}

The majority of the participants expressed their intention to stop smoking in the future before they became old. However, they did not feel it necessary to stop immediately. A few participants did not perceive the need to stop at all. Some participants expressed hopelessness at the advent of stopping because of the craving that made them start smoking again ("To me it won't be worthwhile to stop, because if you stop, then you start craving to smoke again and then you just start smoking again." "Coloured" Urban Female). Those who did not want to stop smoking perceived their smoking friends as a barrier to being successfull.

Their motivation to stop smoking concurred with their perceived disadvantages of smoking. Additionally, the participants spoke of monetary concerns, fear of parent's reaction to their smoking, negative impact on school performance, and cigarettes as the gateway to the use of other substances. Many of the participants mentioned a friend motivating them to stop smoking ("... I was with another friend, he didn't smoke, then he said to me; you must stop smoking, move over to the right side." "Coloured" Rural Male).

One of the strongest hindrances for the participants to stop smoking was friends who co-erced them to smoke even though they wanted to stop ("It will also be very difficult for me, because I don't want to smoke, then my friends will come and fetch me and... they make a zol (hand-rolled cigarette) and give me a puff." "Coloured" Urban Female. "... I tried to stop but then my friends, they said I was a sissy...It doesn't feel right cause you are like the only one that doesn't smoke in the group." "Coloured" Lirban Male).

"White" males said that they smoked by their own choice and would support friends who wanted to quit ("Like my circle of friends, they don't mind if I don't smoke. They don't like say l'm a sissy... There's no peer pressure between us." "That's why you can't really ever say that he started smoking because..., he was never coerced. It was your choice." "White" Urban Male).

\section{Self-efficacy to stop smoking}

Participants thought that it would be difficult to stop smoking because of the influence of friends, the experience of withdrawal symptoms and letting go of the enjoyment of smoking. "Coloured" and "black" participants were more inclined to refer to the influence of friends while "white" participants referred to personal will power to stop smoking ("It will be difficult because it is nice to smoke. It is not good for the body ... we are young and we want to enjoy life and do what we like doing." "White" Rural Male). Others acknowledged that with time, smoking had become a habit and therefore would be difficult to stop.

On the contrary many believed that it would be easy to stop because they were not addicted; they were still smoking by their own decision. Those who reported 
that it would be difficult to stop were more likely to have reported several quit attempts. One of the participants reported that people who could not stop were those who did not want to stop ("If you want to stop you will be able to stop, cause people they say they can't stop, they are people who don"t want to stop..." "White" Urban Male).

\section{Self-efficacy to maintain abstinence}

Participants were asked how they would react if they had recently stopped smoking and then attended a party where a friend offered them a cigarette. Many reported that they would take the cigarette for various reasons. Some wished to please their friends since they believed that all activities should be undertaken together " $I$ will take, because we are having a good time and everything must be done together." "Coloured" Urban Female), others would "crave for a smoke", and some reported that they would take the cigarette and dispose of it later. "White" males were more likely to have reported that they could resist the temptation.

\section{Quit attempts}

The majority of participants had made at least one quit attempt, with several reporting two or more attempts. The attempts lasted between one day to three weeks with the majority falling on the lower end of the scale ("I"ve stopped for a week but then I started getting restless and agitated." "White" Urban Male).

All of the participants tried to stop on their own i.e., "cold turkey". The most frequently cited method to stop was by staying away from smoking friends ("I just had to forget about my friends who smoke. You and your friends shouldn't be together if you want to stop." "Coloured" Urban Female). Other methods to stop smoking included eating sweet things, going to the gym and staying at home. These methods were predominantly mentioned by "coloured" and "black" participants while the "white" adolescents refer to concepts of "self will" and "stopping on their own".

Participants were aware of the various types of nicotine replacement therapy to stop smoking namely, spray, chewing gum, tablets, and drops. Awareness of pharmacological methods was predominant among "white" adolescents.

\section{Addiction}

"Black" and "coloured" participants did not always have cigarettes readily at their disposal. During the description of the search for cigarettes, participants mentioned a range of withdrawal symptoms. Participants also referred to withdrawal symptoms when trying to stop smoking. These included craving, feellng shaky, restlessness, impatience, irritability, agitation and headaches ("...perhaps you didn't smoke yesterday, you have that thing which makes you as if you are mad, like there's something missing in your head, so like if you smoke like that thing subsides." "Black" Urban Male).

When the concept of addiction was explored, participants, especially the "white" boys, were adamant that they were not addicted. They believed that they had full control over their smoking behaviour in deciding when to smoke and when to stop ("I think it would be easy because I am not addicted as yet. I don't smoke to please 
anybody, that's why it will be easy." ...every time is still my own decision." "White" Rural Male). A participant expressed the belief that it is very difficult for young people to become addicted because of limited access to cigarettes and limited place to smoke.

\section{Environmental influence on behaviour}

According to the participants the solution to stop tobacco use should not be confined within the boundaries of the school. They believed that the shops must stop selling cigarettes to adolescents. Some advocated that tobacco usage be banned completely. Despite awareness of the law, shop owners persisted in selling cigarettes to adolescents because they were the greatest source of revenue ("...close the place of tobacco so that it won"t be available... But even these people who are selling know that. The real gain is from young people..., children are the ones who come with money to buy tobacco." "Black" Urban Male). Household shops (common in "black" and "coloured" communities) also encouraged learners to smoke and made it difficult to quit because of ready access. Participants mentioned that tobacco advertising also made it difficult for programmes to work. "Black" participants advocated that programmes must involve both parents and adolescents since many temptations exist outside of the school. They believe that parents could also benefit from these programmes in terms of their own smoking behaviour.

\section{Other forms of tobacco use}

Participants' knowledge of other tobacco products was limited. Usage of other tobacco products was confined to the "black" and "coloured" children mainly of rural descent. These forms were resorted to as means to circumvent the expense involved in purchasing cigarettes and at the same time to continue feeding their need for nicotine. Cigarette butts were used out of desperation to make a zol (handrolled clgarette), donkey dung was broken into pieces and mixed with tobacco to make a zol, grass was broken into pieces and mixed with tobacco to make a zol and Best Blendt or "BB" (loose tobacco) was purchased after a collection among friends; as it would satisfy their craving for a long time at a much cheaper price.

The "white" boys referred to the use of hand rolled cigarettes and pipe smoking by older generations. Rolling cigarettes was cited as a method to stop smoking because of the cumbersome nature of the practice.

\section{Discussion}

This study aimed to gain an understanding of the determinants of smoking and smoking cessation among adolescents in $S A$, a country with ethnic differences that translate into socio-economic differences. The results demonstrate that there are ethnic differences that characterise smoking behaviour of school-going adolescents. These differences should be key considerations in targeting and tailoring interventions to the specific needs of South African adolescents. 
The impact of poverty, racial discrimination, lack of opportunity, and low perceived life chances on adolescent risk behaviour has not been fully explored (Jessor, 1991). This concept is particularly pertinent to the South African context where poverty characterised by racial discrimination has a marked impact on the day to day living of large groups of adolescents. The physical environments in which this study has taken place speaks of acute poverty and deprivation contrasted by extremes of wealth. Poverty is accompanied by the lack of opportunity for positive stimulation and the constructive channelling of the energy that is so abundant during adolescence. Tobacco use seems to be the one affordable "pleasure" within this malaise of poverty. Poor people find it much more difficult to adopt health promoting behaviour (Reading, 1997) because of their social and financial limitations. Poverty reduction is vital for improving health conditions among the poor. Tobacco use and alcohol for that matter are no different in searching for longterm solutions.

The multiple and short length of quit attempts reported by participants resembles a cyclical process between starting smoking, attempting to stop, starting again and attempting to stop. It has been suggested that tobacco dependence be treated as a "chronic disease with remission and relapse" even in the presence of interventions (USDHHS, 2000). This will allow both providers (health workers, educators etc.) and users (smokers) to recognise relapse as a somewhat known and expected entity rather than a sign of failure.

While the majority of the participants stated that they would like to stop smoking eventually, most were not ready to do so immediately. The multiple quit attempts of our participants contrasted by their lack of intention to quit immediately are indicative of the fluidity associated with adolescent smoking behaviour (Foulds, 1999). Stage appropriate intervention strategies are required to move participants to the eventual objective of stopping smoking and should be considered an outcome measure for smoking cessation interventions.

Participants with multiple quit attempts or those surrounded by people who try but fail, tended to perceive quitting as a difficult process. On the other hand, some of the participants underestimated the addictive nature of nicotine believing that it would be easy to stop smoking and done at will. A study in the US has shown that even though only $5 \%$ of adolescents believed that they would be smoking in 5 years time, in fact $75 \%$ were actually still smoking (USDHHS, 1994).

Skill building to cope with withdrawal symptoms, smoking peers and stressful situations where the stimuli or cues to smoke abound, like at parties, should form the first step towards the development of confidence or self-efficacy to quit smoking and remain smoke free. In fact self-efficacy has been shown to be a key determinant of smoking cessation and maintaining abstinence (Mudde, 1994). Developing self-efficacy as part of relapse prevention should also form an integral part of the programme.

The study participants felt that only a few of their friends wanted to stop smoking. This perceived behaviour of others negatively re-inforces their lack of desire to stop smoking. Despite these perceptions, several studies have shown that 
two thirds of high school smokers in fact try to stop smoking (Swart and Reddy, 2000; Burt and Peterson, 1998; Sussman et al., 1998; MMWR, 1998). Programmes would do well to alleviate these misperceptions in order to encourage quit attempts and as a mechanism to move adolescents along the stages of change.

Even though participants believed that they are not addicted to nicotine, the manifestation of nicotine withdrawal symptoms and the sense of hopelessness it induced in terms of quitting indicate otherwise. While many adolescents underestimate their risk of becoming addicted (World Bank, 1999), addiction actually takes place within the first few years of usage. The majority of adolescents try to stop on their own, as is the case in this study; success rates are limited. Acknowledging the presence of withdrawal symptoms and the early onset of addiction among adolescents, efficacious methods including pharmacological interventions will have to be considered for adolescents, especially heavy smokers. The science of addiction and the need for nicotine replacement therapy among adolescents is in its infancy but nonetheless an emerging discipline. However, at a primary level, programmes must teach adolescents how to recognise withdrawal symptoms and develop coping mechanisms to deal with them.

The sheer desperation brought about by nicotine addiction together with the impoverished socio-economic circumstances in SA where "black" and "coloured" adolescents have to earn money to support their addictive behaviour or improvise with creative but often risky alternatives, places them at greater risk. The ethnic difference closely linked to socio-economic status is evidenced by the crass forms of tobacco usage (e.g., mixing tobacco with donkey dung) mentioned by the "black" and "coloured" participants compared to the more conventional form of handrolled cigarettes or pipe smoking by their "white" counterparts.

Our findings, like in other studies (Burt and Peterson, 1998), indicate that peer influence is a powerful determinant of smoking cessation. Despite the overwhelming negative influence of friends on smoking and stopping smoking many participants reported incidences where both smoking and non-smoking friends have had a positive impact on their smoking behaviour. It has been shown that one of the greatest enhancing factors for the use of cessation programmes among school-going adolescents would be if friends were supportive of such endeavours (Gillespie et al., 1995). Peers can play the dual role of offering support (both smoking and non-smoking peers) and providing leadership or guidance (smoking peers) with their own smoking cessation experience.

While the majority of "coloured" and "black" participants reported being coerced or pressured into smoking by peers and that smoking peers were a significant obstacle to quitting, their "white" counterparts especially "white" boys, emphasised that they smoked by choice and that they would support friends who wanted to stop smoking. This ethnic difference was particularly evident in the discussion group that combined both "coloured" and "white" adolescents. It is plausible that contrary beliefs were used as a power play within the framework of "white superiority" created by apartheid. In addition, "white" adolescents do enjoy greater exposure to the outside world and their higher socio-economic status affords them 
independence at an earlier age. These findings suggest that "black" and "coloured" adolescents who are generally from lower socio-economic groups experienced greater direct pressure to start and continue smoking than "white" adolescents who are generally from higher socio-economic groups. The "white" participants allso displayed greater self-efficacy towards non-smoking. These results are similar to a study on the socio-economic differences in smoking among Dutch adolescents (De Vries, 1995). Our study also shows that "white" males, consistent with their greater self-efficacy, were more likely to be able to refuse a cigarette from friends. The impact of the social environment by way of social noms and social pressure to smoke is an especially important consideration in programme design for "black" and "colloured" adolescents. In fact programmes that are designed to change the social environment towards non-smoking are likely to enjoy greater long-term efficacy (De Vries, 1995).

In line with the impact of the social and physical environment on smoking behaviour, the participants pointed out the need for a reciprocal relationship between the community and the school in order to augment and re-inforce behaviour change in the context of the child's daily life. They pointed out that adolescents are exposed to strong temptations like tobacco advertising and easy access to tobacco outside the school environment. "Black" participants elicited the advocacy for community involvement. It is plausible that the political background of "black" adolescents in SA make them recognise the impact of the collective rather than the individual. The call for community involvement particularly among "black" adolescents is consistent with the need for creating a social environment, both among peers and the community as a whole that encourages a social norm of non smoking.

South African society that has a combination of Eastern and African cultures, consisting predominantly of African, Asian and people of mixed descent (classified as "black" people in SA), as well as Western ("white") cultures can also lend some insight into the behavioural differences of these adolescents. Western cultures that have been characterised as independent and individualistic tend to strive for independence, autonomy or control and an expression of their preferences in order to assert their uniqueness within their environment (Triandis, 1995; Hernandez et al., 2001; Iyengar and Lepper, 1999), hence the expression of self-will, control and higher self-efficacy displayed by "white" adolescents. Eastern and African cultures, on the other hand, are characterised as interdependent and collectivist where individuals in most cases act in accordance with the dictates of the social group in pursuit of harmony (Triandis, 1995; Hernandez et al., 2001; Iyengar and Lepper, 1999). It is believed that in interdependent cultures when personal choice interferes with that of the reference group, individuals may then submit to the choices of the reference group in order to maintain harmony or feel a sense of belonging (Iyengar and Lepper, 1999). In our study "coloured" and "black" learners continue smoking in order to conform and remain within the group of smoking peers. It is believed that intrinsic motivation is integrally linked to the attributes of the culture, whether individualistic or collectivist (Hernandez et al,, 2001; Iyengar and Lepper, 1999). 
Therefore interventions that emphasise personal choice among "white adolescents" while influencing the cholce of the reference group for "black" and "coloured" adolescents may enhance motivation for both these groups to remain smoke free or to stop smoking. In addition, the collectivist nature of the "black" culture could also account for the strong desire among these participants for their social group namely, their community to support them in trying to stop smoking.

\section{Conclusions}

The results of this study among South African adolescents demonstrate the need for addressing the psychosocial determinants of smoking and smoking cessation while taking cognisance of ethnic, cultural and socio-economic differences. The differences in the determinants of smoking behaviour allow one to identify subgroups in the performance of the behaviour and therefore develop tailored or targeted interventions. This qualitative study is by principle context bound and context sensitive, and highlights the need for smoking cessation interventions to be grounded within a framework of poverty reduction and social upliftment. With the possibility of greater perceived future prospects and expectations, perhaps adolescents will be afforded the opportunity to make health-promoting decisions and will possibly develop greater self-efficacy to resist addictive behaviours like tobacco use. 


\section{Chapter 3}

\section{The determinants of smoking among adolescents in South Africa}




\section{Abstract}

Background: The design of tobacco control programmes in multi-ethnic societies must be informed by the factors related to cultural differences in smoking

Methods: The I-Change Model, an extension of the Theory of Planned Behaviour, was used to investigate the factors related to smoking among a sample of 3378 Black African, Coloured and White monthly and non-monthly smokers in the Southern Cape-Karoo Region, South Africa.

Results: Across the ethnic groups, non-monthly smokers reported a more positive attitude toward non-smoking, social influences that were more supportive of nonsmoking, higher self-efficacy in stressful, routine and social situations, greater intention not to smoke in the next year, and lower levels of depressive mood and risk behaviour. Regression analyses suggested that the weight of these factors in predicting monthly smoking may differ amongst the ethnic groups. Black African students may benefit from the development of attitudinal cognitions and coping skills to counter peer influence. Coloured students also require skills to resist peer influence and the development of self-efficacy. White students require coping skills in stressful and social situations.

Conclusions: There are more common than unique factors associated with smoking among South African adolescents, although further evaluation of how smoking programmes can be tailored to the needs of adolescents from differing social, economic and cultural backgrounds is required. 


\section{Introduction}

In 2002, the World Health Organisation rated tobacco use as the second most important cause of the Global Burden of Disease (WHO, 2002). The increasing levels of tobacco use among young people in the 1990 s coupled with it's public health and economic burden led to smoking being labelled a paediatric disease or epidemic (Kessler, 1995; Perry et al., 1994). The Global Youth Tobacco Survey estimated that worldwide on average, $33 \%$ of adolescents had ever smoked cigarettes and $18.7 \%$ were current smokers (GYTS, 2002). In South Africa (SA) in $2002,37.6 \%$ of adolescents ever tried smoking and $18.5 \%$ were classified as current smokers (Swart et al., 2004).

Since the 1970s, the social influences approach was adopted in adolescent smoking prevention programmes (Evans, 1976). Even though there is some support for the long-term effectiveness of this approach, lack of significant programme effects in several studies and variability between studies on their internal and external validity, make this conclusion tenuous (Skara and Sussman, 2003). Psychological models addressing the cognitions of smoking, over and above social

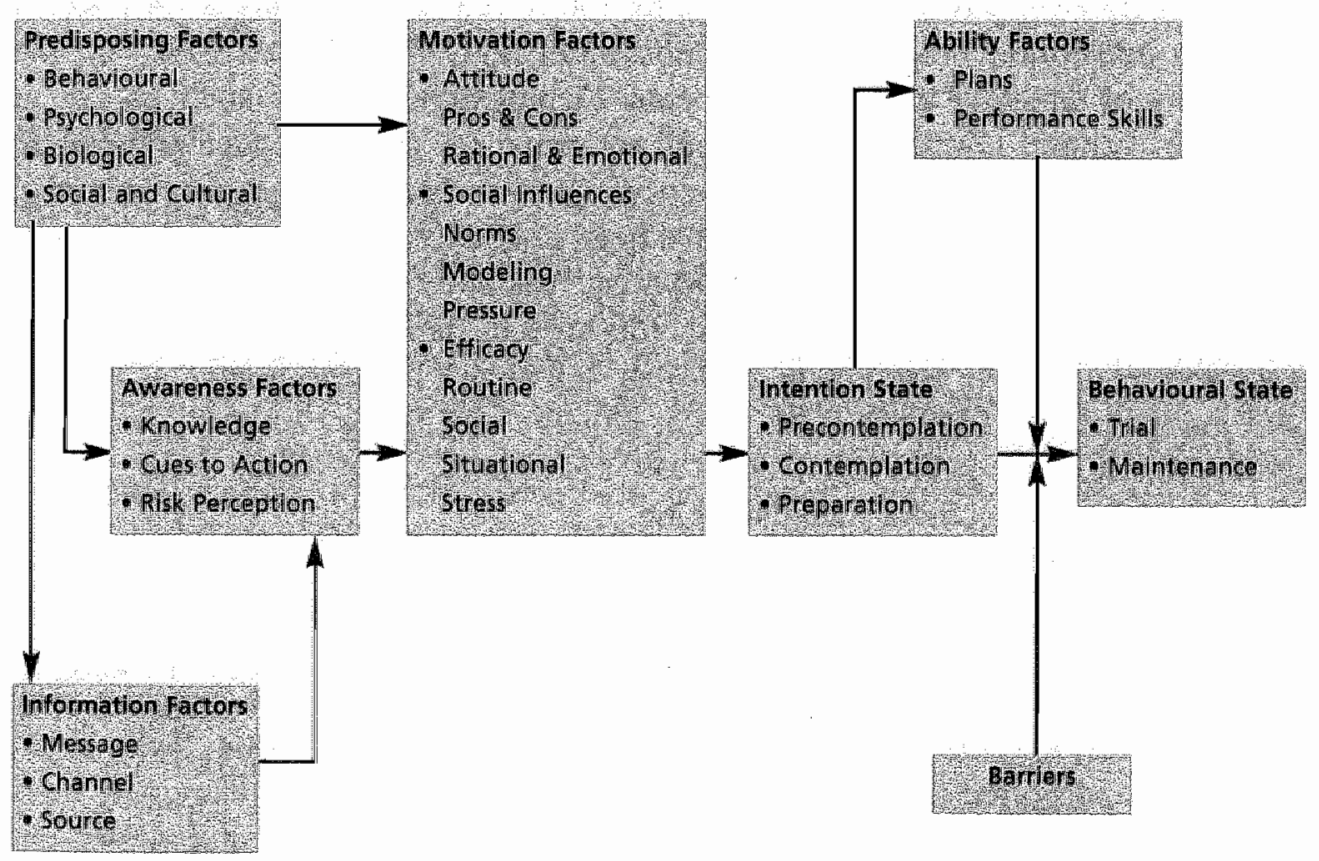

Figure 3.1 An Integrated Model for Change

From "The European Smoking Prevention Framework Approach (ESFA); an example of integrail prevention;" by H. de Vries, M. P. Clemente, H. Storm, A. G. Gonzallez, M. Nebot, T. Prins and S. Kremers, 2003, Health Education Research, 18 , p.612. Copyright 2003 by Oxford University Press. Reprinted with permission of the author. 
influences, such as the integrated model of change (the I-Change Model) (see Figure 3.1) (De Vries et al., 2003c) may be an effective way to develop smoking prevention programmes. The model incorporates insights from the Theory of Reasoned Action (Fishbein and Ajzen, 1975), Social Cognitive Theory (Bandura, 1986) and the Transtheoretical Model (Prochaska, 1983). The model as well as its previous versions (Attitude-Social influence-Self-efficacy Model) has been used to assess the determinants of smoking and to develop and evaluate smoking prevention programmes in several European countries (De Vries et al., 1994, De Vries et al., 1995; De Vries et al., 1988; Dijkstra et al., 1999). The model assumes that the most important determinant of behaviour is behavioural intention which, in turn, is influenced by three proximal factors namely one's overall evaluation of the behaviour (attitude), one's beliefs concerning the beliefs and behaviours of significant others (social influences) and the control that people perceive themsellves to have over performing a behaviour (self-efficacy). Distal factors such as demographic (e.g., age, gender) and psychological factors (e.g., depression) are assumed to influence behaviour via the proximal factors.

The prevalence of tobacco use among adolescents in SA has been recently documented (Swart et al., 2004; Swart et al., 2003). Data is now required on the psychosocial factors related to smoking for the development of empirically based smoking prevention programmes. A substantial body of literature exists on the predictors of smoking among adolescents. Demographic factors such as age at initiation, gender, ethnicity and school performance; cognitive factors such as attitude towards smoking, social influences such as parental and peer smoking; self-efficacy and intention to smoke have been linked to adolescent smoking onset and smoking progression (e.g., see reviews by Tyas and Pederson, 1998; Conrad et al., 1992). Additionally, psychological factors such as depression (Choi et al., 1997; Escobedo et al., 1998; Horn et al., 2004) as well as risk behaviour such as alcohol and marijuana use (Wetzels et al, 2003; Siqueira and Brook, 2003; Rigotti et al., 2000; Everett et al., 1998; LISDHHS, 1994; Holm et al., 2003; Chen et al., 2002a) have been shown to co-vary with smoking.

Ethnic differences have been also reported in both the prevalence and determinants of smoking for adolescents (USDHHS, 1994; Kandel et al., 2004; Kelder et al., 2003; Griesler and Kandel, 1998). In 2002, Black African' adolescents (15.7\%) in SA consistently reported lower prevalence of current smoking than White (21.7\%) and Coloured (38.7\%) adolescents (Swart et al., 2004; Swart et al., 2003). It is purported that culturally-related resilience factors keep smoking rates consistently low among Xhosa-speaking adult (DOH et al., 2002) and adolescent (Swart et al., 2004) females in SA. However, limited data is available on the mechanisms underpinning these differences and whether programmes developed primarily for White adolescents are applicable to other ethnic groups (Skara and

During the Apartheid years, all South Africans were classified into race groups in accordance with the Population Registration Act of 1950 namely, Black African (pieople of African descent), Coloured (people of mixed descent). Indian (people of Indian descent) and White (people of European descent). The authors in no way subscribe to this classification. 
Sussman, 2003; USDHHS, 1998). In fact, the US Surgeon General's report on Tobacco Use Among Racial/Ethnic Minority Groups (1998) referred to the pauciry and methodological weaknesses of studies on the determinants of adolescent smoking amongst ethnic groups.

South Africa is a country where ethnic differences are underpinned by factors such as social, economic, spatial and cultural differences, as ethricity under the apartheid separatist policies was used to discriminate against Black African, Coloured and Indian groups. Despite the transition to a democratic political system in 1994, the effects of a highly skewed distribution of wealth, steep earning inequality, low access to basic services by the poor and unemployment and underemployment are still being felt (UNDPSA, 2003). In 2002, it was estimated that $48.5 \%$ or 21.9 millijon of the SA population fell bellow the national poverty line and that poverty and inequality continued to exhibit strong spatial and racial biases (UNDPSA, 2003). Consequently ethnicity in SA has become a proxy for a group of factors such as social, economic, spatial and cultural differences when these factors are difficult to estimate especially among adolescents in a country in rapid transition. In the present study, ethnic differences in the motivational factors related to smoking onset were investigated with a view to develop culturally sensitive tobacco control programmes for adolescents (Swart et al., 2004; Skara and Sussman, 2003; USDHHS, 1998; Markham et al., 2004).

\section{Methods}

\section{Participants and sampling}

The findings discussed in this chapter are from a sub-sample of the cross-sectional survey conducted in 2002 in the Southern Cape-Karoo Region, Western Cape Province. Grade 9-11 students (14-16 years of age) completed a self-administered questionnaire. Forty-two public schools were eligible to participate in the study. School selection was stratified by ethnicity in accordance with the school's previous race classification under the apartheid government, namely Black African (six schools) „Coloured (17 schools) or White (19 schools), based on previous research (Panday et al., 2003). Previous research (Swart et al., 2003) was also used to estimate the sample of 100 smokers required for each ethnic by gender group. A total of 23 schools were selected to participate in the study, consisting of all six Black African schools, eight randomly selected Coloured schools and nine randomly selected White schools.

The number of classes selected was proportional to the number of grade 9-11 classes in the school, based on an estimated class size of 40 students. Class sellection was stratified by grade and an equal number of classes were randomly selected from each grade. Due to the presence of older students in lower grades, additional classes were selected from the lowest grade. All students in the selected classes were eligible to participate in the study. A total of 121 classes representing 4768 students were selected to participate in the study.

The Research Ethics Committees of the South African Medical Association and 
the Medical Faculty of Umeat University granted ethical approval for the study. Permission was also obtained from the Education Department, principals of selected schools and from parents and students in the selected classes. Parents and students were informed both verbally and in writing that all answers would be treated confidentially and only viewed by the researchers.

\section{Questionnaire}

The questionnaire was administered in three languages, during two regular classroom periods either to individual classes or to groups of classes. The questionnaire was prepared in English and translated from English to Arrikaans and Xhosa. To ensure the accuracy of the translations, the Afrikaans and Xhosa versions of the questionnaire were back translated to English. To guarantee confidentiality, trained research assistants administered the survey in the classroom simulating 'examination like' conditions; teachers were asked to leave the classroom during survey administration. In order to ensure anonymity, students were requested not to write their names on the questionnaires.

The European Smoking Prevention Framework Approach (ESFA) questionnaire (De Vries et al., 2003b; De Vries et al., 2003c) was used as the core of the questionnaire. The questionnaire assessed smoking behaviour, attitude, social influences, self-efficacy expectations, intention not to smoke in the next year, depressive mood, risk behaviour and several demographic items. Additionally, item selection and item formulation used in the ESFA questionnaire were validated and localised to the South African context through data obtained from prior qualitative research (Panday et al., 2003), through focus group discussions during questionnaire development and from a pilot study conducted among 292 Grade 9 English, Afrikaans and Xhosa speaking students in the study area.

\section{Measures}

Smoking behaviour. Adolescents were asked to pick a statement that best described them out of a set of specific smoking-related questions. Adolescents were then categorised as never smokers (never smoked not even one puff), triers (tried smoking once in a while but not monthly), non-smoking deciders (tried smoking less than once a week but not smoking anymore), experimenters or monthly smokers (smoking at least once a month, but not weekly), regular smokers (culrently smoking cigarettes weekly or more), and quitters (quit smoking after having smoked at least once a week) (Kremers et al., 2004). Self-reports of smoking could not be biologically validated due to logistical and financial constraints. However, when anonymity is assured, self-reports have been shown to be reliable and in agreement with biochemical markers (Dolcini et al., 1996). Self-reported smoking was cross-validated using an algorithm consisting of four additional concepts measuring current smoking and lifetime smoking. When incongruent answers were found, participants were given the most unfavourable response (De Vries et al., 2003b).

Attitudes were assessed by two five-point scales measuring pros and cons of non- 
smoking respectively that were identified through factor analyses and as defined in previous research (see Table 3.1) (De Vries et al., 2003b; Kremers et al., 2001a; Kremers et al., 2001b). The pros of non-smoking were measured with a seven-item scale (e.g., 'If I do not smoke it will be very good for my health $(+2)$ or very bad for my health $(-2)^{\prime}$; Cronbach's alpha $\left.(\alpha)=0.86\right)$. The cons of non-smoking were measured with a five-item scale (e.g. "If I do not smoke it will make me feel very relaxed $(-2)$ or very stressed $(+2) ; \alpha=0.68$ ). One item referring to drug use was excluded due to ambiguity in the Xhosa version of the questionnaire.

Social influences. Influences from the social environment were measured by assessing perceived social norms, smoking behaviour and direct pressure from important others: mother, father, grandmother, grandfather, brother(s), sister(s), friends, best friend, classmates and teachers (see Table 3.1). Social norms were measured on a five-point scale assessing students' perceptions of whether important others (combined into family, 6 items, $\alpha=0.86$; friends, 3 items, $\alpha=0.79$; and teacher) thought that they definitely should $(-2)$ or should not $(+2)$ smoke. perceived smoking behaviour assessed the smoking behaviour of mother, father, grandmother, grandfather, brother(s), sister(s) and best friends using a two-point scalle ( $0=$ smoking, $1=$ non-smoking). The seven items were analysed separately as they did not load uniquely on the one perceived smoking behaviour factor. Direct pressure was measured on a five-point scale to assess how often pressure not to smoke ( 0 = never, $4=$ very often) was encountered (combined into family, 6 items, $\alpha=0.90$; friends, 3 items, $\alpha=0.87$; and teacher).

Self-efficacy. Multiple item scales (see Table 3.1$)$ measured how sure $(+2=$ sure that I will not smoke, -2 = sure that I will smoke) students felt that they could refrain from smoking in stressful situations (stress self-efficacy, 10 items $\alpha=0.98$ ), routine situations (routine self-efficacy; 5 items $\alpha=0.94$ ) and social situations (social self-efficacy, 4 items $\alpha=0.93$ ). The items were identified through previous research (De Vries et al, 1988; Lawrance, 1998).

Demographic variables. Characteristics of the participants were provided by asking for ethnicity $(1=$ Black African, $2=$ Coloured, $3=$ White $)$, gender $(0=$ boys, 1 $=$ girls), age (continuous scores), school performance $(0=$ lowest, $1=$ average, $2=$ best), spending money $(0=$ no, $1=$ yes $)$ and religion $(0=$ no religion, $1=$ religious $)$.

Depressive mood. A scale developed by Kandel and Davies (1982) was used to measure depressive mood. Six items using a five-point scale $(0=$ never, $4=$ always $)$ assessed "How often adolescents were bothered or troubled by the following states, namely 'feeling too tired to do things', 'having trouble going to sleep or staying asleep', 'feeling unhappy, sad or depressed', 'feeling hopeless about the future', 'feeling nervous or tense' and 'worrying too much about things'. Mean scores were calculated to produce an index of depressive mood with a range of $0-4(\alpha=0.87)$.

Risk behaviour. Risk behaviour was measured with eight items on a five-point scale $(0=$ never, $1=$ sometimes, 2 = less than once $a$ month, $3=$ not weekly but at least once a month, 4 = at least once a week) assessing use of alcohol, marijuana, methaqualone, other drugs, sniffing substances, gambling, playing the Lotto (form of lottery in SA) and playing truant from school; $\alpha=0.69$. 
Table 3.1 Factors among the psychosocial associates of non-smoking

\begin{tabular}{|c|c|c|c|}
\hline \multirow{2}{*}{$\frac{\text { ITEM }}{\text { At titude }(-2,42)}$} & \multicolumn{2}{|c|}{ FACTORS } & \\
\hline & $\begin{array}{c}\text { Pros of non-smoking } \\
(\alpha=0.86)\end{array}$ & $\begin{array}{l}\text { Cons of non-smoking } \\
(\alpha=0.68)\end{array}$ & \\
\hline improves the smell of my breath & .73 & & \\
\hline It saves me money & .69 & & \\
\hline It is good for ny health & .63 & & \\
\hline it himproves my school performance & .52 & & \\
\hline It limproves my sport performance & .63 & & \\
\hline it improves the collour of my teeth & .65 & & \\
\hline It is wise of me & .72 & & \\
\hline I am more likely to use alcohol & & .55 & \\
\hline It is difficult to be part of a crowd & & .55 & \\
\hline It will make me feel stressed & & .62 & \\
\hline My friends will think worse of me & & .53 & \\
\hline I will gain weight & & $.22^{b}$ & \\
\hline Social Norm: $(-2,+2)$ & $\begin{array}{c}\text { Family } \\
(\alpha=0.86)\end{array}$ & $\begin{array}{l}\text { Friends } \\
(\alpha=0.79)\end{array}$ & \\
\hline Mother & 69 & & \\
\hline Father & .62 & & \\
\hline Grandmother & .57 & & \\
\hline Grandfather & .52 & & \\
\hline Brother (s) & .67 & & \\
\hline Silster ( $(5)$ & .65 & & \\
\hline Friends & & .71 & \\
\hline Best friend & & .78 & \\
\hline Classmates & & .67 & \\
\hline Teachers & & & .70 \\
\hline Direct Pressure $(0,+4)$ & $\begin{array}{c}\text { Faimily } \\
(\alpha=0.90)\end{array}$ & $\begin{array}{l}\text { Friends } \\
(\alpha=0.87)\end{array}$ & \\
\hline Mother & 81 & & \\
\hline Father & .74 & & \\
\hline Grandmother & .76 & & \\
\hline Grandfather & .73 & & \\
\hline Brother (s) & .79 & & \\
\hline Sister (s) & .78 & & \\
\hline Friends & & .82 & \\
\hline Best friends & & .78 & \\
\hline Classmates & & .77 & \\
\hline Teachers & & & .73 \\
\hline Self-efficacy $(-2 ;+2)$ & $\begin{array}{c}\text { Stress } \\
(\alpha=0.98)\end{array}$ & $\begin{array}{l}\text { Routine } \\
(a=0.94)\end{array}$ & $\begin{array}{c}\text { Sacial } \\
(00=0.93)\end{array}$ \\
\hline When you feel bored & 78 & & \\
\hline When you struggle to concentrate & .61 & & \\
\hline When you crawe a clgarette & .53 & & \\
\hline When you feel depressed & .98 & & \\
\hline When you ferell irititable & .82 & & \\
\hline When you feel miserable & .98 & & \\
\hline When you feel nervous & .96 & & \\
\hline When you feel restless & .72 & & \\
\hline When you feel upset & .90 & & \\
\hline When you feel worried & .55 & & \\
\hline Whet you are doing homework & & .91 & \\
\hline When you are hungry & & .54 & \\
\hline When on your way to the shop & & 42 & \\
\hline Whell you are watching telewision & & .83 & \\
\hline When on your way home from school & & .60 & \\
\hline When with others who smoke & & & .66 \\
\hline When with friends who smoke & & & 87 \\
\hline When you are offered a cigarette & & & .94 \\
\hline When friends offer you a cigarette & & & .94 \\
\hline
\end{tabular}

Highest loadings per item $(>, 40)$ are shown.

"Although factor loading $<.40$, this item has been irrcluded in the analysis. 
Intention. Participants' intention not to smoke in the next year was measured by one item on a five-point scale $(-2=$ definitely yes, $+2=$ definitely not $)$ :

\section{Statistical analyses}

Non-monthly smokers (never smokers, triers, non-smoking deciders and quitters; coded as 0 ) and monthly smokers (experimenters and regular smokers; coded as 1) were included in the analyses. Monthly smokers and non-monthly smokers for each ethnic group were compared with regard to denographic variables using logistic regression for dichotomous variables and F-tests for linear varlables. Significant differences $(\mathrm{p}<.01)$ between monthly and non-monthly smokers were found for age, gender, school performance, spending money and religion. These variables were included as covariates in subsequent analyses. Differences in attitude, social influences and self-efficacy between the smoking categories and ethnic groups were analysed using 2 (Smoking Categories: non-monthly smokers vs. monthly smokers) x 3 (Ethnic Groups: Black African vs. Coloured vs. White) covariance analyses (ANCOVAs). Where mean scores were dependent on the interaction of Smoking Categories and Ethnic Groups, simple main effect analyses were conducted to test the relationship between Smoking Categorles and the dependent variable within each ethnic group. Where a significant main effect for Ethnic Group was found (corrected for smoking status), contrast analyses were conducted to determine which ethnic groups differed significantly.

To identify the correlates of monthly smoking within the different ethnic groups, separate logistic regression analyses were conducted for the three ethnic groups with smoking status as the dependent variable. Demographic variables as well as distal factors (depressive mood and risk behaviour) were entered in Block 1 , attitude, social influences and self-efficacy variables in Block 2 , and intention not to smoke in the next year in Block 3 (Holm et al., 2003). For the regression analyses, the subscales for social norms, direct pressure and self-efficacy were combined into one scale each respectively due to the high inter-correlations among the sub-factors. Direct pressure was excluded from the regression analyses due to a suppressor effect among Black African students. A backward deletion procedure was used to determine the final model of variables that relate to smoking status for each ethnic group. Due to the large sample size, the significance level was set at $\mathrm{p}$ $<.01^{2}$.

\section{Results}

\section{Characteristics of the sample}

Of the 4768 students selected to participate in the study, 3869 completed the questionnaire. Due to missing or incomplete data on key variables, 491 cases were

\footnotetext{
Although strength of association or effect size $\left(60^{2}\right)$ is considered a better measure of differences between groups due to its insensitivity to sample size, the calculation of effect size for covariance analyses is limited to equal sample sizes in all cells or balanced designs. The equation is not elaborated for unequal cell sizes.
} 
excluded from the analyses leaving 3378 (559 monthly smokers and 2990 nonmonthly smokers) eligible for the present study (see Table 3.2). The mean age of the participants was 16.23 years ( $\mathrm{SD}=1.65)$ and the overall distribution of males and females was $58.2 \%$ for males and $41.8 \%$ for females. Most students were Black African (52.3\%) followed by Coloured (38.3\%) and White (9.4\%) students. Most students reported that they received spending money $(81.0 \%)$, that they were religious $(80.5 \%)$ and had an average school performance $(58.5 \%)$.

Differences were found on some of the demographic ttems between monthly and non-monthly smokers across the ethnic groups as well as within the ethnic groups (see Table 3.2). Monthly smokers were older than non-monthly smokers. Among the Black African students, the percentage of males who smoked monthly was higher than the percentage of females who smoked monthly. Significant gender differences were not found between White and Coloured monthly smokers and White and Coloured non-monthly smokers respectively. More non-monthly smokers than monthly smokers reported receiving spending money. Non-monthly smokers reported a better school performance than monthly smokers.

\section{Differences between monthly and non-monthly smokers}

Across the ethnic groups, non-monthly smokers reported more pros of nonsmoking, fewer cons of non-smoking, more social norms from family, friends and teachers not to smoke, more direct pressure from friends and teachers to refrain from smoking, fewer important others who smoked, greater self-efficacy during stressful, routine and social situations, a more positive intention not to smoke in the next year, and lower levels of depressive mood and risk behaviour (see Table 3.3).

The differences between monthly and non-monthly smokers differed for the three ethnic groups on the pros of non-smoking, stress and social self-efficacy scales, intention not to smoke in the next year, depressive mood and risk behaviour. Simple main effect analyses showed that non-monthly smokers were more convinced of the pros of non-smoking, displayed higher stress and social selfefficacy and had a more positive intention not to smoke in the next year than monthly smokers in all three ethnic groups, but these patterns were more pronounced among Coloured and White students than among Black African students. Additionally, Black African and Coloured monthly smokers reported higher scores on the depressive mood scale than Black African and Coloured nonmonthly smokers respectively. For all three ethnic groups, monthly smokers engaged in risk behaviour to a greater extent than non-monthly smokers, although the difference was more pronounced among Black African students than among Coloured and White students.

\section{Differences between ethnic groups}

Across the smoking groups, Black African students were less convinced of the pros of non-smoking than Coloured and White students while Coloured students were least convinced of the cons of non-smoking, followed by Black African and, in turn, 


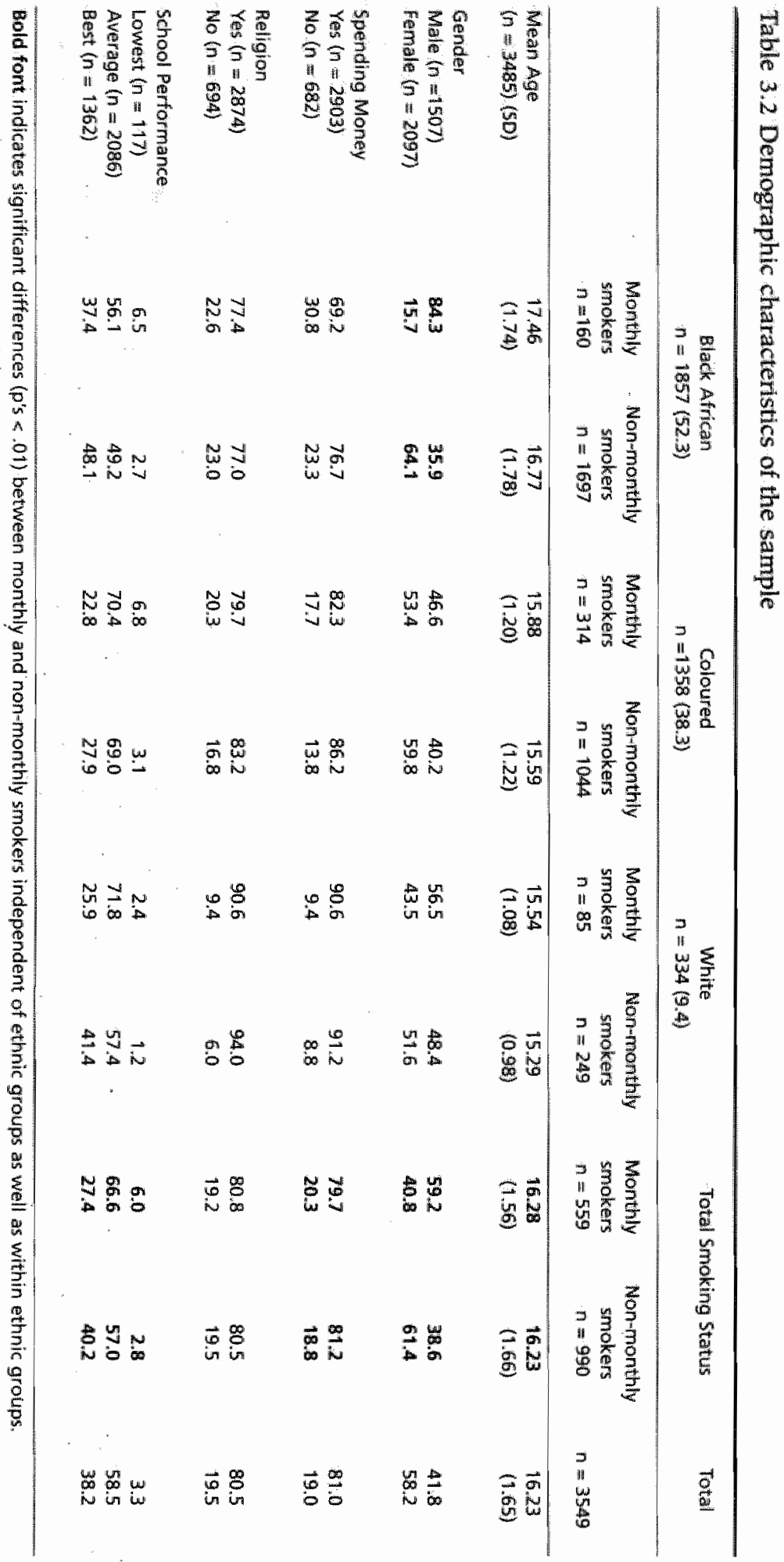




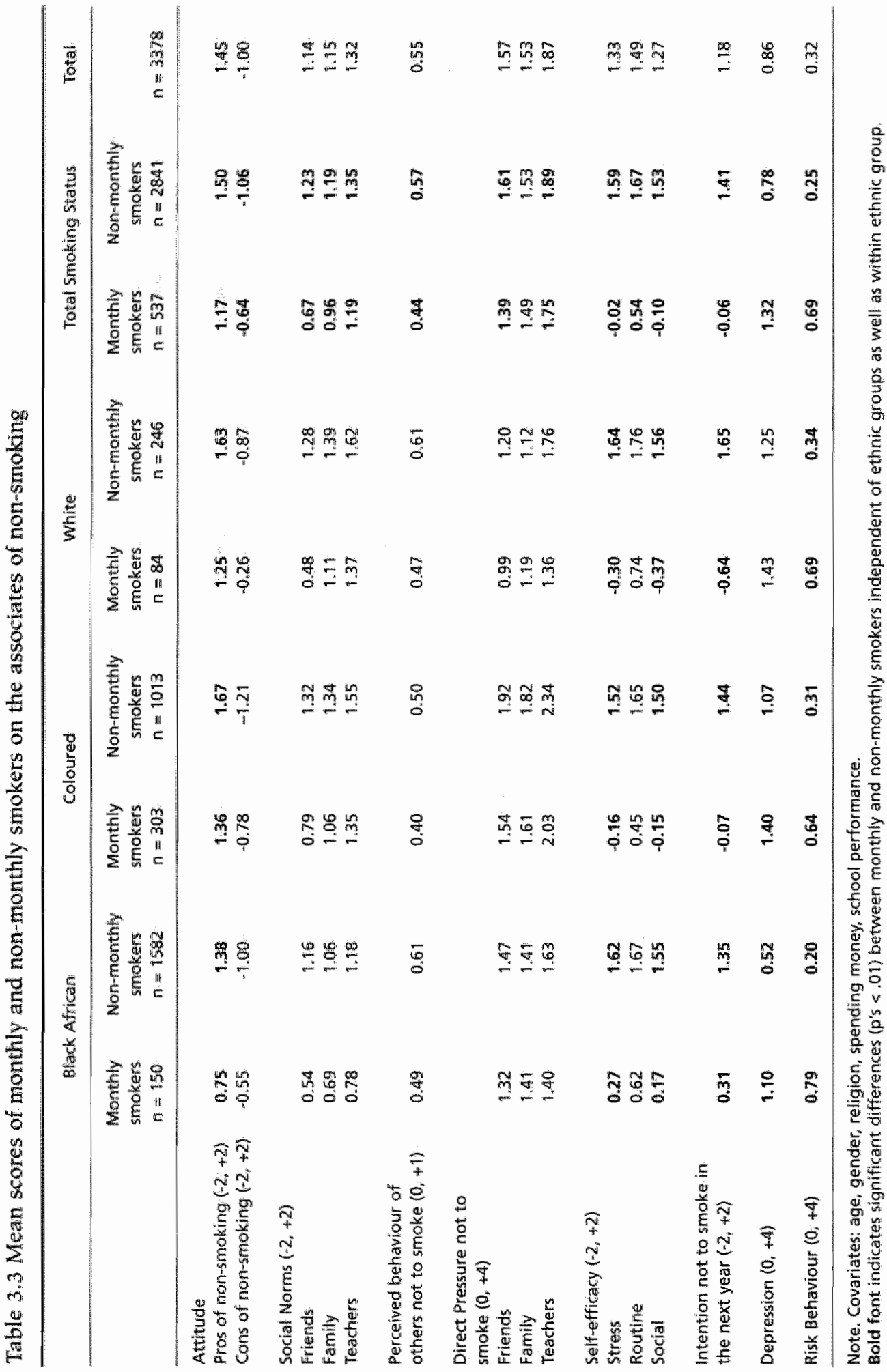


White students (see Table 3.4). Coloured students experienced a stronger social norm from their friends not to smoke than Black African and White students respectively, while Coloured and White students experienced stronger norms not to smoke from their family and teachers as opposed to Black African students. Coloured students also reported more smoking among their important others than Black African and White students. Most Coloured students followed by Black African students and, in turn, White students experienced pressure from their family and friends not to smoke. More Coloured students than Black African and White students experienced pressure from their teacher not to smoke.

While White and Coloured students reported lower stress and social self-efficacy than Black African students, Coloured students reported lower routine self-efficacy than the other two groups. Black African students expressed a more positive intention to smoke in the next year than Coloured and White students. White students reported the highest level of depressive mood, followed by Coloured and, in turn, Black African students. No significant differences were found between the ethnic groups on risk behaviours.

Table 3.4 Mean scores of Black African, Coloured and White students on the associates of non-smoking

\begin{tabular}{|c|c|c|c|c|}
\hline & $\begin{array}{c}\text { Black } \\
\text { African } \\
(n=1732)\end{array}$ & $\begin{array}{l}\text { Coloured } \\
(n=1316)\end{array}$ & $\begin{array}{l}\text { White } \\
(n=330)\end{array}$ & $\begin{array}{c}\text { Total } \\
\langle(n:=3378)\end{array}$ \\
\hline $\begin{array}{l}\text { Attitude } \\
\text { Pros of non-smaking }(-2,+2) \\
\text { Cons of non-smoking }(-2,+2)\end{array}$ & $\begin{array}{r}1.32^{\mathrm{a}} \\
-0.96^{\mathrm{a}}\end{array}$ & $\begin{array}{r}1.60^{\mathrm{b}} \\
-1.11^{\mathrm{b}}\end{array}$ & $\begin{array}{r}1.53^{b} \\
-0.72^{c}\end{array}$ & $\begin{array}{r}1.45 \\
-1.00\end{array}$ \\
\hline $\begin{array}{l}\text { Social norms not to smoke }(-2,+2) \\
\text { Friends } \\
\text { Family } \\
\text { Teachers }\end{array}$ & $\begin{array}{l}1.10^{\mathrm{a}} \\
1.03^{\mathrm{a}} \\
1.14^{\mathrm{a}}\end{array}$ & $\begin{array}{l}1.20^{\mathrm{b}} \\
1.28^{\mathrm{b}} \\
1.59^{\mathrm{b}}\end{array}$ & $\begin{array}{l}1.07^{\mathrm{a}} \\
1.32^{\mathrm{b}} \\
1.56^{\mathrm{b}}\end{array}$ & $\begin{array}{l}1.14 \\
1.15 \\
1.32\end{array}$ \\
\hline $\begin{array}{l}\text { Perceived behaviour of importiant } \\
\text { others not to smoke }(0,+1)\end{array}$ & $0.60^{\mathrm{a}}$ & $0.48^{b}$ & $0.58^{\mathrm{a}}$ & 0.55 \\
\hline $\begin{array}{l}\text { Direct pressure not to smoke }(0,+4) \\
\text { Fritends } \\
\text { Family } \\
\text { Teachers }\end{array}$ & $\begin{array}{l}1.46^{\mathrm{a}} \\
1.41^{\mathrm{at}} \\
1.61^{\mathrm{at}}\end{array}$ & $\begin{array}{l}1.83^{\mathrm{b}} \\
1.78^{\mathrm{b}} \\
2.27^{\mathrm{b}}\end{array}$ & $\begin{array}{l}1.15^{\mathrm{C}} \\
1.14^{\mathrm{C}} \\
1.66^{\mathrm{a}}\end{array}$ & $\begin{array}{l}1.57 \\
1.53 \\
1.87\end{array}$ \\
\hline $\begin{array}{l}\text { Self-efficacy }(-2,+2) \\
\text { Stress } \\
\text { Routine } \\
\text { Social }\end{array}$ & $\begin{array}{l}1.50^{\mathrm{a}} \\
1.58^{\mathrm{a}} \\
1.43^{\mathrm{a}}\end{array}$ & $\begin{array}{l}1.14^{b} \\
1.38^{b} \\
1.12^{b}\end{array}$ & $\begin{array}{l}1.22^{\mathrm{b}} \\
1.50^{\mathrm{a}} \\
1.07^{\mathrm{b}}\end{array}$ & $\begin{array}{l}1.33 \\
1.49 \\
1.27\end{array}$ \\
\hline Intention not to smoke in the next year $\left(-2_{n}+2\right)$ & $1.26^{\mathrm{a}}$ & $1.10^{\mathrm{b}}$ & $1.07^{b}$ & 1.18 \\
\hline Depression $(0,+4)$ & $0.57^{\mathrm{a}}$ & $1.15^{\mathrm{b}}$ & $1.29^{\mathrm{C}}$ & 0.86 \\
\hline Risk Behaviour $(0,+4)$ & 0.25 & 0.39 & 0.43 & 0.32 \\
\hline
\end{tabular}

Note Covariates: age, gender, religion, spending money, schaol performance.

$a, b, c$ significant differences between ethnic groups $\left(p^{\prime} s<.01\right)$. 


\section{Correlates of monthly smoking}

Figure 3.2 shows the correlations of attitudes, social influences and self-efficacy with intention and behaviour (monthly smoking) for the three ethnic groups. The highest correlations were found among the White students whereas the lowest correlations were found among the Black African students. Self-efficacy correlated most strongly with intention for all ethnic groups.

To determine the most important factors associated with monthly smoking for each of the ethnic groups, separate logistic regression analyses were conducted (see Table 3.5). Among the Black African students, in the first step, gender, depressive mood and risk behaviour were significant correlates. In the second step, gender and depressive mood remained as significant correlates, as were having a non-smoking best friend and self-efficacy. In the third step, gender, depressive mood, a nonsmoking best friend, as well as self-efficacy were significant correlates. Among the Black African students, the model correctly classified $47.9 \%$ of the monthly smokers and $98.4 \%$ of the non-monthly smokers respectively.

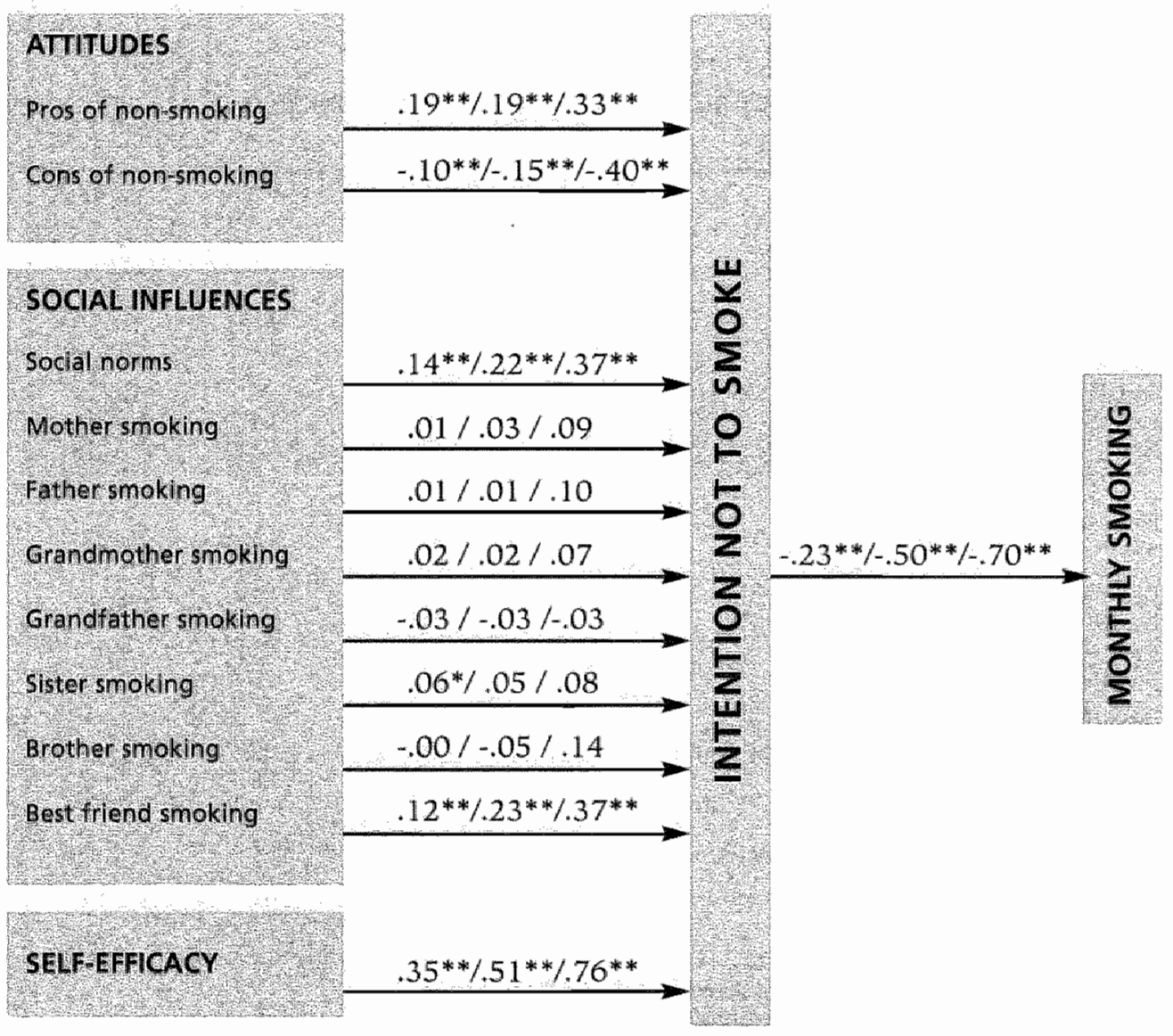

Figure 3.2 Correlations among the psychosocial factors for Black African / Coloured / White students, * p's $<.01$ 
Table 3.5 Correlates of monthly smoking ( $1=$ yes; $0=$ no) anong Black African, Coloured and White students: correlations with smoking status (r) and odds ratios (OR) with $95 \%$ confidence intervals $(95 \% \mathrm{CD})$

r $\quad$ or $\quad$ or

\section{Black African Students}

Demographic wariables

Gender $\left(1=\right.$ girl $_{n} 0=$ boy $)$

Depressive Mood $\left(0=\right.$ never, $^{4}=$ allways)

$\begin{array}{rl}-0.28 * * & 0.11 * * * \\ 0.20 * * & 1.79 * * * \\ 0.37 * * & 2.74 * * *\end{array}$

(0.07-0.18)

Risk Behawiour 0 (neg), 4 (pos)

$0.37 *$

$(1.42+2.26)$

$(2.00-3.77)$

+ ASE Variables

Gender $(1=$ girl, $0=$ boy)

Depressive Mood ( $0=$ never, $4=$ always)

$-0.28 *$

$0.16 *$

$0.20 * *$

$2.08 * *$

$-0.25 *$

$0.48 *$

Best friend non-smoking 0 (negy, +1 (pos)

$-0.49 *$

$0.21 * * 2$

$(0,09-0.27)$

$(1.56-2.76)$

Self efficacy not to smoke -2 (neg), +2 (pos)

+ Intention not to smake

Gender ( $1=$ girl, $0=$ boy $)$

Depressive Mond $(0=$ never, $4=$ always)

Best fritend non-smoking 0 (neg), +1 (pos)

Self-efficacy not to smoke -2 (neg), +2 (pos)

$-0.28^{+1+2}$

$0.15 * * *$

$(0.3 *-0.77)$

$(0.16-0.29)$

\section{Coloumed Students}

Demographic variables

Depressive Mood $(0=$ never, $4=$ always $)$

Risk Behaviour

$\begin{array}{ll}0.17^{* *} & 1.41 * * * \\ 0.30 * * & 3.99 * *\end{array}$

$0.20 *+k$

$2.24 * *$

$(0.090 .27)$

-0.25 *

$0.48 * * *$

$(1.67-3.00)$

-0.49 का

$(0.28-0.72)$

$0.21^{\text {* * * * }}$

$(0.45-0.28)$

* ASE variables

Risk Behavioui"

Best friend non-smoking 0 (neg) +1 (pos)

Self-efficacy not to smoke -2 (neg), +2 (pos)

$0.30 * *$

$2.69 * * *$

$(2.90-5.49)$

* Intention not to smoke

Risk Behaviour 0 (neg) +4 (pos)

Best friend non-smoking 0 (neg) +1 (pos)

Self-efficacy not to simoke $: 2(\mathrm{neg}),+2$ (pos)

intention not to smoke -2 (neg), +2 (pos)

$-0.33^{* k *}$

$0.38 * * *$

$-0.70^{* * x}$

$0.10 * * *$

$(1.77-4.08)$

$(0.25-0.57)$

$(0.07-0,13)$

\section{White Studerits}

Derrographic variables

Risk Behaviour 0 (neg) +4 (pos)

$0.36 *$

$8.17 * * *$

$(4.06-16,4.4)$

- ASE variables

Risk Behaviour 0 (neg) +4 (pos)

$0.36 * *$

4.63 *** *

$=0.74 * *$

$0.07 * *$

$(1.83-11.74)$

Self-efficacy not to smoke -2 (neg), +2 (pos)

+ Irtention not to smoke

Risk Behaviour 0 (neg) +4 (pos)

$0.36 *$

$2.07 * *$

$(1.36-3.19)$

$-0.33^{* * *}$

$0.42 *$ *t

$(0.27-0.63)$

$(0.09-0.17)$

0.50

$(0.50-6.69)$

Self-efficacy not to smoke -2 (neg) +2 (pos)

intention not to smoke 2 (neg) ${ }_{n}+2$ (pos)

$-0.74^{* * *}$

$5.75 * *$

$(2.12-15.65)$

$-0.70$

$0.14 * * *$

$(0.30-0,604)$

Note. "neg' means negative towards non-smoking. 'pos" meanis positive towards non-smoking.

$* p<.01 * * p<.001$ 
Among the Coloured students, in the first step, depressive mood and risk behaviour were significant correlates of monthly smoking. In the second step, risk behaviour, a non-smoking best friend and self-efficacy were significant correlates of monthly smoking. In the third step, risk behaviour, a non-smoking best friend, selfefficacy and intention not to smoke were significant correlates of monthly smoking. Among the Coloured students, the model correctly classified $71.9 \%$ of the monthly smokers and $95.0 \%$ of the non-monthly smokers respectively.

Among the White students, in the first step, risk behaviour was the only significant correlate of monthly smoking. In the second step, risk behaviour and self-efficacy emerged as significant correlates of monthly smoking. In the third step, risk behaviour, seli-efficacy and intention not to smoke in the next year were significant correlates of monthly smoking. Among the White students, the model was able to correctly classify $77.1 \%$ of monthly smokers and $95.0 \%$ of non-monthly smokers respectively.

\section{Discussion}

This study describes the differences in attitude, social influences, self-efficacy, intention not to smoke in the next year, depressive mood and risk behaviour between monthly and non-monthly smokers among Black African, Coloured and White students. Overall, non-monthly smokers displayed a more positive attitude toward non-smoking, were surrounded by a social environment that was supportive of non-smoking and displayed higher self-efficacy not to smoke in stressful, routine and social situations. Non-monthly smokers were also more positive about their intention not to smoke in the next year and reported lower levels of depressive mood and risk behaviour. Holm and colleagues (2003) also found that the cognitive factors distinguished smokers from non-smokers in that smokers held more positive attitudes towards smoking, perceived more positive social norms, smoking and social pressure to smoke from important others, and had lower confidence to refuse cigarettes when with smoking friends.

The interaction patterns between smoking status and the ethnic groups on the pros of non-smoking, self-efficacy sub-factors and intention not to smoke in the next year suggest that smoking status had a different relationship to these factors in each ethnic group. The differences between monthly and non-monthly smokers on these factors were more pronounced among Coloured and White students than among Black African students. For the other cognitive factors, the lack of interaction patterns between smoking status and the ethnic groups suggest that the differences between monthly and non-monthly smokers were the same for each of the ethnic groups. Other studies have also concluded that there are more common than unique ethnic predictors of smoking initiation (Kandel et al., 2004; Griesler et al., 2002).

Black African students as opposed to White and Coloured students, however, reported lower scores on the pros of non-smoking suggesting that they were on average less convinced of the detrimental effects of smoking. The lack of intention 
as a correlate of smoking in the regression analyses as well as the weak fit of the research model in this group, particularly among the monthly smokers, may, in addition, intimate towards distal correlates of monthly smoking such as gender and depressive mood. Additionally, depressive mood, a distal correlate among Coloured students, influenced monthly smoking through the psychosocial variables, as predicted by the I-Change Model; the distal correlates among Black African students (gender and depressive mood), on the other hand, had a direct influence on monthly smoking. While the I-Change Model provides a useful framework for the development of programmes that address the motivational factors associated with smoking among Coloured and White students, further investigation of the attitudinal beliefs, cultural as well as distal factors motivating smoking among Black African adolescents may be required. It is possible that the model did not adequately elaborate cultural factors motivating smoking among Black African students and that the belief components relevant to this group were not adequately measured by the psychosocial factors included in the study.

Even though self-efficacy was a correlate of smoking for all ethnic groups, the covariance analyses showed that Coloured students may require coping skills for all of the self-efficacy sub-factors while White students may benefit mostly from these skills in stressful and social situations. The covariance and regression analyses also highlight the importance of the social environment in smoking for Coloured and Black African students. Coloured students reported higher perceived social morms and direct pressure not to smoke accompanied by higher levels of perceived smoking behaviour among their important others. $A$ smoking best friend was a correlate of monthly smoking for both Coloured and Black African students but not for White students. While other studies have reported peer smoking as predictive of smoking among White students (Griesler and Kandel, 1998; Unger et al., 2001; Sussman et al., 1987), qualitative research in SA demonstrated that White smokers as opposed to Black African and Coloured smokers believed that they smoked by choice and were not influenced by their peers (Panday et al., 2003). Similarly, a six country European study also showed that peer influences may be not always the strongest predictor of adolescent smoking (De Vries et al., 2003a). Community-based programmes in SA would do well to account for the differing influence of the social environment in smoking onset. In fact, it has been shown that social norms and modelling the behaviour of important others can account for the influence of ethnicity on adolescent smoking (Markham et al., 2004; Ellickson et al., 2003).

Risk behaviour was the only distal correlate among Coloured and White students that was not related to monthly smoking through the psychosocial variables and distinguished non-monthly smokers from monthly smokers in these two groups. Danish adolescents also reported an association between smoking and deviant behaviour such as alcohol use and stealing things (Holm et al., 2003). The co-variation and gateway effect of smoking and risk behaviour among adolescents is well documented (Wetzels et al., 2003; Siqueira and Brook, 2003; Rigotti et al, 2000; Everett et al., 1998; USDHHS, 2004; Chen et al., 2002a). However, further 
investigation among adolescents in $\mathrm{SA}$ is warranted to inform the need for comprehensive rather than singular programmes.

While the correlates of smoking for Black African and White adolescents are distinct to each other; the correlates for Coloured adolescents straddle the two groups perhaps reflective of the social and economic transition in post-apartheid SA. Programmes in SA would do well to recognise the influence of the cultural context on smoking behaviour. It is known that factors such as low socio-economic status, poverty, and low educational attainment, that are related to smoking, tend to cluster in certain ethnic groups (Tyas and Pederson, 1998). In fact, smoking prevalence has migrated over time through the socio-economic groups, in both developed and developing countries, and resulted in higher smoking rates among those from lower socio-economic groups (World Bank, 1999). The impact of poverty, racial discrimination, lack of opportunity, and low perceived life chances on adolescent risk behaviour has not been explored fully (Jessor, 1991). As this study could not include robust measures of factors such as socio-economic status and poverty, because they are difficult to estimate among adolescents, ethnicity can be regarded as a proxy for the set of factors that aggregate in some groups. Translation of the ethnic determinants of smoking onset into programme objectives would be an over-simplification of the determinants of ethnic differences and unacceptable in the South African context. Further research is therefore recommended on the extent to which ethnic differences in the determinants of adolescent smoking can be in fact explained by factors such as socio-economic differences, urban/rural differences, poverty and educational attainment. It must be also noted that the cross-sectional nature of the study cannot estimate causality and must be replicated in longitudinal studies.

Even though this paper provides information on the motivational factors related. to smoking, further investigation of distal factors such as awareness factors (e.g., risk perception), information factors (e.g., channels) and several predisposing factors are requited prior to intervention development (see Figure 3.1). Furthermore, an assessment of the readiness of the school environment (including the smoking behaviour of teachers as primary programme providers) to implement smoking programmes must be undertaken to ensure that such programmes are implemented as intended. 


\section{Chapter 4}

\section{The determinants of smoking cessation among adolescents in South Africa}

Wanuscript accepted for publication ast Panday, S, Reddy, S. P. Ruiter R A 


\section{Abstract}

Data is required on the motivational determinants of smoking cessation among a multi-ethnic sample of adolescents in South Africa. The I-Change Model, an extension of the Theory of Planned Behaviour, was used to explore the determinants of smoking cessation among a sample of 1267 Black African, Coloured and White Grade 9-11 monthly smokers and former smokers in the Southern Cape-Karoo region. Across the ethnic groups, former smokers displayed a more positive attitude toward non-smoking, were surrounded by a social environment that was more supportive of non-smoking, displayed higher selfefficacy not to smoke in stressful, routine and social situations and were more positive about their intention not to smoke in the next year. The I-Change Model can be used to address the cognitions of smoking in a multi-ethnic society like South Africa. However, some ethnic tailoring will be required. Black African students will benefit from a focus on attitudinal cognitions and cultural factors that motivate smoking. Coloured students require the involvement of their social environment while White students will benefit from the development of refusal skills in social situations. 


\section{Introduction}

Smoking is one of the chief preventable causes of premature morbidity and mortality (USDHHS, 1994). Tobacco is responsible for 540000 deaths each year in the EU and 461000 deaths in the US (Peto et al., 1994). Cardiovascular disease, for which a causal relationship with tobacco use is known (USDHHS, 2004), is the second largest cause of death in South Africa (SA) (16.6\% in 2000) (Bradshaw et al., 2003).

The US Surgeon General (1994), building on the work of Flay (1993) and others, summarised the process of smoking onset. Adolescents progress from the preparatory phase, where beliefs about smoking are formulated, to trying a few cigarettes, followed by experimenting with smoking on an irregular basis and then onto regular smoking on at least a weekly basis. While some adolescents exit this continuum after having smoked regularly, many adolescents stop smoking after experimenting with only a few cigarettes. Kremers and colleagues (2001a) recently labelled the latter group as non-smoking deciders. An understanding of the motivational factors related to smoking in this group wil॥ provide exit points earlier in the smoking continuum before adolescents progress onto dependence where quitting is known to be more difficult (Colby et al., 2000a). Furthermore; the emergence of signs of dependence earlier in the trajectory of smoking even among monthly smokers (DiFranza et al., 2000; Panday et al., 2004a) may provide insight into the limited effectiveness of existing cessation programmes that focus primarily on daily or weekly smokers (Backinger et al., 2003a).

Effective techniques have been identified for adult cessation (Lancaster et al., 2000). Yet a limited number of studies have addressed cessation techniques for youth (Backinger et al., 2003b). Psychological models such as the integrated model of change (I-Change Model) (De Vries et al., 2003c) may be an effective way to identify the motivational determinants of smoking. The model incorporates insights from the Theory of Reasoned Action (Fishbein and Ajzen, 1975), Social Cognitive Theory (Bandura, 1986) and the Transtheoretical Model (Prochaska and DiClemente, 1983). The model as well as its previous versions (Attitude-Social influence-Self-efficacy Model) have been used to assess the determinants of smoking and to develop and evaluate smoking prevention programmes in several European countries (De Vries et al., 1994; De Vries et al., 1995; De Vries et al., 1988; Dijkstra et al., 1999). The model assumes that the most important determinant of behaviour is behavioural intention which, in turn, is influenced by one's overall evaluation of the behaviour (attitude), one's beliefs concerning the beliefs and behaviours of significant others (social influences) and the control that people perceive themselves to have over performing a behaviour (self-efficacy). Distal variables such as demographic (e.g., age, gender) and psychological factors (e.g., depression) are assumed to influence behaviour via the motivational factors.

Several studies (Epstein et al., 1998; Markham et al., 2004; Riedel et al., 2003; USDHHS, 1994), including studies in SA (Swart et al., 2004), have reported lower smoking rates among Black adolescents than among White adolescents. Yet little is 
known about the mechanisms underpinning these differences or whether programmes developed primarily for White adolescents are applicable to other ethnic groups (USDHHS, 1998). Black African" and Coloured smokers in SA considered their smoking peers as barriers to stop smoking while White students indicated that they would support their peers to stop (Panday et al., 2003). Studies in the UK also showed that the social environment through modelling and social norms can, in fact, account for ethnic differences in smoking (Markham et al., 2004). Research among adolescents in SA has primarily focused on documenting the prevalence of tobacco use (Swart et al., 2004; Swart et al., 2003) and to our knowledge data is unavailable on the factors related to smoking. Our study investigated ethnic differences in the factors related to smoking cessation with the view to develop evidence-based and culturally sensitive tobacco control programmes for adolescents (Siqueira et al., 2001; Swart et al., 2004; USDHHS, 1998).

\section{Methods}

\section{Participants and Sampling}

The findings reported in this chapter are from a sub-sample of the cross-sectional survey conducted in 2002 in the Southern Cape-Karoo Region, Western Cape Province. Grade 9-11 students (general age range of $14-16$ years) completed a selfadministered questionnaire. Forty-two public schools were eligible to participate in the study. School selection was stratified by ethnicity in accordance with the school's previous race classification under the apartheid government, namely Black African (six schools), Coloured (17 schools) or White (19 schools). Previous research (Swart et al., 2003) was used to estimate the sample size of 100 smokers required for each ethnic and gender group. A total of 23 schools were selected to participate in the study, consisting of all six Black African schools, eight randomly selected Coloured schools and nine randomly selected White schools.

The number of classes selected was proportional to the number of grade 9-11 classes in the school, based on an estimated class size of 40 students. Class selection was stratified by grade and an equal number of classes were randomly selected from each grade. Due to the presence of older students in lower grades, additional classes were selected from the lowest grade. All students in the selected classes were eligible to particlpate in the study. A total of 121 classes representing 4768 students were selected to participate in the study.

The Research Ethics Committees of the South African Medical Association and the Medical Faculty of Umea University granted ethical approval for the study. Permission was also obtained from the Education Department, school principals and from parents and students in the selected classes. Parents and students were informed in writing of the purpose of the study and that all answers would be treated confidentially and only viewed by the researchers.

During the Apartheid years, all South Africans were classified into ethmic groups in accordance with the Population Registration. Act of 1950 namely, Black African (people of African descent), Colloured (preople of mixed descent), Indian (people of Indian descent) and White (people of European descent). The authors in no way subscribe to this classification. 


\section{Questionnaire}

The questionnaire was administered in three languages during two regular classroom periods either to individual classes or to groups of classes. The questionnaire was prepared in English and translated from English to Afrikaans and Xhosa. To ensure the accuracy of the translations, the Afrikaans and Xhosa versions of the questionnaire were back translated to English.

To guarantee students" confidentiality, trained research assistants adninistered the survey in the classroom simulating 'examination like' conditions; teachers were asked to leave the classroom during survey administration. An introductory letter was read out to the students informing them of the purpose of the study, that participation was voluntary and reassuring them that their confidentiality would be maintained. Additionally, to ensure their anonymity, students were requested not to write their names on the questionnaires.

The European Smoking Prevention Framework Approach (ESFA) questionnaire (De Vries et al., 2003b; De Vries et al., 2003c) was used as the core of the questionnaire. The questionnaire assessed smoking behaviour, attitude, social influences, self-efficacy expectations, intention not to smoke in the next year and several demographic items. Item selection and item formulation used in the ESFA questionnaire were validated and localised to the South African context through data obtained from prior qualitative research (Panday et al., 2003), through focus group discussions conducted during questionnaire development and from a pilot study conducted among 292 Grade 9 English, Afrikaans and Xhosa speaking students in the study area.

\section{Measures}

Smoking Behaviour. Adolescents were asked to pick a statement that best described them out of a set of specific smoking-related questions. Adolescents were then categorised as never smokers (never smoked not even one puff), triers (tried smoking once in a while but not monthly), non-smoking deciders (tried smoking less than once a week but not smoking anymore), experimenters or monthly smokers (smoking at least once a month, but not weekly), regular smokers (currently smoking cigarettes weekly or more), and quitters (quit smoking after having smoked at least once a week) (Kremers et al., 2004). Self-reports could not be biologically validated due to logistical and financial constraints. However, when anonymity is assured, self-reports have been shown to be reliable and in agreement with biochemical markers (Dolcini et al., 1996). Self-reported smoking was crossvalidated using an algorithm consisting of four additional concepts measuring current smoking and lifetime smoking. When incongruent answers were found, participants were given the most unfavourable response (De Vries et al, 2003b).

Attitudes were assessed by two five-point scales measuring the pros and cons of non-smoking that were identified through factor analyses and in accordance with previous research (see Table 4.1) (De Vries et al., 2003b; Kremers et al., 2001a; Kremers et al., 2001 b). The pros of non-smoking were measured with a seven-item scale (e.g., "If I do not smoke it will be very good for my health $(+2)$ or very bad for 
my health $(-2)^{\prime}$; Cronbach's alpha $\left.(\alpha)=0.86\right)$. The cons of non-smoking were measured with a five-item scale (e.g., 'If I do not smoke it will make me feel very relaxed $(-2)$ or very stressed $(+2) ; \alpha=0.68$ ). One item referring to drug use was excluded due to ambiguity in the Xhosa version of the questionnaire.

Social influences. Influences from the social environment were measured by assessing perceived social norms, smoking behaviour and direct pressure from important others: mother, father, grandmother, grandfather, brother(s), sister(s), friends, best friend, classmates and teachers. Social norms were measured on a fivepoint scale assessing students" perceptions of whether important others (combined into family, $\alpha=0.89$, friends, $\alpha=0.79$, and teacher, see Table 4.1) thought that they definitely should $(-2)$ or should not $(+2)$ smoke. Perceived smoking behaviour assessed the smoking behaviour of mother, father, grandmother, grandfather, brother(s), sister(s) and best friends using a two-point scale $(0=$ smoking, $1=$ nonsmoking). The seven items were analysed separately as they did not load uniquely on the one perceived smoking behaviour factor. Direct pressure was measured on a five-point scale to assess how often direct pressure not to smoke was encountered (combined into family, $\alpha=0.90$, friends, $\alpha=0.87$ and teacher, see Table 1) $(0=$ never, $4=$ very often $)$.

Self-efficacy. Multiple item scales measured how sure $(+2=$ sure that I will not smoke, -2 = sure that I will smoke) students' felt that they could refrain from smoking in stressful situations (stress self-efficacy, 10 items $\alpha=0.98$ ), routine situations (routine self-efficacy; 5 items $\alpha=0.94$ ) and social situations (social selfefficacy; 4 items $\alpha=0.93$ ) (see Table 4.1 ). The items were identified through previous research (De Vries et al., 1988; Lawrance, 1998).

Demographic variables. Characteristics of the participants were provided by asking for ethnicity $(1=$ Black African, $2=$ Coloured, $3=$ White $)$, gender $(0=$ boys: $1=$ girls), age (continuous scores), school performance $(0=$ lowest, $1=$ average, 2

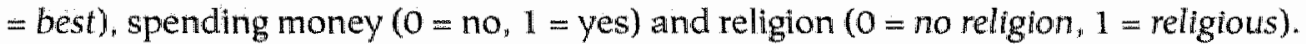

Depressive mood. A scale developed by Kandel and Davies (1982) was used to measure depressive mood. Six items using a five-point scalle ( $0=$ never, $4=$ always $)$ assessed "How often adolescents were bothered or troubled by the following states", namely. "feeling too tired to do things", "having trouble going to sleep or staying asleep', 'feeling unhappy, sad or depressed', 'feeling hopeless about the future', 'feeling nervous or tense' and 'worrying too much about things". The scores were summed to produce an index of depressive mood with a range of $0-24$ $(\alpha=0.98)$.

Intention. Participants' intention not to smoke in the next year was measured by one item on a five-point scale $(-2=$ definitely, $+2=$ definitely not $)$.

\section{Statistical analyses}

For the purposes of this analysis, former smokers (non-smoking deciders and quitters, coded as 1) were compared to monthly smokers (coded as 0). Monthly smokers and former smokers for each ethnic group were compared with regard to demographic variables using logistic regression for dichotomous variables and 
Table 4.1 Factors among the psychosocial associates of non-smoking

\begin{tabular}{|c|c|c|c|}
\hline \multirow{2}{*}{$\frac{\text { ITEM }}{\text { Attitude }(-2,+2)}$} & \multicolumn{2}{|c|}{ FACTORS } & \\
\hline & $\begin{array}{l}\text { Pros of non-smoking } \\
\quad(\alpha=0.86)\end{array}$ & $\begin{array}{c}\text { Cons of non-smaking } \\
\qquad(\alpha=0.68)\end{array}$ & \\
\hline It improves the smell af my breath & .75 & & \\
\hline lt saves me money & .70 & & \\
\hline It is good for my health & .63 & & \\
\hline It improves my school performance & .45 & & \\
\hline It improves my sport performance & .64 & & \\
\hline It improves the colour of my teeth & .68 & & \\
\hline It is wise of me & .71 & & \\
\hline I am more likely to use alcohol & & .52 & \\
\hline 盺 is difficult to be part of a crowd & & .55 & \\
\hline It will make me feel stressed & & .61 & \\
\hline My friends will think worse of me & & .49 & \\
\hline I will gain weight & & $22^{b}$ & \\
\hline Social Norms $\left(-2_{x}+2\right)$ & $\begin{array}{c}\text { Familyy } \\
(\alpha=0.89)\end{array}$ & $\begin{array}{l}\text { Friends } \\
(\alpha=0.79)\end{array}$ & \\
\hline Mother & .51 & & \\
\hline Father & .64 & & \\
\hline Grandmother & .89 & & \\
\hline Grandfather & .76 & & \\
\hline Brother (s) & .50 & & \\
\hline Sister (s) & .54 & & \\
\hline Fritends & & .83 & \\
\hline Best friend & & 81 & \\
\hline Classmates & & .69 & \\
\hline Teachers & & & .52 \\
\hline Direct Pressure $(0,+4)$ & $\begin{array}{c}\text { Family } \\
(\alpha=0,90)\end{array}$ & $\begin{array}{l}\text { Friends } \\
(\alpha=0.87)\end{array}$ & \\
\hline Mother & .49 & & \\
\hline Father & .60 & & \\
\hline Grandmother & .86 & & \\
\hline Grandfather & .81 & & \\
\hline Brother (s) & .51 & & \\
\hline Sister (s) & .59 & & \\
\hline Friends & & .90 & \\
\hline Best friends & & .91 & \\
\hline Classmates & & .76 & \\
\hline Teachers & & & .67 \\
\hline Self-efficacy $(-2 ;+2)$ & $\begin{array}{c}\text { Stress } \\
(\alpha=0.98)\end{array}$ & $\begin{array}{c}\text { Row tine } \\
(\alpha=0.94)\end{array}$ & $\begin{array}{c}50 \mathrm{lat} \\
(000.93)\end{array}$ \\
\hline When you feel bored & .91 & & \\
\hline When you struggle to concentrate & .87 & & \\
\hline When you crawe a cigarette & 87 & & \\
\hline When you feel depressed & .89 & & \\
\hline When you feel irritable & .92 & & \\
\hline When you feell miserable & .90 & & \\
\hline When you teel nervous & .91 & & \\
\hline When you feel restless & .91 & & \\
\hline When you feel upset & .89 & & \\
\hline When you feel worried & .90 & & \\
\hline When you are doing homework & & .79 & \\
\hline When you are hungry & & .80 & \\
\hline When you are on your way to the shop & & .88 & \\
\hline When you are watching television & & .83 & \\
\hline When you are on your way home from school & & .86 & \\
\hline When with others who smoke & & & .74 \\
\hline When with friends who smoke & & & .78 \\
\hline When friends offer you a cigarette & & & .86 \\
\hline When you are offered a cigarette & & & .85 \\
\hline
\end{tabular}

"Highest loadings per item (s 40) are shown.

Although factor loading $<.40$, this item has been included in the analysis. 
F-tests for linear variables. Significant differences $(p<.05)$ between monthly smokers and former smokers were found for age, gender, school performance, spending money, religion and depressive mood. These variables were included as covartates in subsequent analyses. Differences in attitude, social influences and self-efficacy between the smoking categories and ethnic groups were analysed using 2 (Smoking Categories: monthly smokers vs. fomer smokers) x 3 (Ethnic Groups: Black African vs. Coloured vs. White) covariance analyses (ANCOVA's). Where mean scores were dependent on the interaction of Smoking Categories and Ethnic Groups, simple main effect analyses were conducted to test the relationship between Smoking Categories and the dependent variable within each ethnic group. Where a significant effect for Ethnic Group was found, contrast analyses were conducted to determine which ethnic groups differed significantly.

To identify the correlates of former smoking, separate logistic regression analyses were conducted for the three ethnic groups using smoking status as the dependent variable. Demographic as well as other distal variables were entered in Block 1 , attitude, social influences and self-efficacy in Block 2 and intention not to smoke in the next year in Block 3 (Holm et al., 2003). For the regression analyses, the subscales for social norms, direct pressure and self-efficacy were combined into one scale each due to the high correlations between the sub factors. A backward deletion procedure was used to determine the final model of variables that relate to smoking status for each ethnic group. The significance level was set at $p<.05$.

\section{Results}

\section{Characteristics of the sample}

Of the 4768 students selected to participate in the study, 3869 completed the questionnaire. Two hundred and thirty eight cases were excluded from the analyses due to non-completion of $10 \%$ or more of the questionnaire as well as missing or incomplete data on key variables. A total of 1267 participants (567 monthly smokers and 700 former smokers) were eligible for the present study (see Table 4.2). The mean age of the participants was 16.06 years $(\mathrm{SD}=1.53$ ) and the overall distribution of males and females was $51.0 \%$ for males and $49.0 \%$ for females. Most students were Coloured (58.1\%), followed by Black African (27.1\%) and White (14.8\%) students. Most students reported an average school performance (64.6\%), that they received spending money $(83.2 \%)$ and that they were religious $(80.8 \%)$. The mean level of depressive mood for the sample was 6.88 ( $\mathrm{SD}=5.32)$.

Differences were also found between monthly smokers and former smokers across the ethnic groups as well as within the ethnic groups (see Table 4.2). Among the Black African students, the percentage of males who smoked monthly was higher than the percentage of females who smoked monthly $(\mathrm{p}<.05)$ while among the Coloured students the percentage of females who smoked monthly was higher than the percentage of males who smoked monthly $(p<.05)$. Across the ethnic groups, students in the monthly smoking group were older than students in the former smoking group $(p<.05)$. More Coloured monthly smokers than former 


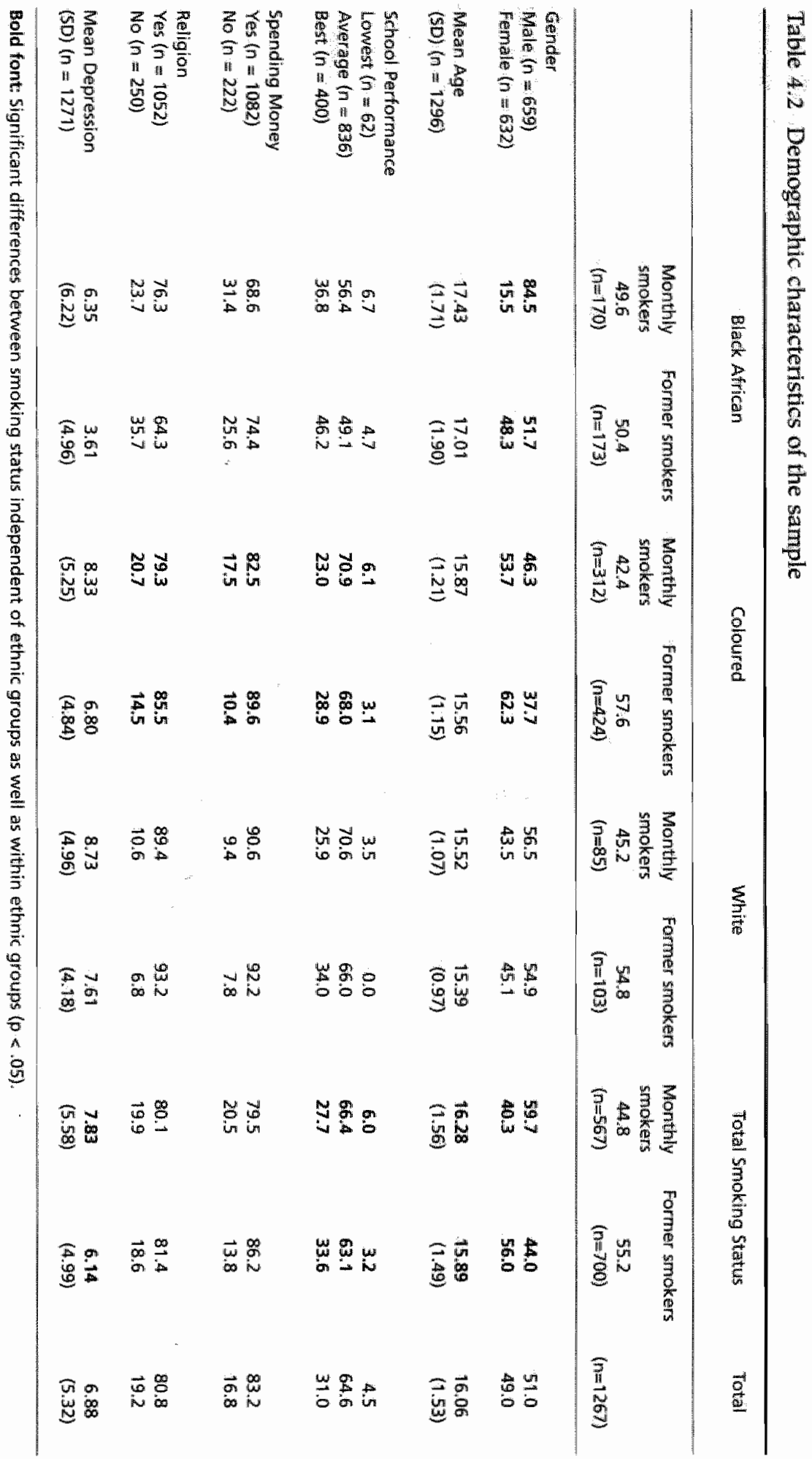


smokers reported an average school performance $(\mathrm{p}<.05)$, not receiving spending money $(\mathrm{p}<.05)$ and not being religious $(\mathrm{p}<.05)$. Additionally, across ethnic groups, monthly smokers reported higher scores on the depressive mood scale than former smokers $(\mathrm{p}<.05)$.

\section{Differences between monthly smokers and former smokers}

The analyses showed that across ethnic groups, former smokers reported more pros of non-smoking $(\mathrm{p}<.001)$, fewer cons of non-smoking $(\mathrm{p}<.001)$, more social norms from family $(p<.001)$, friends $(p<.001)$ and teachers not to smoke $(p<.01)$, more direct pressure from friends $(p<.05)$ and teachers $(p<.05)$ to refrain from smoking, perceived fewer important others who smoke $(p<.001)$, greater selfefficacy during stressful $(\mathrm{p}<.001)$, routine $(\mathrm{p}<.001)$ and social situations $(\mathrm{p}<$ .001 ), and a more positive intention not to smoke in the next year $(p<.001)$ (see Table 4.3).

The differences between monthly smokers and former smokers on the attitude and social influence scales were no different within each of the ethnic groups as interaction patterns were not found between Smoking Categories and Ethnic Groups. There were, however, significant interaction patterns on the stress ( $\mathrm{p}<$ $.001)$, routine $(p<.001)$ and social $(p<.001)$ self-efficacy scales. Simple main effect analyses showed that former smokers displayed higher stress, routine and social self-efficacy than monthly smokers in all three ethnic groups ( $p$ 's $<.001$ ), but that these patterns were more pronounced among Coloured and White students than among Black African students.

\section{Differences between the ethric groups}

Across the smoking categories, Black African students were less convinced of the pros of non-smoking than Coloured and White students $(\mathrm{p}<.001)$ while White students were least convinced of the cons of non-smoking, followed by Black African and, in turn, Coloured students ( $p<.001$ ) (see Table 4.4).

Smoking within the context of the social environment was particularly important for Coloured adolescents. Coloured students experienced a stronger social norm from their friends not to smoke than Black African and White students respectively $(p<.01)$ while Coloured and White students experienced stronger noms not to smoke from their family $(p<.001)$ and teachers $(p<.001)$ as opposed to Black African students. Coloured students also reported more smoking in their social environment than Black African and White students ( $p<.001)$. Coloured and Black African students as opposed to White students experienced more direct pressure from their family $(\mathrm{p}<.001)$ and friends $(\mathrm{p}<.001)$ not to smoke. Coloured students as opposed to Black African and White students also experienced significantly more direct pressure from their teacher not to smoke $(\mathrm{p}<.001)$.

While White students reported greater routine self-efficacy than Black African and Coloured students $(p<.05)$, they reported lower social self-efficacy $(p<.05)$ than the other two groups. White students also expressed a less positive intention not to smoke in the next year than Black African and Coloured students $(p<.01)$. 


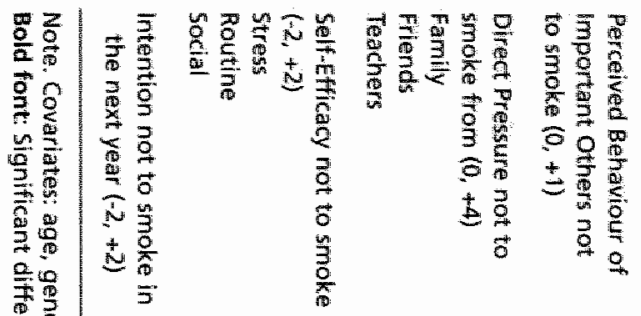

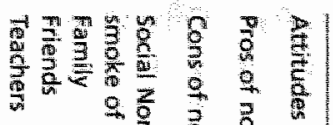

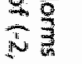

过吕

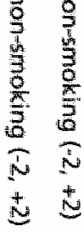

雪量

䨐

蕓高

要

高高

욱을

(․․․

苦魚

落

혹응

兽

竞星

융

돔.:

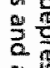

路

要

害吕

음

:

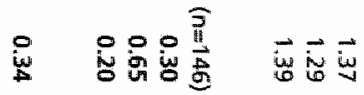

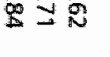

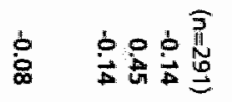

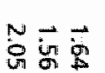

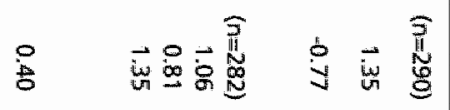

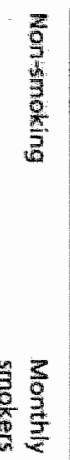

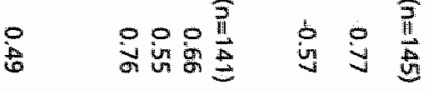

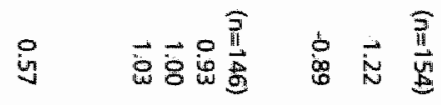

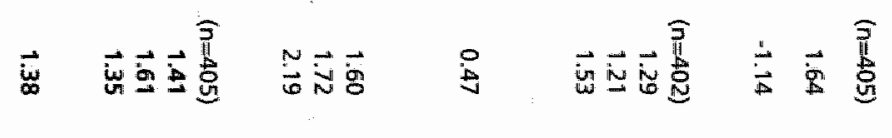

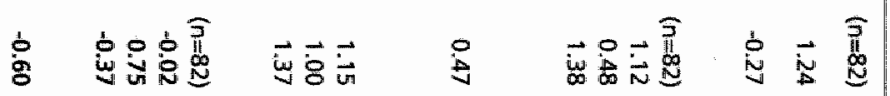

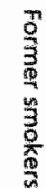

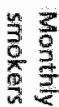

$\hat{\mathrm{g}}$

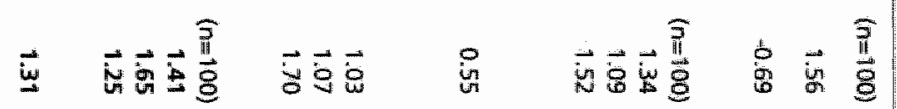

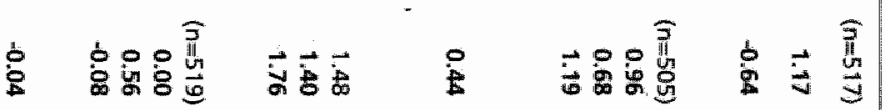

管喜

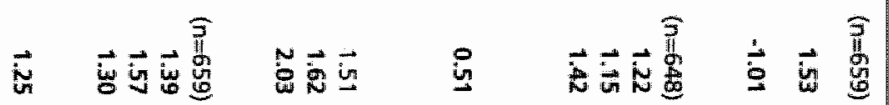

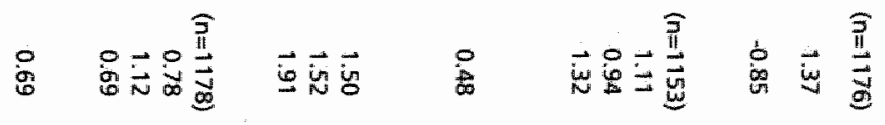

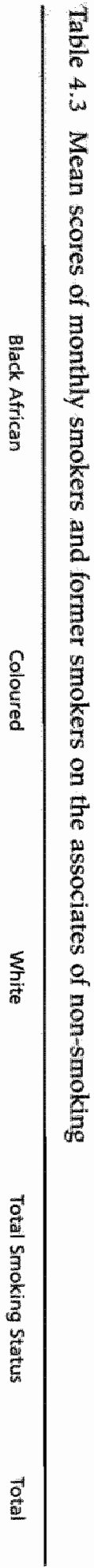


Table 4.4 Mean scores of Black African, Coloured and White students on the associates of non-smoking

\begin{tabular}{|c|c|c|c|c|}
\hline \multirow[b]{2}{*}{ Non-smoking } & \multicolumn{3}{|c|}{ Ethnic Groups } & \multirow{2}{*}{$\begin{array}{c}\text { Total } \\
(n=1176)\end{array}$} \\
\hline & $\begin{array}{c}\text { Black } \\
\text { African } \\
(n=299)\end{array}$ & $\begin{array}{l}\text { Coloured } \\
(n=695)\end{array}$ & $\begin{array}{l}\text { White } \\
(n=182)\end{array}$ & \\
\hline Pros af non-smoking $(-2,+2)$ & $1.00^{\mathrm{a}}$ & $1.52^{\mathrm{b}}$ & $1.41^{\mathrm{b}}$ & 1.37 \\
\hline Cons of non smoking $(-2,+2)$ & $0.73^{a}$ & $-0.99 b$ & $-0.50^{\complement}$ & -0.85 \\
\hline Social Worms not to smoke of $(-2,+2)$ : & $(n=287)$ & $(n=684)$ & $(n=182)$ & $(n=1153)$ \\
\hline Family & $0.80^{a}$ & $1.19^{b}$ & $1.24^{\mathrm{b}}$ & 1.11 \\
\hline friends & $0.78^{\mathrm{a}}$ & $1.05^{b}$ & $0.81^{\circ}$ & 0.94 \\
\hline Teachers & $0.90^{\mathrm{a}}$ & $1.46^{\mathrm{b}}$ & $1.46^{\mathrm{b}}$ & 1.32 \\
\hline $\begin{array}{l}\text { Perceived behaviour of important athers } \\
\text { not to smoke }\left(0_{v}+1\right)\end{array}$ & $0.53^{\mathrm{a}}$ & $0.44^{b}$ & $0.52^{\mathrm{a}}$ & 0.48 \\
\hline \multicolumn{5}{|l|}{ Direct Pressure not to smoke from $\left(0_{i}+4\right)$} \\
\hline Pamily & $1.50^{\mathrm{a}}$ & $1.61^{\mathrm{a}}$ & $1.08^{b}$ & 1.50 \\
\hline Friends & $1.50^{a}$ & $1.66^{\mathrm{a}}$ & $1.03^{b}$ & 1.52 \\
\hline Teachers & $1.62^{\mathrm{a}}$ & $2.13^{b}$ & $1.55^{\mathrm{a}}$ & 1.91 \\
\hline Self-Efficacy not to smoke $(-2,+2)$ & $(n=300)$ & $(n=696)$ & $(n=182)$ & $(n=1178)$ \\
\hline Stress & 0.81 & 0.76 & 0.77 & 0.78 \\
\hline Routine & $1.03^{\mathrm{a}}$ & $1.13^{\mathrm{a}}$ & $1.25 b$ & 1.12 \\
\hline Social & $0.72^{\mathrm{a}}$ & $0.72^{a}$ & $0.52^{\mathrm{b}}$ & 0.69 \\
\hline Intention not to smoke in the next year $(-2,+2)$ & $0.61^{a}$ & $0.78^{a}$ & $0.45^{b}$ & 0.69 \\
\hline
\end{tabular}

Note. Covarlates: agle, gender, religion, spending money, school performance, depressive maod.

a. b. cignificant differences between ethnic groups $(p<.05)$.

\section{Correlates of former smoking}

To determine the most important factors associated with former smoking for each of the ethnic groups, separate logistic regression analyses were conducted (see Table 4.5).

Among the Black African students, in the first step, gender and depressive mood were significant correlates ( $\mathrm{p}$ 's <.001). In the second step, gender and depressive mood remained as significant correlates ( $p$ 's $<.001$ ), as were having a non-smoking brother $(p<.05)$ and self-efficacy $(p<.001)$. In the third step, gender $(p<.001)$, depressive mood $(p<.001)$, a non-smoking brother $(p<.05)$ and self-efficacy $(p<$ $.001)$ remained as significant correlates. The emergence of religious practices as a marginally significant correlate $(p<.05)$ aroused suspicion about a potential suppressor effect. Examination of the signs of the correlation between smoking status and religion (albeit a low correlation, $\mathrm{r}=-0.13, \mathrm{p}<.05$ ) and the beta of the logistic regression excluded the possibility of suppressor effects. Among the Black African students, the model correctly classified $76.4 \%$ of the monthly smokers and $79.2 \%$ of the former smokers respectively. 
Table 4.5 Correlates of former smoking ( $1=$ yes, $0=$ no) among Black African, Coloured and White students: correlations with smoking status (I) and odds ratios (OR) with $95 \%$ confidence intervals $(95 \% \mathrm{CI})$

-

$+$

OR

$95 \times$

Black African Students

Demographic variables

Gender: $(1=$ girl, $0=$ boy $)$

Depressive Mood: $(0=$ never, $4=$ allways $)$

$0.35^{*}$

$7.61 * \div \times$

$-0.24 *$

$0,89 * 2 *$

$(4.12-14.10)$

+ ASE Vartables

Gender: $(1=$ girl, $0=$ boy $)$

Depressive Mood: $(0=$ never, $4=$ always $)$

Brother non-sumoking: 0 (neg) +1 (pos)

Self-efficacy not to smoke: -2 (neg) +2 (pos)

$0.35^{*}$

$7.13^{* * *}$

$-0.24 *$

$0,88 *$

$0.15^{* 2 *}$

$2.21 *$

0.51 in

3: 59 क*

$(0.85 \times .93)$

* Intention not to smoke

Gender: $(1=$ girl, $0=$ boy $)$

Religion: $(1=$ yes, $0=$ no)

Depressive Moad: $(0=$ never; $4=$ alwaysi)

Brother mon-smoking: 0 (neg) +1 (pos)

Self-efficacy not to smoke: -2 (neg),+2 (pos)

$0.35 *$

$-0.113^{*}$

$-0.24 *$

$0.115 *$

$0.51 *$

$-0.13 *$

0.09 *

$0.13 *$

$0.09^{*}$

$-0.15 *$

$0.10 * *$

Selfefficacy not to smoke: -2 (neg) +2 (pos)

* Intention not tó smake

Spending Money: $(1=$ yes, $0=$ no)

Attitude cons: -2 (pos) +2 (neg)

Direct Pressure not to smoke: 0 (neg) +4 (pos)

Best friend non-smoking: 0 (neg) +1 (pos)

Selfefficacy not to smoke: -2 (neg) +2 (pos)

intention not to smoke: -2 (neg) +2 (pos)

White Students

\section{+ ASE variables}

Self-efficacy not to smake: -2 (neg) +2 (pos)

* Intention not to smoke

Direct Pressure not to smoke: 0 (meg) +4 (pos)

Self-efficacy nott to smoke: -2 (neg), +2 (pos)

Intention not to smoke: -2 (negl, +2 (pas)
$-0.25 * *$

0.03

$0.29 * t$

$0.68^{* *}$

$\begin{array}{ll}0.10^{* *} & 2.01^{*} \\ 0.25^{*} & 0.70^{*} \\ 0.03^{*} & 0.77^{*} \\ 0.29^{*} & 11.96^{* *} \\ 0.68^{*} & 5.59^{*} \\ 0.53^{*} & 1.71^{*}\end{array}$

(11.04-3.89)

$(0.50 \cdot 0.98)$

$(0.63-0.95)$

(1, 24-3.11)

(4.09.7.63)

(1.43-2.05)

$(0.52 \cdots 1.01)$

$(0.62-0.93)$

(1.44-3.48)

(5.49-10.01)

$0.68^{*}$

9.91 * w

$(5.23-48.78)$

$\begin{array}{ll}0.02 & 0.54 \\ 0.68 * * & 6.28 * * \\ 0.61 * * & 2.03^{* *}\end{array}$

(0.29-1.01)

$(3.06-12.93)$

(1.37-3.00)

Note. "neg" means negative towards non-smoking. "pos' means positive towards non-smoking.

${ }^{*} \mathrm{p}<.05, * * \mathrm{p}<.01, * * \mathrm{p}<.001$ 
Among the Coloured students, in the first step, age $(p<.05)$, gender $(p<.01)$, spending money $(\mathrm{p}<.05)$, school performance $(\mathrm{p}<.05)$, and depressive mood $(\mathrm{p}<$ $.001)$ were significant correlates of former smoking. In the second step, spending money $(\mathrm{p}<.05)$, perceived cons of non-smoking $(\mathrm{p}<.05)$, a non-smoking best friend $(\mathrm{p}<.001)$ and self-efficacy $(\mathrm{p}<.001)$ were significant correlates of former smoking. Direct pressure not to smoke $(\mathrm{p}<.01)$ was inversely related to former smoking. In the third step, spending money $(\mathrm{p}<.05)$, perceived cons of non-smoking $(\mathrm{p}<.05)$, direct pressure not to smoke $(p<.05)$, a non-smoking best friend $(p<.01)$, selfefficacy $(\mathrm{p}<.001)$ and intention not to smoke $(\mathrm{p}<.001)$ were significant correlates of former smoking. Due to the inverted sign of the beta for direct pressure not to smoke, the possibility of a suppressor effect was explored. Smoking status and direct pressure did not correlate significantly $(r=0.03, p=0.38)$ and low correlations were also found between direct pressure and other correlates ( $r$ 's $<0.24)$. In-depth analyses ${ }^{2}$ showed that the suppressor effect was not directly bound to one specific variable. Among the Coloured students, the model correctly classified $78.7 \%$ of the monthly smokers and $88.8 \%$ of the former smokers respectively.

Among the White students, in the first step, the identified correlate did not reach significance. In the second step, self-efficacy $(\mathrm{p}<.001)$ emerged as a significant correlate of former smoking. In the third step, self-efficacy $(p<.001)$ and an intention not to smoke in the next year $(p<.01)$ were significant correlates of former smoking. Direct pressure not to smoke $(p<.05)$ was again inversely related to former smoking. Suppressor effects were also explored for direct pressure not to smoke even though the sign of the beta and that of the correlation with smoking status were congruent. Again in-depth analyses were unable to identify the specific suppressor. Among the White students, the model was able to correctly classify $81.5 \%$ of monthly smokers and $88.8 \%$ of former smokers respectively.

\section{Discussion}

This study describes the differences in attitude, social influences, self-efficacy and intention not to smoke in the next year between Black African, Coloured and White monthly smokers and former smokers. Across the ethnic groups, former smokers displayed a more positive attitude toward non-smoking, were surrounded by a social environment that was supportive of non-smoking and displayed higher selfefficacy not to smoke in stressful, routine and social situations. Former smokers were also more positive about their intention not to smoke in the next year. Chassin, Presson and Sherman (1985) reported similar findings in that quitters had fewer smoking friends and both their parents and friends were more negative about them smoking. Redmond (2002) also showed substantially higher intention not to smoke in future among reducers compared to maintainers of regular smoking.

\footnotetext{
Attempts were made to isolate the suppressor by excluding the congruent predictors one at a time. 5ocial pressure and social norms were each in turn removed from the analyses: sub-factors were also created for social pressure, social morms and self-efficacy. The low correlation between social pressure and self-efficacy refuted the hypotheses that self-efficacy was the suppressor. Several independent variables may make the isolation of the suppressor difficult and reference is made to suppressor situations rather than specific suppressor variables.
} 
Although monthly smokers and former smokers differed on the self-efficacy subfactors in each ethnic group, these differences were more pronounced annong Coloured and White students than among Black African students. For all of the other cognitive factors, the lack of interaction patterns between smoking status and the ethnic groups suggest that the differences between monthly smokers and former smokers were the same within each of the ethnic groups. However, the lack of power to detect differences within the ethnic groups cannot be excluded.

Our study demonstrates that social cognitive models such as the 1-Change Model that were primarily developed in western cultures can be used to address the motivational determinants of smoking cessation in a multi-ethnic society like SA. This finding is supported by the ability of the regression model to correctly classify monthly smokers and former smokers from all three ethnic groups. Markham and colleagues (2004) also showed the appropriateness of the I-Change Model in an ethnically diverse population in the UK. However, our results do suggest the need for some ethnic sensitivity. Even though self-efficacy was a correlate of former smoking for all three ethnic groups, the covariance analyses showed that Black African and Coloured students require a focus on routine self-efficacy while White smokers require coping skills in social situations. Among the Coloured students, the study highlights the importance of the social environment to stop smoking. A non smoking best friend was a correlate of former smoking as has been shown in other studies (Arisa and Nebot, 2002; Burt and Peterson, 1998; Chassin et al., 1985; Ershler et al., 1989). Coloured students also reported higher perceived social norms, direct pressure and smoking behaviour among important others. In fact, King and colleagues (2003) demonstrated the instrumental role that the social environment plays in youth smoking in SA. Direct pressure not to smoke, however, seemed to be negatively related to former smoking in this group as a result of a suppressor effect.

Across the smoking categories, Black African students reported lower scores on the pros and cons of non-smoking suggesting that they were less convinced of the detrimental effects of smoking. The lack of attitudinal and intention cognitions as correlates of former smoking in the regression analyses as well as the weaker fit of the model in this group also intimate towards distal correlates of former smoking such as gender, religion and depressive mood.

Contrary to other studies (Arisa and Nebot, 2002; Brownson et al., 1990; Burt and Peterson, 1998), gender showed some cultural specificity in that Black African females were more likely to stop smoking than Black African males. Black African women in SA, however, have displayed greater propensity to quit smoking (DOH et al., 2002). Cultural resilience factors reflected by consistently low smoking rates in this group (DOH et al., 2002) and a social taboo against smoking may underpin this finding in our study. Similarly, a lower level of depressive mood as a correlate of former smoking and the inverse association between religion and former smoking among Black African students requires further investigation. The finding among Coloured students that increased spending money is a correlate of former smoking may be indicative of the inextricable link between socio-economic status, ethnicity 
and smoking (World Bank, 1999). In a developing country, like SA, macro economic development may positively enhance the effect of tobacco control programmes.

It is known that factors such as low socio-economic status,. poverty and educational attainment tend to cluster in certain ethnic groups (Tyas and Pederson. 1998). This is particularly relevant in the South African context where apartheid resulted in large social, economic and spatial differentials amongst the ethnic groups (UNDPSA, 2003). Our study could not include reliable measures of socioeconomic status and poverty as they proved difficult to estimate among adolescents in a country in rapid transition. Future studies must investigate the extent to which ethnic differences in the determinants of smoking can be in fact explained by factors such as socio-economic status and poverty. Furthermore, the power of the study to detect differences within the ethnic groups was possibly low. Alternative strategies must be identified to stratify by ethnicity as the increasing racial integration of schools makes stratification at the school level difficult.

Although Kremers and colleagues (2001a) demonstrated that non-smoking deciders and ex-regular smokers are a heterogeneous groups, both groups in the study showed a similar pattern of lower risk for future smoking than experimenters and regular smokers. However, further studies are required to disentangle the motivational determinants of non-smoking deciders and ex-regular smokers. 


\section{Chapter 5}

\section{Nicotine dependence and withdrawal symptoms among adolescents in South Africa}




\section{Abstract}

Aims: This study describes the prevalence of and differences in nicotine dependence, withdrawal symptoms, depressive mood and risk behaviour between male and female weekly and monthly smokers in South Africa.

Design: A cross-sectional study was conducted among 554 Grade 9-1 I weekly and monthly smokers in the Southern Cape-Karoo Region. School selection was stratified by ethnicity and class selection was stratified by grade.

Measurements: The self-administered questionnaire assessed smoking behaviour, nicotine dependence using the Fagerström Tolerance Questionnaire, withdrawal symptoms using DSM IV criteria, depressive mood and risk behaviour. Differences between the gender groups and smoking status were analysed using covariance analyses.

Findings: Weekly smokers displayed substantial levels of dependence with $11.6 \%$ classified as highly dependent. Over one in two weekly smokers reported two or more withdrawal symptoms. Although dependency levels and withdrawal symptoms were higher among weekly smokers, the levels were not negligible among monthly smokers. Weekly smokers reported higher levels of depressive mood and risk behaviour than monthly smokers. Females reported higher levels of nicotine dependence, withdrawal symptoms, depressive mood and lower levels of risk behaviour than males. Gender differences were not found on the number of cigaretres smoked in a week.

Conclusions: Smoking cessation programmes must also focus on nicotine dependence and withdrawal symptoms to help adolescents quit smoking and consider pharmacotherapy for highly dependent adolescent smokers. Prevention programmes must provide non-daily smokers skills to identify and cope with possible withdrawal symptons. The public health implications of higher levels of dependence and withdrawal symptoms among females warrant validation using other research instruments. 


\section{Introduction}

Smoking rates among adolescents remain high and has led to smoking being labelled a paediatric disease or epidemic (Kessler, 1995; Perry et al., 1994). In the US, current smoking rates among adolescents rose from $27.5 \%$ in 1991 to $36.4 \%$ in 1997 but declined to $21.9 \%$ by 2003 (MMWR, 2004). In South Africa (SA) current smoking decreased from $23.0 \%$ in 1999 to $18.5 \%$ in 2002 (Swart et al., 2004). The SA Global Youth Tobacco Survey, conducted in 1999 and 2002, showed that the percentage of monthly smokers who expressed a desire to stop smoking and actually made quit attempts remained high in both years of the study $73.9 \%$ and $72.6 \%$ (1999) vs. $76.6 \%$ and $74.4 \%$ (2002) respectively (Swart et al., 2004). The majority of adolescent smokers thus want to stop smoking and actually make quit attempts (Warren et al., 2000); success rates though are limited. A review of 66 youth smoking cessation programmes reported a mean overall cessation rate of $12 \%$ across active treatment groups compared to $7 \%$ in the control groups (Sussman, 2002).

While a growing number of studies focus on cognitive-behavioural modeis to facilitate smoking cessation among adolescents, there is limited theoretical literature available on nicotine dependence among adolescents (Shadel et al., 2000), perhaps as a result of the notion that prolonged use of nicotine is required before signs of dependence emerge (USDHHS, 1994). Recent studies, however, have reported signs of dependence early in the trajectory of tobacco use (DiFranza et al., 2000; DiFranza et al., 2002a; O'Loughlin et al., 2003). Dependence and withdrawal symptoms have been demonstrated among adolescent daily smokers much like adult smokers. Furthermore, adolescent smokers can experience withdrawal symptoms outside of formal quit attempts (Stanton et al. 1995) and further studies are recommended in this area (Colby et al., 2000a). The US Surgeon General's Report on Smoking among Young People (1994) concluded that most adolescent daily smokers are addicted to nicotine and want to stop smoking but are unable to do so.

Attempts are being made to clarify the dimensions of nicotine dependence for youth. In the interim, parallels have been drawn between the stanclard features of substance dependence and nicotine dependence. Nicotine dependence consists primarily of positive reinforcement through the compulsive use of nicotine and negative reinforcement to avoid nicotine withdrawal symptoms (Shadel et al., 2000). Nicotine withdrawal is characterised by craving, depressed mood, Insomnia, irritability, frustration, anger, anxiety, difficulty concentrating, restlessness, decreased heart rate and weight gain (American Psychiatric Association, 1994).

In the absence of theoretically based and psychometrically validated indices to measure dependence among adolescents (Colby et al., 2000b), tools for psychometric analysis and clinical diagnosis among adults have been used to measure dependence and withdrawal. The Fagerström Tolerance Questionnaire has been adapted for adolescents and demonstrated satisfactory internal consistency and agreement with biochemical markers (Prokhorov et al., 2000; Prokhorov et al., 
1996). The Diagnostic and Statistical Manual of Mental Disorders (DSM IV) (1994) provides criteria for diagnosing nicotine withdrawal and has been used to measure withdrawal symptoms among adolescents (Prokhorov et al., 2001; Rojas et al, 1998).

The literature is also ambiguous with regards to gender differences in nicotine dependence and withdrawal symptoms (Colby et al., 2000a). Stanton (1995) found no gender differences in dependence among adolescent smokers even though females smoked fewer cigarettes per day; Rojas et al., (1998) showed that male adolescents reported higher nicotine dependence than female adolescents which was accompanied by higher smoking rates among males whereas O'Loughlin and colleagues (2003) as well as DiFranza and colleagues $(2000 ; 2002 \mathrm{a} ; 2002 \mathrm{~b})$ showed that females reported more nicotine dependence symptoms than males. A review of the evidence on nicotine dependence and withdrawal symptoms concluded that further research is needed to understand gender differences in nicotine dependence and withdrawal symptoms among adolescents and to test the applicability of existing measures across differing cultures (Colby et al., 2000a).

Smoking among South African adolescents differs along gender lines with higher rates among males $(26.7 \%$ ) than females (11.5\%) (Swart et al., 2004). To our knowledge, data is not available on nicotine dependence or withdrawal symptoms among adolescents in South Africa. This information is necessary for the development of comprehensive smoking cessation programmes that consider both the behavioural and physiological processes of smoking for adolescents. Furthermore, an in-depth understanding of the differences between subgroups of the target audience, will allow for programmes to be tailored to their needs.

This study describes the prevalence of and differences in nicotine dependence, withdrawal symptoms, depressive mood and risk behaviours among a sample of weekly and monthly smokers. The latter two factors were included as a result of the body of evidence that shows co-variation of smoking with psychological factors such as depression (Chol et al., 1997; Escobedo et al., 1998; Horn et al., 2004; Rojas et al., 1998; Zhu et al., 1999) as well as deviance prone behaviour such as alcohol and marijuana use (Everett et al, 1998; Jessor, 1991; Proimos et al., 1998; Rigoti et al., 2000; Siqueira and Brook, 2003; UiSDHHS, 1994; Wetzels et al., 2003). The limited evidence on gender differences in nicotine dependence as well as the gender-specific smoking rates in SA also motivate for a study of gender differences in these factors.

\section{Methods}

\section{Participants and sampling}

The findings described in this chapter of the thesis emanate from a sub-sample of the cross-sectional survey conducted in 2002 in the Southern Cape-Karoo Region, Western Cape Province. Grade 9-11 students (14-16 years of age) completed a self-administered questionnaire. Forty-two public schools in the region with grade 9-11 students were eligible to participate in the study. School selection was 
stratified by ethnicity, in accordance with the previous race classification of schools under the apartheid government, namely Black African (six schools), Coloured ( 17 schools) or White (19 schools), based on previous research (Panday et al., 2003). Previous research (Swart et al., 2003) was also used to estimate the sample of 100 smokers required for each ethnic by gender group. A total of 23 schools were selected to participate in the study, consisting of all six Black African schools, eight randomly selected Coloured schools and nine randomly selected White schools.

The number of classes selected was proportional to number of grade 9-11 classes in the school, based on an estimated class size of 40 students. Class selection was stratified by grade and an equal number of classes were randomly selected from each grade. Due to the presence of older students in lower grades, additional classes were selected from the lowest grade. All students in the selected classes were eligible to participate in the study. $A$ total of 121 classes representing 4768 students were selected to participate in the study.

The Research Ethics Committees of the South African Medical Association and the Medical Faculty of Umea University granted ethical approval for the study. Permission was also obtained from the Education Department, principals of selected schools and from parents and students in the selected classes. Parents and students were informed both verbally and in writing that all answers would be treated confidentially and only viewed by the researchers.

\section{Questionnaire}

The questionnatre assessed smoking behaviour, nicotine dependence, withdrawal symptoms, depressive mood, risk behaviour and several demographic items. The questionnaire was localised to the South African context through data obtained from prior qualitative research (Panday et al., 2003), through focus group discussions conducted during questionnaire development and from a pilot study among 292 Grade 9 English, Afrikaans and Xhosa speaking students in the study area. To guarantee confidentiality, trained research assistants administered the survey in the classroom simulating 'examination like' conditions; teachers were asked to leave the classroom during survey administration. Additionally, to protect their anonymity, students were requested not to write their names on the questionnaires.

The questionnaire was administered in English, Afrikaans or Xhosa, during two regular classroom periods either to individual classes or to groups of classes. The questionnaire was prepared in English and translated from English to Afrikaans and Xhosa. To ensure the accuracy of the translations, the Afrikaans and Xhosa versions of the questionnaire were back translated to English.

\section{Measures}

Smoking behaviour. Adolescents were asked to pick a statement that best described

During the Apartheid years, all South Africans were classified into race groups in accordance with the Population Registration Act of 1950 namely, Black African (people of African descertit), Coloured (people of mixed descert). Indian (people of indian descent) and White (people of European descent). The authors in no way subscribe to this classification. 
them out of a set of specific smoking-related questions. Adolescents were then categorised as never smokers (never smoked not even one puff), triers (tried smoking once in a while but not monthly), non-smoking deciders (tried smoking less than once a week but not smoking anymore), experimenters or monthly smokers (smoking at least once a month, but not weekly), regular or weekly smokers (currently smoking cigarettes weekly or more), and quitters (quit smoking after having smoked at least once a week) (Kremers et al., 2004). Self-reports of smoking could not be biologically validated due to logistical and financial constraints. However, when anonymity is assured, self-reports have been shown to be reliable and in agreement with biochemical markers (Dolcini et al., 1996). Selfreported smoking was cross-validated using an algorithm consisting of four additional concepts measuring current smoking and lifetime smoking. When incongruent answers were found, participants were given the most unfavourable response (De Vries et al., 2003).

Nicotine dependence. The Fagerström Tolerance Questionnaire (FTQ) as adapted and validated by Prokhorov and colleagues for adolescents $(2000 ; 1996)$ was used to measure nicotine dependence. Eight items on a continuous scale (except for "smoking more during the first two hours of the day") assessed "inhaling when smoking', 'time to first cigarette', 'cigarette they would hate to give up', 'difficulty in refraining from smoking in forbidden places', 'smoking when ill", 'smoke more in the morning' and 'number of eigarettes smoked each day'. The items were summed to produce an index of nicotine dependence with a range of $0-9$ (Cronbach's alpha $(\alpha)=0.60$ ). Those smokers who displayed an FTQ score of 6 or higher were considered highly dependent (Fagerström and Schneider, 1989).

Withdrawal symptoms. The criteria set out in the Diagnostic and Statistical Manual of Mental Disorders (1994) were used to assess withdrawal symptoms (WSI). Eight items assessed how students 'feel when you tried to stop smoking or when you have not smoked for a while' namely, 'miserable and sad', 'trouble sleeping', 'irritable', 'nervous and tense', 'unable to concentrate', 'restless', 'hungry' and 'craving'. Yes/No alternatives were given for each of the items and summed to produce an index with a range of $0-8(\alpha=0.86)$. Prior research in SA (Panday et al., 2003) as well as other studies (Dappen et al., 1996; Prokhorov et al., 2001; Rojas et al. 1998; Siqueira et al., 2001; Stanton, 1995), have reported craving as a withdrawal symptom. Hence craving was included in the index.

Number of clgarettes smoked. The number of cigarettes smoked in a week was assessed with one item on a continuous scale. Scores were combined to produce a five-point scale $(1=<1$ cigarettes, $2=1-5$ cigarettes, $3=6-10$ cigarettes, $4=11$ -20 cigarettes, $5=>20$ cigarettes).

Depressive mood. A scale developed by Kandel and Davies (Kandel and Davies, 1982) was used to measure depressive mood. Six items using a 4-point scale $(0=$ never, 4 : a a ways) assessed "How often adolescents were bothered or troubled by the following states', namely 'feeling too tired to do things', 'having trouble going to sleep or staying asleep', 'feeling unhappy, sad or depressed', 'feeling hopeless about the future', 'feeling nervous or tense' and 'worrying too much about things'. The 
scores were summed to produce an index of depressive mood with a range of $0-$ $24(\alpha=0.86)$.

Risk behaviour. Risk behaviour was measured with eight items on a 5-point scale $(0=$ never, 1 = sometimes, 2 = less than once a month, $3=$ not weekly but at least once a month, 4 = at least once a week) assessing use of alcohol, marijuana, methaqualone, other drugs, sniffing substances, gambling, playing the Lotto (form of lottery in SA) and playing truant from school $(\alpha=0.77)$.

Demographic variables. Characteristics of the participants were provided by asking for ethnicity ( $1=$ Black African, $2=$ Coloured, $3=$ White), age (continuous scores) and school performance $(0=$ lowest, $1=$ average, $2=$ best $)$.

\section{Statistical analyses}

For the purposes of this analysis, weekly smokers (coded as 0 ) were compared to monthly smokers (coded as 1). Male and female weekly and monthly smokers were compared on demographic variables using logistic regression for dichotomous variables and $F$-tests for linear variables. Significant differences $(p<.05)$ were found for age, school performance, and ethnicity. These variables were assessed further with regards to their contribution to the prediction of the dependent variables. Subsequently, age and ethnicity were included as covariates for the measurement of nicotine dependence, withdrawal symptoms and number of cigarettes smoked, while age and school performance were included as covariates for the measurement of depressive mood and risk behaviour. Differences in nicotine dependence, withdrawal symptoms, number of cigarettes smoked in a week, depressive mood and risk behaviours between Gender and Smoking Categories were analysed using 2 (Gender: male vs. female) x 2 (Smoking Category: weekly smokers vs. monthly smokers) covariance analyses (ANCOVA's). Where mean scores were dependent on the interaction of Smoking Categories and Gender, simple main effect analyses were conducted to test, on the one hand, the relationship between Gender and the dependent variable within each Smoking Category, and, on the other hand, the relationship between Smoking Categories and the dependent variable within each Gender Group. Where an interaction effect was found, significant main effects of Gender and Smoking Status are indicated on the table. Furthermore, Pearson's correlations on nicotine dependence, withdrawal symptoms, number of cigarettes smoked, depressive mood and risk behaviour are reported. The significance level was set at $p<.05$.

\section{Results}

\section{Characteristics of the sample}

Of the 4768 students selected to participate in the study, 3869 completed the questionnaire. Due to incomplete data on key variables, 257 cases were excluded from the analyses. Among the remaining cases $(\mathrm{n}=3612)$ the prevalence of weekly smoking was $11.2 \%(n=404)$ while the prevalence of monthly smoking was $6.8 \%$ $(n=246)$. Inconsistent data on the FTQ and WSI scales led to the exclusion of 7 
weekly smokers and 89 monthly smokers to produce a total of 554 participants ( 397 weekly smokers and 157 monthly smokers) eligible for the present study (see Table 5.1). The mean age of the participants was 16.30 years $(\mathrm{SD}=1.56)$ and the overall distribution of males and females was $59.4 \%$ for males and $40.6 \%$ for females. Most students were Coloured $(56.1 \%)$ followed by Black African (28.3\%) and White $(15.6 \%)$ students. Most students reported an average school performance (66.2\%).

As can be seen from Table 5.1, weekly smokers were significantly older than monthly smokers; males were also significantly older than females. Independent of smoking status, significantly more Black students were male, and significantly more Coloured students were female. Among the White weekly smokers, more students were male as opposed to the White monthly smokers where more students were female. In addition, significantly more weekly smokers than monthly smokers reported an average school performance.

\section{Prevalence of nicotine dependence and withdrawal symptoms}

The mean level of nicotine dependence for weekly and monthly smokers was 2.83 $(\mathrm{SD}=1.84)$, while just over $9.5 \%(\mathrm{n}=53)$ of the sample met the criteria for a high level of nicotine dependence (FTQ $\geq 6$ ) (see Table 5.2). The mean level of withdrawal symptoms reported for the sample was $2.84(\mathrm{SD}=2.68)$. Craving was the most frequently reported withdrawal symptom and hunger the least reported withdrawal symptom (see Table 5.3). While $30.0 \%(n=167)$ of the sample reported experiencing no withdrawal symptoms at all, $47.1 \%(n=262)$ of the sample reported experiencing more than two withdrawal symptoms.

\section{Differences between weekly smokers and monthly smokers}

Across the Gender Groups, weekly smokers reported higher levels of nicotine dependence, withdrawal symptoms, number of cigarettes smoked, depressive mood and risk behaviour than monthly smokers (see Table 5.2). A substantial percentage of weekly smokers $(11.6 \%, n=46)$ reported a high level of nicotine dependence (FTQ $26)$. More weekly smokers $(64.5 \% ; \mathrm{n}=254)$ than monthly smokers $(28.5 \% ; \mathrm{n}=45)$ reported craving, $\chi^{2}(1)=58.83, p<.001$ ) as was the pattern for all of the other withdrawal symptoms ( $p$ 's <.001) with $55.9 \%(n=222)$ of weekly smokers reporting more than two withdrawal symptoms. Weekly smokers smoked between $6-10$ cigarettes in a week while monthly smokers smoked between $0-1$ cigarette in a week.

\section{Differences between males and females}

Across the Smoking Categories, females reported higher levels of nicotine dependence, withdrawal symptoms and depressive mood and lower levels of risk behavlour than males (see Table 5.2). Although males reported smoking more cigarettes in a week than females, this was not a significant difference. In-depth analysis showed that the only FTQ item on which females $(47.2 \%, \mathrm{n}=126)$ differed substantially from males $(39.7 \%, \mathrm{n}=149)$, though not significantly, was that they experienced more difficulty in refraining from smoking in forbidden places, $\chi^{2}(1)=$ $16.41, \mathrm{p}=.06$ 


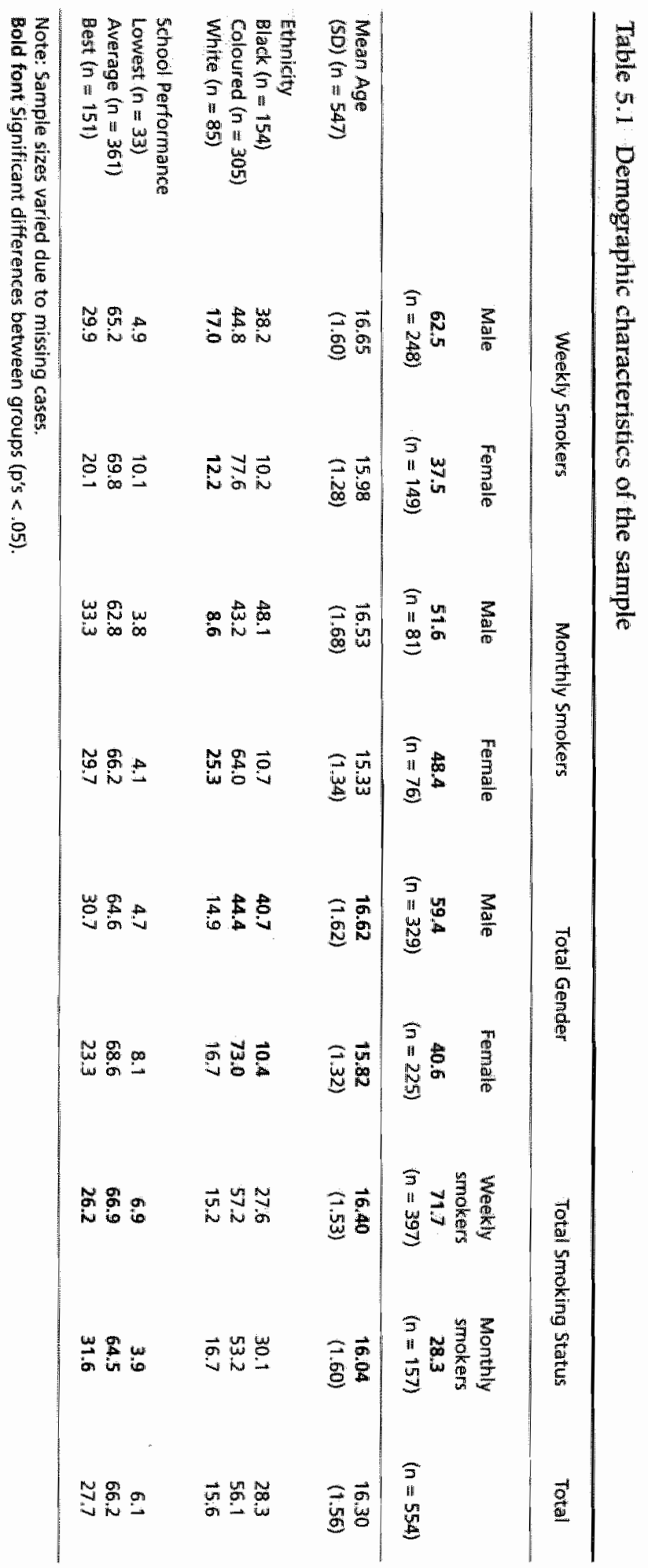




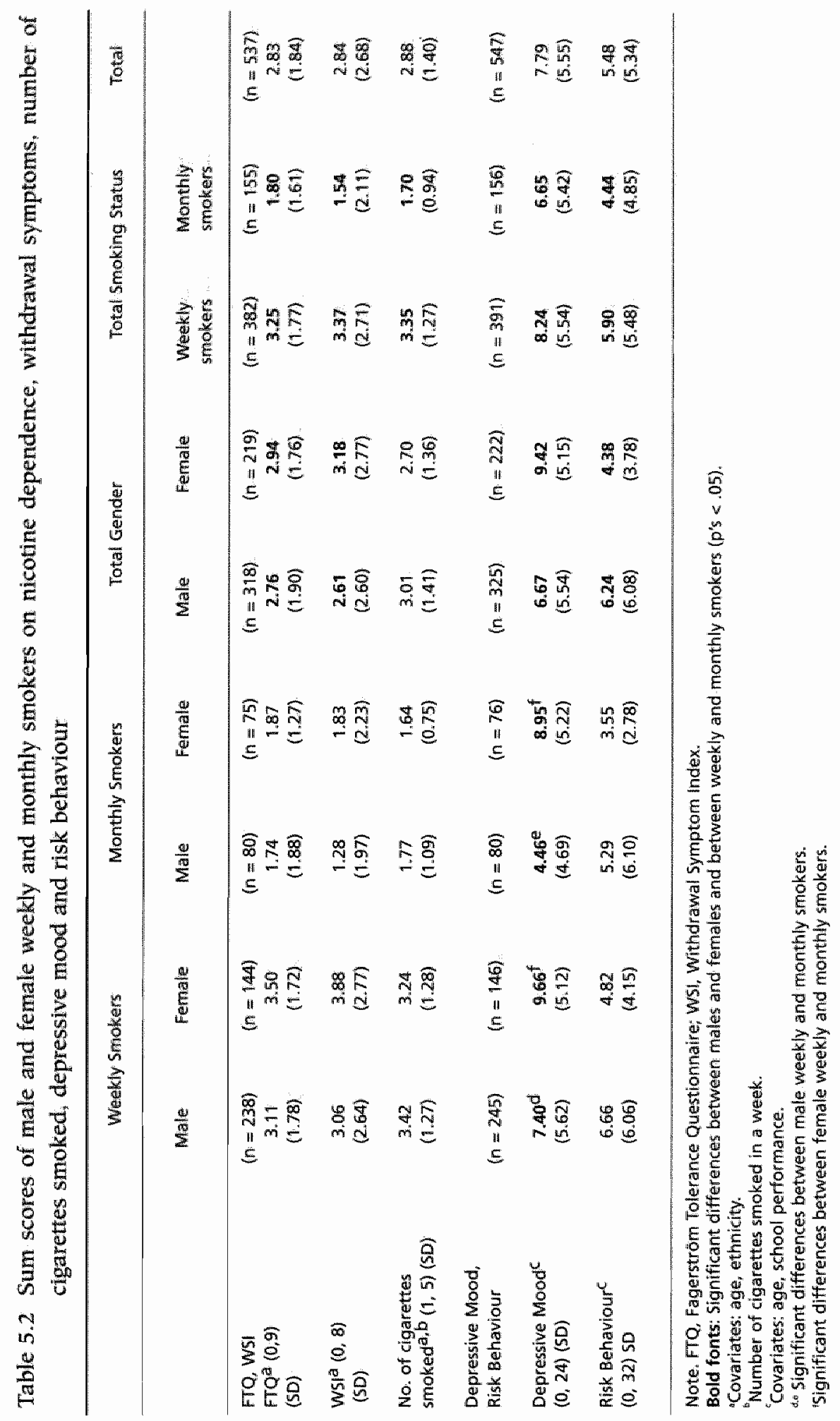




\section{Interaction pattern between smoking categories and gender}

The differences between males and females as described above were similar for the different smoking categories (see Table 5.2). Depressive mood was the only item on which a significant interaction pattern of Smoking Category and Gender was found. Simple main effect analyses showed that for both weekly smokers and monthly smokers, females reported higher levels of depressive mood than males (see Table 5.2). What is more, male weekly smokers reported higher levels of depressive mood than male monthly smokers whereas female weekly smokers did not report significantly different levels of depressive mood than female monthly smokers.

Table 5.3 Prevalence of withdrawal symptoms by smoking status $\mathrm{n}(\%)$

\begin{tabular}{lccc}
\hline Withdrawal Symptom & Weekly Smokers & Monthly Smokers & Totak \\
\hline Craving & $254(64.5)$ & $45(28.5)$ & $299(54.2)$ \\
Irritable & $181(45.7)$ & $36(22.8)$ & $217(39.2)$ \\
Restless & $175(44.6)$ & $29(18.4)$ & $204(37.1)$ \\
Nerwous and tense & $166(42.0)$ & $36(22.6)$ & $202(36.5)$ \\
Miserable and sad & $164(41.4)$ & $27(17.0)$ & $191(34.4)$ \\
Unable to concentrate & $140(35.5)$ & $30(18.9)$ & $170(30.7)$ \\
Trouble sleeping & $136(34.3)$ & $24(15.4)$ & $160(28.9)$ \\
Hunger & $118(30.0)$ & $99(12.0)$ & $137(24.9)$ \\
\hline
\end{tabular}

Note. Sample sizes varied due to missing data.

"Range $392-397$, Range 156 - 159, Range 550- 555 .

\section{Correlation analyses}

The correlations in Table 5.4 show that nicotine dependence, withdrawal symptoms, number of cigarettes smoked a week, depressive mood and risk behaviour were significantly correlated with each other. Nicotine dependence was most highly correlated with the withdrawal symptom index followed by the number of cigarettes smoked in a week.

Table 5.4 Correlations of weekly and monthly smokers on nicotine dependence, withdrawal symptoms, number of cigarettes smoked, depressive mood and risk behaviour

\begin{tabular}{|c|c|c|c|c|c|}
\hline Variable & 1 & 2 & 3 & 4 & 5 \\
\hline $1 \mathrm{FTQ}$ & - & $.51^{*}$ ik & $.48 * *$ & $.25 * *$ & $.26 * *$ \\
\hline 2 WSI & & - & $.35 * *$ & $32^{*}$ & $20^{* \cdot 4}$ \\
\hline 3 No. of cigarettes moked & & & - & $13^{*}$ & $.114 \%$ \\
\hline 4 Depressive Mood & & & & “ & $.19 * 4$ \\
\hline 5 Risk.k. Behaviour & & & & & $\therefore$ \\
\hline
\end{tabular}

Note. FTQ, Fagerströn Tolerance Questionnaire; WSI, Withdrawal Symptom Index.

Number of cigarettes smoked in a week.

$p<.01, n=556$ 


\section{Discussion}

This study describes the prevalence and differences in nicotine dependence, withdrawal symptoms, depressive mood and risk behaviour between a sample of weekly and monthly smokers. Additionally, gender differences in these four factors were also investigated with the aim of assessing the need for gender-sensitive smoking cessation interventions. To the best of our knowledge, these findings represent the first formative research on nicotine dependence and withdrawal symptoms among South African adolescents.

Overall, weekly smokers displayed substantial levels of nicotine dependence with $11.6 \%$ of weekly smokers classified as highly dependent. Prokhorov and colleagues (1996) as well as Riedel and partners (2002) reported $20 \%$ and $17 \%$ respectively of their adolescent sample as highly nicotine dependent with samples comparable in age although they smoked more cigarettes per day. Over one in two (55.9\%) weekly smokers and $47.1 \%$ of our total sample also reported experiencing two or more withdrawal symptoms. Rojas and partners (1998) reported a slightly lower percentage of monthly smokers (34.9\%) experiencing two or more withdrawal symptoms. The DSM IV criteria for withdrawal symptoms do not include craving, yet our study and other studies (MMWR, 1994; Dappen et al., 1996; Prokhorov et al., 2001; Rojas et al., 1998; Siqueira et al., 2001; Stanton, 1995) have consistently reported craving as the chief withdrawal symptom reported by adolescent smokers, hence its inclusion in the withdrawal symptom index.

Our findings concur with other studies that substantial numbers of adolescents smokers experience nicotine dependence and withdrawal symptoms (Prokhorov et al., 2001; Prokhorov et al., 1996; Rojas et al., 1998; Stanton et al., 1996), even nondaily smokers (DiFranza et al., 2000; DiFranza et al., 2002a; O'Loughlin et al., 2003; Rojas et al., 1998). Smoking cessation programmes that include methods to help adolescents cope with nicotine dependence and withdrawal symptoms are therefore required. Pharmacotherapy may be also required to assist those adolescents who are highly dependent on nicotine. The effectiveness of nicotine replacement therapy (NRT) and bupropion to quit smoking among adults has been demonstrated (Hurt et al., 1997; Silagy et al., 2004). However, the limited research in this field among adolescents suggests that both NRT and bupropion are ineffective (Hurt et al., 2000; Killen et al., 2004; Smith et al., 1996) although they have helped to decrease the number of cigarettes smoked. It has been suggested that cognitive-behavioural therapy may be better suited to the behavioural and social nature of smoking among adolescents and that NRT, whose safety has been demonstrated among adolescents in existing studies (Hurt et al., 2000; Smith et al., 1996); should be reserved for highly dependent adolescent smokers preferably administered in the clinical setting (Adelman, 2004; McDonald et al., 2003).

While non-daily smokers may be the target for prevention programmes, the substantial levels of withdrawal symptoms experienced may perpetuate experimentation with smoking and mediate the transition to regular smoking. As adolescents progress along the stages of the smoking continuum, the balance of 
programme content must be shifted to reflect both prevention and cessation strategies. Our results suggest that non-daily smokers will benefit from skills to identify and cope with withdrawal symptoms. To facilitate early intervention, however, much more empirical research is needed on the progressive onset of nicotine dependence and withdrawal symptoms. In fact, Colby and colleagues (2000a) recommended that nicotine dependence like smoking onset or smoking cessation should be viewed as a 'dynamic, unfolding process' rather than a singular event. Certainly in a developing country like SA, the existing levels of nicotine dependence and withdrawal symptoms among non-daily smokers, the lack of empirical support for the effectiveness of phamacotherapy among adolescents and the challenge to the public health system to deliver treatment even to highly dependent smokers amidst several competing health priorities, provides a compelling argument for earlier interventions to prevent or delay smoking onset and to promote cessation before adolescents reach nicotine dependence.

Females in this study reported higher levels of nicotine dependence and withdrawal symptoms although they did not differ significantly from males in the number of cigarettes smoked. However, females experienced substantially more difficulty in refraining from smoking in forbidden places. O'Loughlin and colleagues (2003) and DiFranza and partners $(2000 ; 2002 \mathrm{a} ; 2002 \mathrm{~b})$ also found higher rates of nicotine dependence symptoms among females than males even though levels of cigarette consumption were similar between the two groups. A similar pattern of higher nicotine dependence has been reported among adult females (Kandel er al., 1997; Kandel and Chen, 2000). It has been suggested that females report higher nicotine dependence because of biological differences in the metabolism of nicotine, differences in the topography of smoking or that they report more symptoms (Colby et al., 2000a; Kandel and Chen, 2000; O'Loughlin et al., 2003). Our findings suggest that the gender difference in nicotine dependence is most likely the result of lower self-efficacy among females as this was the only FTQ item on which the groups differed substantially. This finding may lend weight to the criticism levelled at the FTQ in that it may be not measuring physlological dependence but behavioural dependence and may be inappropriate for measuring the early onset of dependence (Colby et al."2000b; DiFranza, et al., 2002a). Additionally, the low internal consistency of the FTQ in our study as reported elsewhere (Chen et al., 2002b; Horn et al., 2003), suggests a need for adolescent measures of nicotine dependence before definitive conclusions can be drawn with regards to the gender-specific nature of dependence. DiFranza and colleagues (2000; 2002a; 2002b) have shown positive findings with the Hooked on Nicotine Checklist (HONC) for adolescents. While attempts are made to clarlfy the dimensions of dependence, these findings as well as our other studies on the motivational determinants of smoking cessation (Panday et al., in press), highlight the importance of enhancing self-efficacy to promote cessation.

Weekly smokers reported higher levels of depressive mood and risk behaviour than monthly smokers; females also reported higher levels of depressive mood while males reported higher levels of risk behaviour. Other studies have also shown 
higher levels of depression among female monthly smokers than male monthly smokers (Rojas et $a$ l., 1998). The covariation of risk behaviour among adolescents is well documented (Everett et al., 1998; Jessor, 1991; Proimos et al., 1998; Rigotti et al., 2000; Siqueira and Brook, 2003; USDHHS, 1994; Wetzels et al., 2003). Further studies are required to analyse the impact of psychological factors and deviance prone behaviour on nicotine dependence and the ability to stop smoking.

The findings are subject to some limitations. The nicotine dependency scale was not vallidated using biochemical measures due to financial and logistic constraints: However, studies have shown agreement between self-reports of nicotine dependence and biochemical measures (Prokhorov et al., 2000; Rojas et al., 1998). The cross-sectional nature of the study cannot estimate causality and must be replicated in longitudinal studies. Due to small cell sizes in the study, ethnic differences could not be elaborated. Further studies will be required in SA to investigate the cultural specificity of dependence and withdrawal symptoms. 


\section{Chapter 6}

\section{Access point analysis. What do adolescents in South Africa say about tobacco control programmes?}




\section{Abstract}

This paper explores adolescent preferences for the setting, timing, delivery format, provider and key elements of tobacco control programmes. The need for programme sensitivity towards urban/rural, gender and ethnic subgroups is also discussed. Schools were purposively selected from the Southern Cape-Karoo Region, South Africa. Twelve prevention and rine cessation focus group discussions were conducted with grade $6-8$ students and grade $8-9$ smokers and ex-smokers respectively. Adolescent had similar preferences for prevention and cessation programmes. Although they were unaware of smoking prevention or cessation programmes, they reported a willingness to participate in such programmes. Programmes should be primarily school-based and supported by outof-school activities over weekends and holidays. Non-judgemental and empathetic teachers and peers, as well as ex-smokers were preferred as programme providers. School-based participatory delivery formats should be supported by communitybased mass media approaches. Programmes can be jointly presented to boys and girls of diverse ethnic backgrounds with some gender sensitive sessions. Programme participation and sustainability would be enhanced if it was exciting, fun-filled and integrated into their daily lives. School-based programmes must be embedded within comprehensive approaches that involve community and policy level interventions. 


\section{Introduction}

Since the 1970 's adolescent smoking prevention programmes have been schoolbased and theory-driven using the social influences approach (Evans, 1976). Even though there is some support for the long-term effectiveness of this approach, lack of programme effects in several studies and variability between studies in their internal and external validity, cloud the reliablity of this method (Skara and Sussman, 2003). Recommendations have been made for comprehensive approaches that address multiple determinants at the individual, community and policy levels (Bracht, 1999; De Vries et al., 2003c; Glynn, 1989; Klepp et al, 1993; Lantz et al., 2000; Tones and Tilford, 1994; USDHHS, 1994). Such approaches have resulted in significant reduction in smoking among adolescents (Biglan et al., 2000; Perry et al., 1992; Vartiainen et al., 1998) and other unhealthy behaviours such as alcohol use (Williams et al., 1999).

The integrated planning model (I-Plan Mode]), previously known as the ABC Planning Model (De Vries, 1998) (see Figure 6.1), supports comprehensive approaches to improve the effectiveness of anti-smoking strategies. The model incorporates insights from the PRECEDE-PROCEED Mode) (Green and Kreuter, 1991), the Community Change Model (Bracht, 1990) and the Diffusion of Innovations Model (Rogers, 1983) and consists of three phases namely, Analysis, Behavioural Intention and Continuation. In the Analysis phase, the motivational determinants that underpin the educational objectives of smoking programmes are

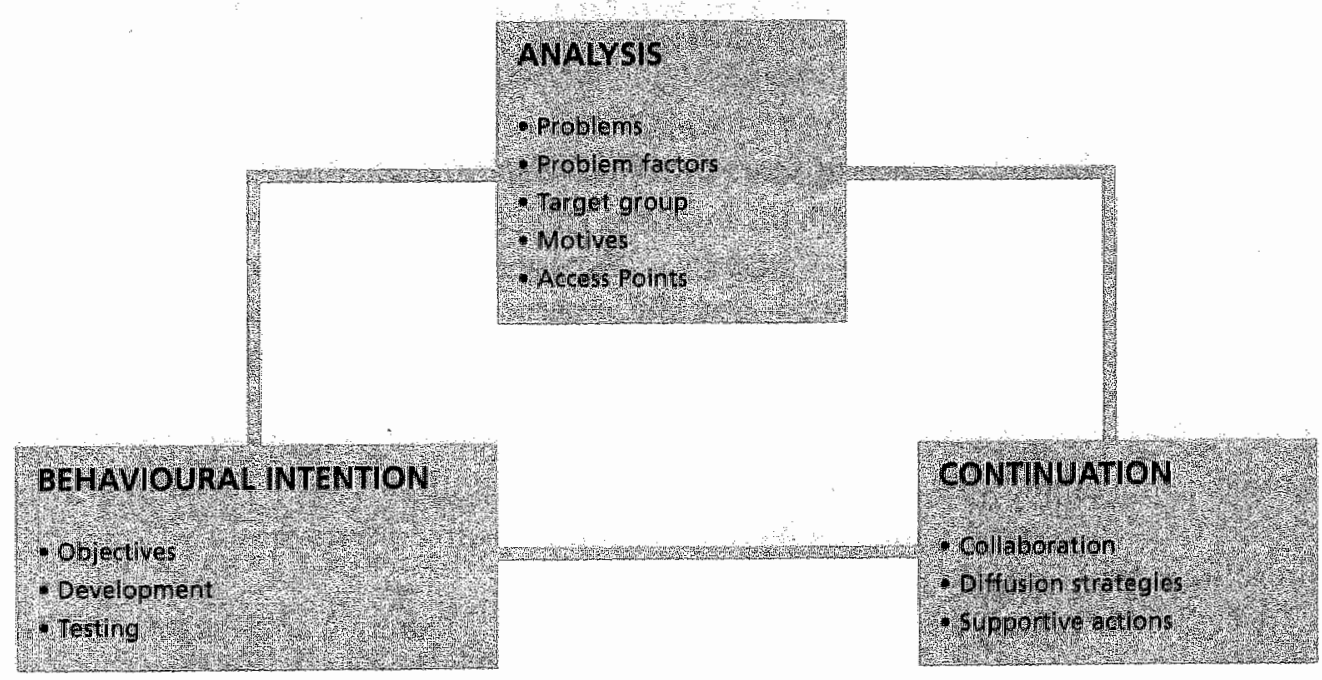

Figure 6.1 The I-Plan Model

From "Planning and Evaluating Health Promotion," by H. de Vries, In "Evaluating Health Promotion," by S. David and R. Weston, 1998, Cheltenham: Stanley Thornes. Copyright 1998 by Stanley Thornes (Publishers) Ltd. Adapted with permission of the author. 


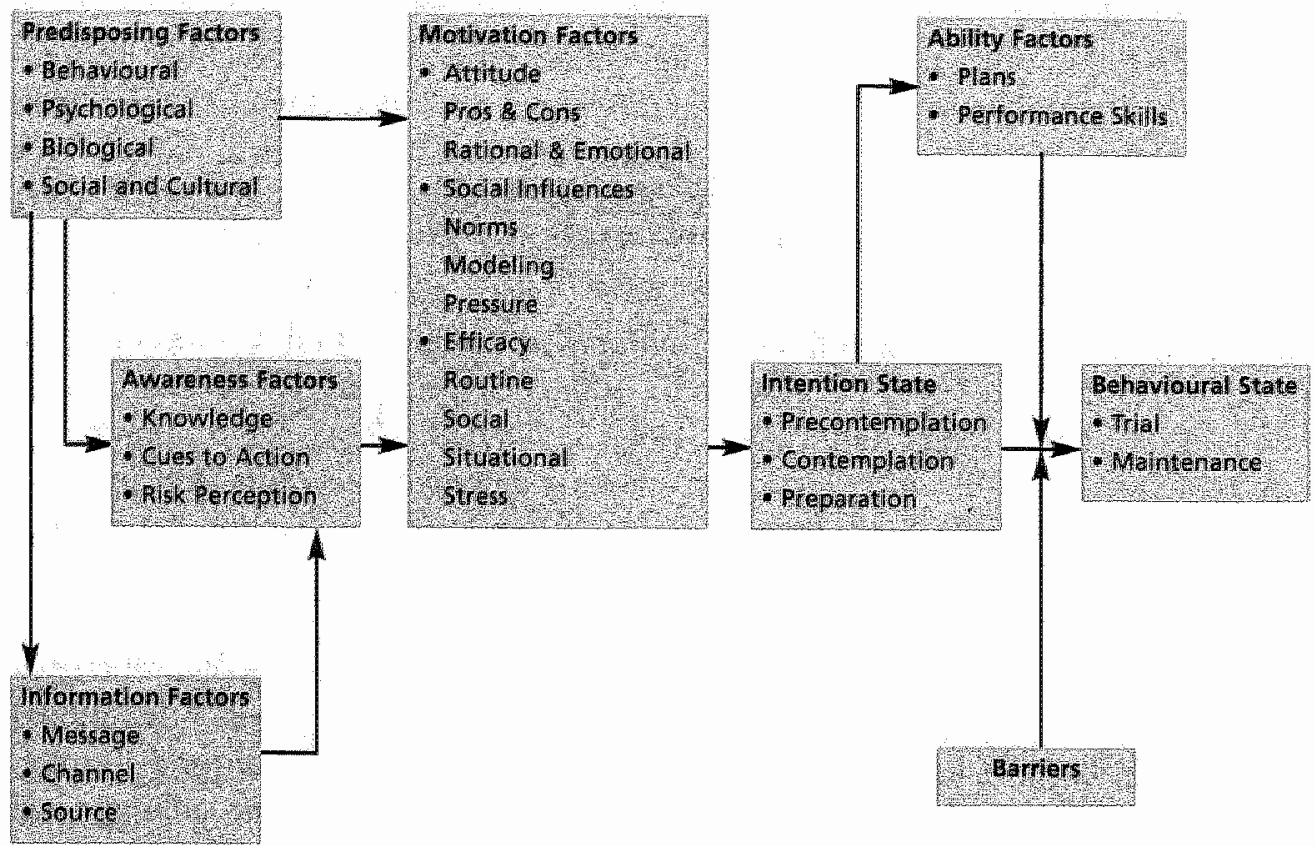

Figure 6.2 An Integrated Model for Change

From "The European Smoking Prevention Framework Approach (ESFA): an example of integral prevention," by H. de Vries, M. P. Clemente, H. Storm, A. G. Gonzalez, M. Nebot, T. Prins and S. Kremers, 2003, Health Education Research, 18, p.612. Copyright 2003 by Oxford University Press. Reprinted with permission of the author.

identified using the I-Change Model (De Vries et al., 2003c). The I-Change Mode] (see Figure 6.2) incorporates insights from the Theory of Reasoned Action. (Fishbein and Ajzen, 1975), Social Cognitive Theory (Bandura, 1986) and the Transtheoretical Model (Prochaska and DiClemente, 1983). The Analysis Phase of the I.-Plan Model also includes an exploration of the channels through which the target audience can be accessed, known as an Access Point Analysis (see Figure 6.1). Access Point Analyses have been used to identify out-of-school settings for smoking programmes in three European countries (Bullock et al., 1996) and as a precursor to intervention development in a six European country study on smoking prevention for young people (De Vries et al., 2003b).

Access Point Analyses resonate closely to Social Marketing that segments the audience according to four basic marketing decisions, namely product, price, place and promotion (Walsh et al., 1993). For example, product decisions refer to the design of the product (e.g., smoking programmes) and match the desirability of the product to the target audience. Price refers to the cost (e.g., fee, effort to participate in the programme) that an individual must accept to use the product or service. Place refers to the channels through which the product or service can be delivered to the 
participants (e.g., programme setting, provider, delivery format) and promotion refers to strategies to engage the target audience to use the product or service (e.g., recruitment and retention). This information allows for the formulation of better targeted and more effective messages, more appropriate message design, more effective delivery and better reception by the public' (Lefebvre and Rochlin, 1997).

One of the cardinal principles of health promotion activities is empowerment of the target group through their active participation in programme development (Bracht et al., 1999; Parcel et al., 2000). Participatory approaches allow interventions to be tailored to the needs of adolescents and may increase the acceptability and participation in such programmes (Bennett and Tonkin, 2003; Bracht et al., 1999; Michaud, 2003). Community analyses, in assessing the needs for health programmes, implicitly identify settings, programme providers and delivery formats. For example, through community analysis in Tanzania, soccer players were identified as role models for HIV/AIDS interventions (Klepp et al., 1999; Rissel and Bracht, 1999). Community wide approaches also use formative research to identify the programme content through behavioural need assessments with adolescents and other gatekeepers such as teachers (Hanewinkel and Asshauer, 2004; Perry et al., 1985; Williams et al., 1999). However, little direct attention has been paid to other components that may influence the programmes' impact such as the provider, setting, delivery methods and programme context (Best et al., 1988). School-based smoking prevention studies have compared various types of programme providers (such as teachers, peers, a combination of teachers and peers, health educators and nurses) and delivery methods (such as group discussions, role play, videos and films) (Best et al., 1988). The providers and delivery methods used across studies, however, have been diverse and the inconsistency both within and across studies have limited the ability to make definitive conclusions on the efficacy of these programme components (Best et al., 1988).

The I-Change Model (De Vries et al., 2003c) has provided a useful framework for addressing the motivational factors for tobacco control programmes among adolescents in South Africa (SA) although some gender and ethnic talloring is required (Panday et al., 2003; Panday et al., 2004a; Panday et al., 2004b; Panday et al, in press). To ensure that interventions are also culturally sensitive, we explored adolescent preferences for the setting, timing, provider, delivery format as well as key elements of tobacco control programmes within urban/rural, gender and ethnic subgroups in SA. Both the prevention and cessation components of the tobacco control project included. Access Point Analyses which were conducted among students in the same study area. Considering that prevention and cessation are essentially elements of the same smoking continuum and the limited resources available to address multiple health priorities in SA, it was decided that a comparison of the prevention and cessation access point analyses would be undertaken. 


\section{Methods}

\section{Participants and sampling}

The smoking prevention and cessation studies were conducted among school-going adolescents in the Southern Cape-Karoo Region, Western Cape Province, SA. Schools were purposively selected based on their locality (urban or rural) and ethnicity in accordance with the school's previous race classification under the apartheid government (Black African, Coloured or White).

Smoking prevention study: Twelve focus group discussions were conducted with grade 6,7 and 8 students (12-14 years old) of mixed gender. Class selection was determined based on the recommendations of the school principals. After a detalled explanation of the study, 117 students, consisting of smokers and nonsmokers ( 60 females and 57 males) volunteered to participate in the study. To ensure confidentiality, all research procedures were conducted in the absence of teachers.

Smoking cessation study: The findings discussed in this chapter were derived from the nine focus group discussions conducted among grade 8 and 9 smokers and ex-smokers of the same gender and in most cases ethnicity. One class each of grade 8 and 9 students (13-14 years old) was randomly selected from each school. A brief questionnaire was used to gather data on students' age, gender, grade and smoking status. Current smokers (smoked a cigarette or a part thereof in the previous 30 days) and ex-smokers (stopped smoking and smoke-free for at least six months) were invited to participate in the focus group discussions. Where the prevalence of smoking was low in a class, more than one class was sampled per grade. Of the total of 74 students ( 24 females and 50 males) invited to participate in the study, 60 students ( 20 females and 40 males) agreed to participate. To ensure confidentiality, teachers were asked to leave the classroom during the research procedures.

\section{Consent}

The Ethics Committees of the South African Medical Research Council and Faculty of Medicine and Dentistry, Umeả University provided ethical approval for the prevention and cessation studies respectively. Permission to conduct the studies was also obtained from the Department of Education, school principals, parents and students. Participants were informed both verbally and in writing that participation was voluntary and that the confidentiality of their information would be ensured. Permission was also obtained from participants to tape record the focus group discussions.

\section{Focus group discussion guides}

Structured focus group discussion guides were developed based on the I-Change

\footnotetext{
During the Apartheid years, all South Africans were classified into race groups in accordance with the Population Registration Act of 1950 namely. Black African (people of African descent), Coloured (people of mixed descent). Indien (people of Indian descent) and White (people of European descent). The authors in no way subscribe to this classification.
} 
Model (De Vries et al, 2003c) and information from literature reviews. Themes explored included awareness of and participation in tobacco control programmes, the preferred setting, timing, provider and delivery format as well as key elements of tobacco control programmes.

The focus group discussion guides were prepared in English and translated from English to Afrikaans and Xhosa. To ensure the accuracy of the translations, the Afrikaans and Xhosa versions of the focus group discussion guides were back translated to English. The prevention focus group discussion guide was piloted among students in the study area and the cessation focus group discussion guide was piloted among students in Cape Town but adjusted to the dialect in the study area. The focus group discussions were approximately 90 minutes in duration and were moderated by the researchers and trained research assistants. A debriefing session was held after each focus group discussion to include new questions identified during the course of the previous discussion. The data were transcribed and translated into English according to uniform guidelines. To verify the accuracy of the translations, sections of the Xhosa and Afrikaans transcriptions were translated by a second person.

\section{Data analysis}

The data analysis process was managed using QSR Nudist version 4. Data were analysed thematically. The focus group discussion guides were used to create a tree of themes and new themes were assigned to data that did not fit the existing codes. At the first level, themes within the prevention and cessation focus group discussions were synthesised; at the second level, urban/rural, gender and ethnic similarities and differences were explored; while at the third level, similarities and differences between the cessation and prevention focus group discussions were identified. Quotations from the prevention and cessation focus group discussions are annotated as follows: PUS = Prevention Urban School, PRS = Prevention Rural School, CUS $=$ Cessation Urban School and CRS $=$ Cessation Rural School.

\section{Results}

\section{Awareness of and participation in programmes}

Students' awareness of and willingness to participate in programmes to prevent or quit smoking were explored. Students were neither aware of nor had participated in tobacco use prevention or cessation programmes. The cessation focus groups expressed a willingness to participate in cessation programmes should they make the decision to stop smoking. Some of the participants were, in fact, fearful of a programme as they were not ready to stop smoking. However, one of the participants likened the usefulness of a smoking cessation programme to that of Alcoholics Anonymous (AA):

I don't think these patches, and stuff like that work lbelcause after a while you just start smoking again. So like with the drinking thing, like AA, those people stop. I think that a programme for smoking will work. [CUS] 


\section{Setting and timing of programmes}

In discussing preferred locations for smoking prevention and cessation programmes, the school environment was suggested as the preferred setting (see Table 6.1) for three major reasons. Firstly, it compelled students to attend the programme. Secondly, schools were perceived as more accessible than alternative venues such as the community hall. Thirdly, prevention and cessation programmes were regarded as an exciting alternative to the day-to-day school curriculum:

If it is in school time, they [students] haven't really got a choice, whether they wanna [want to] listen to it or not, they just do it. [PUS]

Because a lot of children come to school and you know instead of doing boring work you can do that fun programme. [PUS]

Some participants suggested out-of-school settings such as churches, parks, community centres, youth centres or clubs, special camps arranged over weekends or even at private homes. Students also requested assistance not to smoke at places such as video arcades where they spend their free time away from the supervision of adults. Participants in the cessation focus group discussions felt that the setting of the programme did not matter as much as the environment being comfortable and allowing them to socialise with friends:

Ja [Yes], ... where children hang out like video arcades you should have advertised that smoking is bad because there are children there who smoke and there are no parents or friends to guide them there.... [PUS]

Table 6.1 Summary of components for tobacco control programmes among adolescents in South Africa

\begin{tabular}{|c|c|}
\hline Programme Components & Recommendations \\
\hline Programme setting & $\begin{array}{l}\text { Primarlly at the school } \\
\text { Out-of-school settings where adolescents spend their time }\end{array}$ \\
\hline Programme timing & $\begin{array}{l}\text { Primarlly school hours } \\
\text { Out-of-school activities over weekendsi and holidays }\end{array}$ \\
\hline Programme providers & $\begin{array}{l}\text { Non-judgemental and empathetic teachers and peers } \\
\text { Ex-smokers who have experience in smoking }\end{array}$ \\
\hline Programme delivery format & $\begin{array}{l}\text { School-based participatory approaches such as small group } \\
\text { discussions, role plays and dramas } \\
\text { Community-based mass media interventions such as televisions } \\
\text { programmes and posters }\end{array}$ \\
\hline Key elements of the programme & $\begin{array}{l}\text { Recruitment: exciting, funwflled activities } \\
\text { Sustainability: integrate the programme into diaily lives } \\
\text { Comprehensiwe approaches with community and pollicy level } \\
\text { interventions to support school-based programmes. }\end{array}$ \\
\hline Subgroups within the programmes & $\begin{array}{l}\text { Joint programmes } \\
\text { Some gender-sensitive sessions } \\
\text { Sensitivity to the socio-economic status of the community }\end{array}$ \\
\hline
\end{tabular}


Some participants felt that prevention and cessation programmes should be extended to weekends and school holidays as adolescents smoked more during these times compared to school days. The combination of the need to appear cool, the influence of friends, going out and contrarily boredom, resulted in an increase in the number of cigarettes smoked over weekends and holidays. Other participants believed that programmes run over weekends and holidays would infringe on their private time:

During the December holidays I went out a lot with friends, then you tend to smoke a bit more, about ten per night. But now, about one or two per week. [CRS]

It is nice for me now to smoke only about three, four per month, I don't want to anymore, but during the holidays there is nothing to do, like sport or such things, then you rather smoke. And you also want to be cool during the holidays then you smoke more than during schooi time. [CRS]

\section{Programme providers}

Potential providers of prevention and cessation programmes were discussed. The choice of a programme provider seemed to be determined by the past smoking experience of the provider rather than whether they were adults or peers. Both the prevention and cessation focus groups preferred ex-smokers who had experienced the health effects of tobacco use to facilitate smoking programmes (see Table 6.1). Additionally, the cessation focus groups highlighted that ex-smokers would be able to share their experiences of coping with an addictive behaviour:

He lost his vocal cords but it sounds weird, so scary because he had the microphone to his neck and actually ... you have a visual, you have somebody who's been through it. It actually scared them [students] off from smoking. [PUS]

I think we should get somebody who was very seriously addicted to smoking to tell how it was and how it feels now. [CRS]

Many participants in both the prevention and cessation focus groups expressed mixed feelings about adults who smoke (parents, teachers, health workers and religious leaders) as programme providers. This scepticism arose from the hypocrisy associated with adult smokers who reprimand adolescents for smoking. Some participants believed that potential programme providers need to stop smoking in order to increase their credibility as role models. Participants also objected to the disciplinary stance adopted towards smoking. They felt that the best way that adults could help was by communicating with them, expressing their willingness to help and building a trusting relationship with them:

The teachers are also sometimes the children's role models.... So, the children actually look up to their teachers and if the teacher smokes, they will also smoke. [PUS] 
My mother said if she should catch me smoking then she will buy a packet of cigarettes and she will force me to eat up a whole packet of cigarettes and if I do it all the time then she will let me eat cigarettes again. [CRS]

They [parents] have to come to you with a better attitude, like he cares more. He comes to you now; 'oh, I'll ground youl' It's a sign that he doesn't really care. That's not playing a part in you by grounding you. [CRS]

Both the cessation and prevention focus groups were in favour of peers as programme providers. Much like the choice of adults as programme providers, some participants preferred smoking peers as they 'know how it feels' while others preferred non-smoking peers as they have higher credibility to present anti-smoking programmes. The prevention focus groups also specified that they preferred regular friends over high-achieving peers as programme providers. Contrarily, participants also called for the involvement of role models such as their sporting heroes to serve as champions of the anti-tobacco message:

I think friends who have stopped are better, because they know how it is and they know the disadvantages. Friends who have never smoked before don't know what to say, because they don't know what it is like to stop. [CRS]

Yeah, it doesn't have to be like the "hoof seun" [head boy] and the "hoof dogter" [head girl] or prefects and stuff. It just has to be normal people like me. [PUS]

\section{Delivery format of the programme}

Participants were asked about the best ways that the programme could be presented to them. Both the prevention and cessation focus groups preferred participatory approaches that allowed for interaction with the programme provider as opposed to being passive recipients of information (see Table 6.1). Many participants preferred the use of small group discussions as it provided an oppottunity to share ideas and to relate to others with similar experiences as well as the involvement of friends who could provide the moral support that they needed to resist smoking. Other participatory approaches such as role-plays and dramas were also regarded as acceptable delivery formats provided that the messages were explicit:

Get a drama group ... you could have some humour in it and then some really

like sad parts, something that's really interesting and touching, I think. [PRS]

Participants provided explanations for why other delivery formats were less preferred. One-on-one sessions with a provider or participation in large group discussions that emanated from a disciplinary standpoint would render them shy; incline them to be less honest and less attentive. Lectures were also considered as boring and were unlikely to be effective:

Firstly, we"ve had it with the principall standing there in his very smart suit and 
going on and on ... about smoking and how bad it is for you and in English nobody needs! He keeps ramming it in, this is really, neally bed for you and it does this to your lungs' and you just go to sleep. [PRS]

Some participants compared video shows to lectures as it did not provide the opportunity for feedback. Other participants believed that video shows or movies that were exciting and used ex-smokers as the actors could facilitate a discussion on tobacco. Television programmes, such as talk shows and drantas that are dedicated to health issues as opposed to posters, were also preferred as their evolving storyline and associated images would sustain their interest:

I think $T V$ and radio and thiags you listen to and watch are the best things because posters you see them once and look at them and you read them ... and you just don't think about them because they are just always there and they get boring and you don't notice them. Whereas with TV programmes you watch them [be]cause something different is happening every time. [PRS]

\section{Key elements of the programme}

During the course of the focus group discussions, participants raised several issues that were critical to the success of smoking prevention and cessation programmes. Participants believed that the programme's appeal could be enhanced if it took advantage of opportunities in their daily lives to promote non-smoking, for example accepting the challenge to be smoke-free so as to excell at sport. They also requested that it be a fun-filled experience where the focus on smoking was implicit and would inadvertently get smokers to quit:

It must almost be as if you don't feel you are there for a programme, then you will stop without even knowing about it. [CRS]

Participants believed that multi-sectoral approaches that reach beyond the individual level to encompass the community are also required (see Table 6.1). Interventions that address adult smoking were seen as essential as adolescents model the behaviour of adults. Participants also referred to other social problems in their communities such as high rates of alcohol use and poverty which they regarded as inter-related with tobacco use. Interventions at the legislative level such as increases in the price of cigarettes were regarded as effective measures to decrease smoking rates. Adolescents also made an appeal for the provision of recreational facilities that would provide an alternative to smoking and drinking:

Interviewer: When should the programme take place?

Participant: Sunday afternoon at the school...Then the people are not drunk...it is quiet. The peopie are sober... [PRS]

Children want money for bread and she says 'no, I only have money for a cigarette, where am I going to get a cigarette if I give you this money', those kind of things. So she'd rather stay hungry because of smoking. [PUS] 
... there is no play park or something like that ... now the children smoke or drink to kill time... UPUSI.

\section{Subgroups within the programmes}

Participants were asked whether programmes needed to be presented separately to males and females. Two reasons were offered as to why gender groups should be combined in smoking programmes. Firstly, males and females smoked together and secondly, differing perspectives on smoking could be presented by each of the gender groups. However, a few participants felt that boys and girls would be shy to reveal personal information in the presence of the other gender group such as initiating smoking to impress girls although other participants believed that honesty precluded the need for shyness. Some participants stressed that the motivation to quit was gender-specific as a result of their "minds working differently" [PRS], hence requiring separate programmes. The participants concluded that the programme could be presented to both gender groups with some gender-sensitive sessions (see Table 6.1).

There were few urban-rural and ethnic differences in the elements of smoking prevention and cessation programmes. The differences that were found seem to be related to the socio-economic disparities amongst the ethnic groups in SA. Adolescents in rural schools felt that community-based programmes could not take place in school, due to the long travelling distances between the community and the school. They suggested that the programme take place at the farmer's hall in the evening so that adults could participate. Furthermore, while Black African and Coloured participants referred to reading material as an effective means to represent the health effects of tobacco use, White participants reported that reading material would be ignored and discarded. They referred to the mass media and other innovative technologies such as computer games as effective delivery formats for smoking programmes:

I think that you should show this person things that are caused by smoking.

Most people like to have books that show people with thin bodies. Explain to this person that, you are going to be like this and that, if you want to stop you'll be healthy. [CUS]

I think seeing that we're now going towards the computer age, they should make some computer games with that non-smoking, you know, like may be the little guy killing people that smoke. [PRS]

\section{Discussion}

This paper describes adolescent preferences for the setting, timing, provider and delivery format of tobacco control programmes as part of the I-Plan Model for programme development. Furthermore, key elements of tobacco control programmes are discussed as well as the need for adapting the programme to urban/rural, gender and ethnic subgroups. Adolescents expressed similar preferences for smoking prevention and cessation programmes thus supporting the 
concept that prevention and cessation respond to stages along the same smoking continuum. In a country with several competing health priorities, these similarities minimise the financial and infrastructural investment required to integrate tobacco control programmes into the school curriculum and diffuse them across the education system.

Participants were neither aware of nor had participated in smoking prevention or cessation programmes as has been found in other studies (Balch, 1998). They were, however, willing to participate in such programmes as they recognised that the addictive nature of tobacco use necessitates structured programmes with adequate social support, much like Alcoholics Anonymous.

Students preferred the school as the primary programme setting. School-based programmes have shown consistent, though modest, positive effects in delaying smoking onset (Glynn, 1989; Rooney and Murray, 1996; Thomas, 2004; Tobler et al., 2000). In offering access to large groups of adolescents for a sustained period and the opportunity to positively channel peer pressure, the school setting has proven to be a useful entry point for addressing socially motivated behaviours such as tobacco use. Some participants felt that the choice of the setting should be based on the comfort that the environment offered and the ability to socialise with friends. Stanton (1995) also reported that adolescent smokers preferred smoking programmes to take place during school time and that it would be easier to participate if friends were involved.

Participants believed that the programme should be extended to settings where they spend their free time especially over weekends and vacations when more cigarettes are smoked. Comprehensive approaches have augmented school-based programmes with out-of-school activities for smoking (Ausems et al., 2002; Biglan et al., 2000; De Vries et al., 2003b; De Vries, et al., 2003c; Perry et al., 1992; Vartiainen et al., 1998) and for other health behaviours such as alcohol use (Komro et al., 1996). The latter programme used peer-initiated, out-of-school, drug-free social activities such as movies held at school on weekends, dances and beach parties (Komro et al., 1996).

Participants regarded the development of mutual trust and empathy as essential characteristics of the programme provider. In fact trust is regarded as the most important quality of people that adolescents rely on for help (Fothergill and Ballard, 1998). Motivational interviewing that is characterised by non-judgemental, nonconfrontational, empathetic, and supportive approaches may be an effective technique for adolescent smoking programmes (Lawendowski, 1998; Resnicow et al., 2002). This technique has been used in the treatment of substance use and various other problem behaviours including smoking among adolescents (Resnicow et al., 2002).

While some adolescents preferred smokers as programme providers due to their experience in smoking, others preferred non-smokers due to their higher credibility. Both groups favoured ex-smokers as programme providers as they could offer personal experience in coping with an addictive behaviour and realism to the health consequences of tobacco use that are difficult for adolescents to percelve. 
Meetings with rehabilitated addicts have been used in smoking programmes (Erhard, 1999) although caution must be exercised as fear appeals have been shown to be ineffective (USDHHS, 1994).

Adolescents had neither a preference for teachers nor peers as programme providers. The sustainability of school-based smoking prevention programmes in practice would depend on teachers as primary programme providers. Creating opportunities for smoking teachers to quit smoking may increase their credibility as programme providers. Furthermore, the use of education or counselling strategies by teachers to address smoking as a health issue may help change the perception that the school views smoking as a disciplinary issue (Hamilton et al., 2003).

Participants also rejected the disciplinary stance adopted by their parents towards smoking. They called for parents to communicate with them and express a willingness to help. Authoritative parenting that is characterised by emotional support, appropriate behavioural monitoring, and clear, bidirectional communication may be more effective in dealing with smoking than authoritarian parenting that is associated with fearful, timid behaviour (Baumrind, 1966; Darling and Steinberg, 1993; Maccoby and Martin, 1983). More research is required in SA on the influence of parenting styles and practices on smoking behaviour.

Adolescents in the prevention focus group discussions preferred their regular friends as programme providers over high-achieving peers. Care should be exercised in the selection of peers to ensure that those in leadership positions are not automatically chosen. Smoking (Perry et al., 1989), alcohol-use (Perry et al., 1993) and nutrition (Story et al., 2002) programmes have effectively used peer leaders elected by classmates as programme providers. Although there is some evidence for the effectiveness of peer-led health education, the method is not that easy to establish and to sustain (Erhard, 1999; Klepp et al., 1993; Telch et al., 1990). Some evidence exists that peer-leaders as a support to teacher-led programmes can be effective (Glynn, 1989; Mellanby et al., 2000) although more research on the effectiveness of this method is required (Mellanby et al, 2000).

Students preferred participatory delivery formats such as small group discussions that allowed for the sharing of ideas and experiences as well as moral support from friends. Balch (1998) also showed that small group discussions involving trusted friends would be an effective means to help adolescents quit smoking. Participants believed that didactic methods such as video shows could be effective if they were used to facilitate discussions on tobacco use and if they could identify with the actors. In fact, a study that presented a social pressure curriculum using a videotape was more effective when it was supported by peer leaders (Telch et $a l ., 1990$ ).

While participants considered television programmes with changing story lines, as effective delivery formats, they regarded posters whose novelty faded with time, as ineffective. Plano Clark (2000) also reported that adolescents felt that antismoking media messages needed to be more interesting and target youth better to effectively influence smoking. Mass media campaigns can have long-term effects on aclolescent smoking rates if they are based on sound marketing principles, are 
theoretically driven, and messages are based on the needs and interest of the target group (Lantz et al., 2000; Vartiainen et al., 1998). Taken together, these findings suggest that school-based participatory delivery formats must be supplemented with community-based mass media approaches.

Participants stressed that the programme needed to be fun-filled and exciting to attract their attention. Balch (1998) concluded that smoking cessation interventions will require considerable promotion to increase programme participation. Participants also felt that the sustainability of the programme depended on how well it was integrated into and accounted for the cultural context in which they live. They referred to high smoking rates among adults and other social problems such as alcohol use and poverty. They commented on the lack of recreational facilities and the affordability of cigarettes that perpetuate smoking. These findings are consonant with the ecological perspective of health promotion that recognises individuals as inter-related to the larger social context in which they live, work and play (Green et al., 2000; Sallis and Owen, 1997; Tones and Tilford, 1994). Multi-sectoral solutions at the meso- (community) and macro-levels (policy) are therefore required to enhance the efficacy of school-based smoking programmes. Comprehensive approaches such as the Minnesota Heart Health Programme (Perry et al., 1992), the North Karelia Youth Project (Vartiainen et al., 1998) and recently the first randomised control trial (Biglan et al., 2000) have shown how school-based smoking programmes can be supported by communitywide interventions such as media advocacy, family communication and sale to minors to reduce adolescent smoking rates.

While most participants felt that smoking programmes could be jointly presented to boys and girls, some gender-sensitive sessions were recommended due to the sensitivity of discussing issues such as initiating smoking to impress girls. Other studies also concluded that the function and meaning of smoking in the social lives of boys and girls are different (Lambert et al., 2001-2002). While girls, for example, use smoking to cope with distress and boredom, boys smoke when they are stressed or angry (Lambert et al., 2001-2002). The study also concluded that girls avoided addressing the topic of smoking to control weight as it might have been too personal, intimate or threatening to be discussed (Lambert et al., 2001-2002). The use of participatory delivery formats such as small group discussions could acconmodate these gender-sensitive sessions in co-education schools. Additionally, smoking programmes can be presented to a racially diverse audience as few ethnic differences, related to the socio-economic disparities between the ethnic groups in SA, were found in this study as well as the motivational factors related to smoking (Panday et al., 2003; Panday et al., 2004b; Panday et al., in press). However, sensitivity must be applied to the ability of the community to participate in and sustain programmes that are high in financial and infrastructural demand.

Even though participants stressed the influence of friends in smoking during our assessment of the motivational factors (Panday et al., 2003), they did not articulate the need for skills development to resist such influences. Both our qualitative (Panday et al., 2003) and quantitative (Panday et al., 2004b; Panday et al., in press) 
research findings have shown the need for coping skills to resist smoking in various stressful, social and routine situations. Additionally, Botvin and colleagues (1995) have demonstrated the long-term effectiveness of teaching a combination of social resistance skills and general life skills in reducing tobacco, alcohol and marijuana use.

Despite the similarities across the ethnic groups in SA for the motivational factors and methods to access adolescents for smoking programmes, testing must be ongoing to ensure the cultural and language appropriateness of message framing. The definitive preferences of adolescents for programmatic components lend support to the need for Access Point Analyses to become explicit objectives of programme planning models much like the I-Plan Model. Furthermore, to generalise the qualitative findings, the Access Point Analyses must be used to develop survey research instruments. Even though the majority of the concepts explored in the prevention and cessation focus group discussion guides were similar, slight variations resulted in some issues being explored either in the prevention or cessation study. 


\section{Chapter 7}

General Discussion 


\section{Introduction}

In 1998, at the outset of this project, data was unavailable in SA on either the prevalence or the factors related to smoking among adolescents. Exploratory studies on smoking prevention among adolescents reported signs of dependence among 12 to 14 year old smokers. Thus the need for studies on the associations of smoking, smoking cessation and the channels through which adolescents can be accessed for tobacco control programmes was identified. In the interim, The SA Global Youth Tobacco Survey sketched the epidemiological picture of tobacco use among adolescents (Swart et al., 2004; Swart et al., 2003). Ever smoking declined significantly from $47.6 \%$ in 1999 to $37.6 \%$ in 2002 while current smoking decreased from $23 \%$ in 1999 to $18.5 \%$ in 2002 . A similar pattern was seen among adults in that smoking rates declined from 34\% in 1996 (Reddy et al., 1996) to $24 \%$ in 1998 (DOH et al., 2002). In the absence of other tobacco control interventions, the only plausible explanation for the decreased smoking rates was the sustained strengthening of tobacco control legislation and excise taxes over time that culminated in the implementation of the comprehensive Tobacco Products Control Amendment Act in 2001. In many ways SA is a success story of how rigorous legislative controls can positively influence smoking rates. The World Health Organisation acknowledged that there is no 'magic bullet' for tobacco control (Yach and Ferguson, 1999) and perhaps the better strategy to sustain the decrease in smoking rates would be to use multi-pronged approaches that address tobacco use at multiple levels (De Vries et al., 2003c; Glynn, 1989; Lantz et al., 2000; Reddy, 1999a; Reddy et al., 2003; USDHHS, 1994), a strategy employed by SA for both research and programme development (Reddy, 1999a). The task of implementing interventions at the micro and meso levels surely must be informed by empirical data on the motivational factors of both smoking and smoking cessation. The studies described in this thesis, the first to our knowledge in SA, fulfill this need.

Smoking prevalence in SA (Swart et al., 2004), as in other countries (USDHHS, 1998\%, differs along ethnic lines yet little is known about the mechanisms underpinning these differences and whether smoking programmes that were primarily developed for White adolescents are applicable to other ethnic groups (Skara and Sussman, 2003; Tyas and Pederson, 1998; USDHHS, 1998). Race or ethnicity in SA is a loaded term for during apartheid it was used to propagate social, economic, cultural and spatial differences. In a country in rapid transition the meaning and impact of these factors sometimes prove complex and difficult to estimate among adolescents. Consequently, ethnicity has become a proxy for these factors. In this thesis, ethnic differences in the motivational factors related to smoking onset and smoking cessation were investigated with a view to develop culturally sensitive tobacco control programmes for adolescents (Markham et al., 2004; Skara and Sussman, 2003; Swart et al., 2004; USDHHS, 1998).

This thesis aimed to investigate the motivational factors related to smoking onset and smoking cessation as well as the channels through which adolescents could be accessed for tobacco control programmes. Furthermore, the need for cultural and 
gender sensitivity in programme development was also investigated. The I-Change Model was used to assess attitudes (pros and cons of non-smoking), social influences (perceived social norms, smoking behaviour and direct pressure) and self-efficacy (stress, routine and social) as proximal factors that are related to intention and smoking behaviour, while depressive mood, risk behaviour, dependence and withdrawal symptoms were investigated as pre-disposing factors of smoking onset and smoking cessation.

The concluding chapter integrates and discusses the project's findings, highlights the project"s contribution to tobacco control research among adolescents in South Africa (SA), discusses methodological limitations and makes recommendations for intervention development and for future research.

\section{Motivational factors related to smoking among adolescents}

Even though theory-based programmes are the sin qua non of health promotion programmes, the application of theories in contexts other than where they were developed remains to be answered. Culture is one of the factors that may determine the fit between theories and health-related behaviours. Pasick (1997) defined culture as a unique shared set of values, beliefs and practices that are directly associated with a health-related behaviour, that are indirectly associated with a health-related behaviour or that influence acceptance and adoption of the health education message. Researchers are advised to test the applicability of existing theories in other cultural contexts rather than trying to fit culture into research with other primary aims (Pasick, 1997). Before theory testing begins, qualitative and quantitative testing should be undertaken to establish comparable meaning of constructs, the cultural relevance of measurement tools and translation of measurement tools to appropriate languages ensuring that the comparable meaning is retained. The testing of the stages of tobacco acquisition questionnaire and the decisional balance scale (Chen et al., 2003) as well as the Fagerström tolerance questionnaire for adolescents in China (Chen et al., 2002b) are two examples of cross-cultural validation of tobacco use measures in other settings.

Taken together the results of Chapters 3 and 4 showed that smoking among adolescents in SA, like other countries, is associated with negative attitudes towards non-smoking, lower support from the social environment not to smoke, lower self-efficacy not to smoke and lower intention not to smoke in future. To prevent smoking onset and to promote cessation, programmes must convince smokers of the benefits of non-smoking and provide them viable alternatives for the useful functions that smoking fulfills such as calming the nerves or accessing peer groups, teach them skills to resist the influence of smoking peers and increase their self-efficacy to resist smoking in stressful, social and routine situations. Our results also provided insight into items that may be more relevant for the subgroups studied in this thesis. The differences between smokers and non-smokers as well as amongst the ethnic groups, however, do not imply that separate programmes are needed, rather that some beliefs may be more pertinent for certain groups than 
others warranting specific attention during programme development. Furthermore, cross cultural learning can be fostered in multi-ethnic programmes such as the resilience factors that sustain low smoking rates in the Black African community.

Our results also demonstrated that the I-Change Model (De Vries et al., 2003c) provides a satisfactory framework to achieve these cognitive-behavioural objectives for South African adolescent smokers. The European Smoking Prevention Framework Approach (ESFA) successfully used the I-Change Model as a basis for developing school-based smoking prevention programmes in six European countries (De Vries et al., 2003c). Furthermore, a study in the LIK also concluded that interventions aimed at changing the motivational determinants of smoking based on the I-Change Model, would be equally effective amongst diverse ethnic groups (Markham et al., 2004). Similarly, a study to test the cultural applicability of the social influences approach in China showed that considerable similarities existed in the motivational determinants of smoking between Californian and Chinese adolescents despite differences in cultures and social systems (Unger et al.,2002).

Even though the long-term effectiveness of school-based smoking prevention curricula based on the social influences approach is tenuous, proposals for more comprehensive approaches that involve the social context (Backinger et al., 2003a), still regard school-based programmes as the backbone of smoking prevention interventions. Additionally, a recent review of smoking cessation studies for adolescents concluded that programmes based on cognitive-behavioural models demonstrated promise (McDonald et al., 2003).

In sum, the results of this study showed that the application of the social cognitive approach is feasible in the South African context and can provide a platform for programme development for the various subgroups studied in this thesis. However, due cognisance must be given to the the cultural and gender specificity of some of the salient beliefs discussed later on.

\section{Prevention and cessation: elements of the same smoking continuum}

The results of Chapters $\mathbb{1}$ and 5 highlighted the importance of augmenting such cognitive-behavioural tobacco control programmes for adolescents with skills to cope with dependence. The qualitative findings in Chapter 2 showed that adolescent smokers displayed signs of dependence and that their attempts to stop smoking, though multiple, were unsuccessful. Chapter 5 leant quantitative support to adolescents' experience of dependence outside of formal quit attempts. Smoking cessation programmes that include methods to help smokers cope with depenclence are therefore required. Additionally, our results suggested that pharmacotherapy may be also necessary to assist those smokers who are highly dependent on nicotine. The lack of evidence of the effectiveness of NRT or bupropion from the few clinical trials among adolescents (Hurt et al., 2000; Killen et al., 2004; Smith et al., 1996) coupled with the belief that smoking is more behaviourally or socially oriented among adolescents (Adelman, 2004; McDonald et al., 2003), has led to much scepticism regarding the use of NRT for adolescents. Until such time that 
more empirical data becomes available on the effectiveness of NRT among adolescents, its use will be limited to highly dependent adolescents smokers administered in the clinical setting (Adelman, 2004; McDonald et al.; 2003).

It must be noted that the substitution of cigarette smoking with smokeless tobacco use as a cessation method is fraught with health risks as the latter increases the incidence of oral cancer, oral leukoplakia, diseases of gingival and periodontal tissues and is associated with an adverse cardiovascular risk profile (Gupta et al, 2004). NRT, on the other hand, has been approved as a clinically appropriate therapy for smoking cessation. While smokeless tobacco use was beyond the scope of this study, further research is required in this area as $14 \%$ of South African adolescents use tobacco products other than cigarettes (Swart et al, 2004).

In Chapter 5, females reported higher levels of dependence and withdrawal symptoms although they did not differ significantly from males in the number of cigarettes smoked. Our findings suggested that the gender difference in dependence was most likely the result of lower self-efficacy among females as this was the only FTQ item on which males and females differed substantially. However, the FTQ has been criticised for not measuring physiological dependence but rather behavioural dependence (Colby et al., 2000b). More research is therefore required to differentiate psychological and physlological dependence before definitive conclusions can be reached about gender differences in dependence.

A substantial number of non-daily or monthly smokers in our study also reported experiencing dependence and withdrawal symptoms. Difranza and colleagues (2000) demonstrated that $63 \%$ of adolescent monthly smokers showed one or more signs of dependence and that $22 \%$ reported symptoms of dependence within four weeks of becoming monthly smokers. Our results suggested that non-daily smokers will indeed benefit from skills to identify and cope with withdrawal symptoms. It has been suggested that one of the reasons for the failure of recent smoking cessation interventions is that they do not include less than daily smokers (Backinger et al., 2003a). The transition from experimentation to dependence seems less distinct than earlier anticipated suggesting that smoking prevention and cessation cannot be viewed as mutually exclusive processes. The autonomy theory proposed that dependence occurs when either the physical or psychological effects of nicotine become a barrier to quitting (Difranza et al, 2002a). As adolescents progress along the stages of the smoking continuum, the balance of programne content must be shifted to reflect both prevention and cessation strategies. To facilitate early intervention, however, more research is needed on the progressive onset of psychological and physiological dependence.

This thesis extended the traditional boundaries of smoking cessation by identifying the motivational factors of those who try smoking but stop (nonsmoking deciders), a group recently isolated along the smoking continuum (Kremers et al., 2004; Kremers et al., 2001a), in addition to regular smokers who quit (quitters) (Chapter 4). It is estimated that as many as $50-67 \%$ of those who try smoking do not go on to become regular smokers and that up to two thirds of those who do become regular smokers want to quit but find it an increasingly difficult 
process (MMWR, 1998; USDHHS, 1994). Our findings on the motivational factors related to non-smoking deciders provide some insight as to why some adolescents progress onto regular smoking while others decide not to continue. Certainly in a developing country like SA, the existing levels of dependence among non-daily smokers, the lack of empirical support for the effectiveness of pharmacotherapy among adolescents and the challenge to the public health system to deliver treatment even to highly dependent smokers amidst several competing health prionities (NRT does not feature on the essential drug list of public hospitals), provides a compelling argument for earlier interventions to prevent or delay smoking onset and to promote cessation before adolescents reach dependence.

In conclusion our findings suggest that tobacco control programmes for adolescents must include skills to cope with dependence and that pharmacotherapy may be required for highly dependent adolescent smokers. Furthermore, an understanding of the motivational factors of those who experiment with smoking but stop provides an earlier entry point for interventions before adolescents progress onto physiological and psychological dependence.

\section{Ethnic and gender differences in the associations with smoking}

The investigation of ethnic and gender differences in both the proximal (attitude, social influences and self-efficacy) and distal factors (nicotine dependence, withdrawal symptoms, demographic factors, depressive mood and risk behaviour), showed that there were more common than unique ethnic factors related to smoking and smoking cessation (see Chapters 3,4 ). The commonalities in patterns also revealed that in some cases the relative weight of these factors may be different for the ethnic and gender subgroups. An understanding of the relative importance of the proximal and distal factors for each of these subgroups will help tailor tobacco control programmes to their specific needs.

While intention not to smoke was a correlate of smoking onset (Chapter 3) and smoking cessation (Chapter 4) for both Coloured and White students, intention was not associated with smoking onset or cessation among Black. African students. The lower scores on average on the detrimental effects of smoking, the weaker fit of the regression models and the significance of distal factors such as gender and depressive mood among Black African students, suggest that factors other than the proximal associates may be more important in determining smoking in this group. Smoking rates among Black African people in SA have remained consistently low and in fact have shown the sharpest decline in the last decade despite targeted advertising campaigns by the tobacco industry (van Walbeek, 2002, 2003). It is therefore plausible that the cultural belief system towards smoking including some protective resilience factors were not adequately elaborated in this group.

In conclusion, while the I-Change Model provides a satisfactory explanatory framework for both smoking prevention and cessation among all South African adolescents, further investigation of attitudinal beliefs, distal and cultural factors may be required among Black African adolescents. 


\section{Self-efficacy: the art of refusal}

Even though participants stressed the influence of friends in smoking during the qualitative assessment outlined in Chapters 2 and 6, they had not articulated the need for skills development to resist such influences. Chapters 3 and 4, however, highlighted the importance of the role of self-efficacy in both smoking onset and cessation for all the ethnic groups. These chapters also pointed towards the selfefficacy sub-factors that may benefit each of the ethnic groups. While Coloured students may benefit from an emphasis on coping skills in general, White students require an emphasis on refusal skills in social situations. Botvin and colleagues' Life Skills Training Programme (1980) has proven to be effective in addressing multiple determinants of tobacco use including saying "no" to tobacco, alcohol and other drugs, developing a positive self-image and making independent decisions without being influenced by peers, the media and others.

In summary, training in refusal skills in social, routine and stressful situations should form one of the integral components of tobacco control programmes for adolescents in SA.

\section{The social context of smoking}

Ethnic differences were most pronounced in the discussion on peer influence towards smoking and smoking cessation. In the qualitative study (Chapter 2), Coloured and Black African students reported that they were pressured by their peers into smoking and that their peers were a significant obstacle to quitting. White adolescents, on the other hand, believed that they smoked by choice and would stop smoking at will. Consonant with these findings, best friend smoking was a correlate of smoking onset for Coloured and Black African students in Chapter 3 and for smoking cessation among Coloured students in Chapter 4. Peer smoking was neither a correlate of smoking onset nor smoking cessation among White students. While some studies reported peer smoking as a predictor of smoking among White students (Griesler and Kandel, 1998; Sussman et al., 1987; Unger et al., 2001), our qualitative and quantitative studles consistently reported otherwise. Even though peer smoking is one of the most consistent predictors of adolescent smoking (Tyas and Pederson, 1998), due cognisance must be given to the fact that $\mathrm{SA}$ is a melting pot of cultures, the majority of which can be characterised as collectivist in nature. This is applicable to the Coloured and Black African ethnic groups where the influence of family, friends and the community are central to the construction of these collectivist cultures (Airhihenbuwa and Obregon, 2000).

In fact, Chapters 3 and 4 also quantitatively demonstrated the importance of the social environment, through perceived social norms, direct pressure and smoking behaviour of important others for both smoking onset and cessation among Coloured adolescents. Bearing in mind the consistently high smoking rates among Coloured adults (DOH et al., 2002; Reddy et al., 1996), our results are a testament to the influence of the social environment in making smoking normative for Coloured adolescents, hence the high smoking prevalence rates in this group. 
Studies have shown that the social environment via social norms and modelling the behaviour of important others can account for the influence of ethnicity on smoking (Ellickson et al., 2003; Markam et al., 2004). In line with the ecological perspective of health promotion (Green et al., 2000; Sallis and Owen, 1997; Tones and Tilford, 1994) adolescents in Chapters 2 and 6 made reference to the fact that the sustainability of tobacco control programmes depended on how well it was integrated into and accounted for their social environment.

Additionally, in Chapters 2 and 6 , adolescents also commented on the relative ease with which cigarettes could be accessed and the negative influence of marketing and advertising. The SA GYTS in 2002 reported that despite the ban on the sale of cigarettes to children under 16 years of age since 1993 and the ban on advertising since $2001,54 \%$ of grade $8-10$ students were able to buy their cigarettes in a store and $69.5 \%$ of students reported exposure to tobacco advertising (Swart et al, 2004). Comprehensive approaches that include interventions at the meso (e.g., community) and macro-levels (policy) are therefore required to enhance the efficacy of school-based tobacco control programmes. In fact, the limited long-term effectiveness of stand-alone school-based curricula has led to recommendations for comprehensive approaches towards adolescent tobacco control (Backinger et al., 2003a; Lantz et al., 2000; Wakefield and Chaloupka, 2000). The I-Plan Model (De Vries, 1998) is an example of a health promotion planning model that recognises the integral link between individuals and the context in which they live. Comprehensive approaches have been successfully adopted in school-based tobacco control programmes including the ESFA study (Biglan et al., 2000; De Vries et al., 2003c; Perry et al., 1992; Vartiainen et al., 1998). The I-Change Model through its elaboration of predisposing factors (biological, psychological, behavioural and socio-cultural) takes into account the contribution of factors such as media, advertising and access to cigarettes on the proximal factors and smoking behaviour. Further research is required in SA on the extent to which smoking behaviour can be explained by these meso and macro level factors.

In conclusion our findings advocate for school-based programmes that are supported by interventions at the community and legislative levels. Programme development should be sensitive to the relative importance and influence of the social environment on adolescent behaviour amongst the various subgroups studied in this thesis.

\section{The cultural context of smoking}

Even though the motivational factors related to adolescent smoking are generic to most countries, varying mostly in the relative importance of the mix of factors, the influence of the cultural climate on smoking behaviour must be factored into programme development. Ethnicity in SA has been used as a political tool and has come to represent a panoply of factors such as social, economic, spatial and cultural differences. The findings across the chapters discussed in this thesis resonate closely with these differences. Chapter 2 reminded us that qualitative research is context 
bound and spoke of the malaise of poverty in the study area where "smoking is the one pleasure in life'. Black African and Coloured adolescents mixed tobacco with donkey dung to make a substantial cigarette which placed them at even greater risk. Chapter 4 referred to increased spending money as a correlate of quitting among Coloured students and related this finding to the impact of socio-economic deprivation among the ethnic groups. Chapter 4 demonstrated that Black African females were more likely to quit smoking which is contrary to gender patterns of smoking cessation. Yet this is in line with the low smoking rates among both Black African adult (DOH et al., 2002) and adolescent females (Swart et al., 2004), the social taboo against smoking in this culture and the increased likelihood of quitting found among Black African adult females (DOH et al., 2002). It is clear that tobacco use is grounded in the context in which it is used providing further support for the ecologic perspective of health promotion (Sallis and Owen, 1997). The World Health Organisation recognised the inextricable link between poverty and tobacco use that creates a 'vicious circle from which it is often difficult to escape' (WHO, 2004). It is known that tobacco consumption is higher among the poorer and that for the poor, money spent on tobacco, means money not spent on basic necessities, such as food, shelter, education and healthcare (WHO, 2004; World Bank, 1999). Chapter 6 bears testament to the deprivation that tobacco use results in for the poor:

Children want money for bread and she says 'no, I only have money for a

cigarette, where am I going to get a cigarette if I give you this money', those kind of things. So she'd rather stay hungry because of smoking.

[Prevention Urban School]

Therefore, the bi-directional relationship between tobacco use and poverty implies that as much as programmes to reduce tobacco use would impact on poverty, overall macro-economic development that results in poverty alleviation and social upliftment will also help to prevent and reduce tobacco use in SA. This will hopefully translate into greater future prospects and perhaps more health promoting choices for South African adolescents.

\section{Smoking: an inter-related behaviour}

As a secondary outcome, our study also investigated the need for multi-faceted approaches through the interplay of proximal and distal factors influencing smoking onset and smoking cessation. The assumption that smoking takes place in a vacuum is a myopic view of the multiple social, psychological, biologic and emvironmental processes that influence smoking (Backinger et al., 2003a). Health promotion activities aimed at encouraging healthy lifestyles, especially in resource constrained environments, must reach beyond single health behaviours (Jessor, 1991; Yach and Ferguson, 1999) to develop the range of skills and psychological levels of competencies necessary to resist the influences generic to multiple risk behaviours. In our study, weekly smokers reported higher levels of depressive mood and risk behaviour than monthly smokers (Chapter 5). Furthermore, these factors 
showed some ethnic and gender-specificity. Depressive mood was a correlate of smoking onset (Chapter 3) and inversely related to quitting for Black African adolescerts (Chapter 4), while risk behaviour was a correlate of smoking onset among Coloured and White students (Chapter 3 ). Females reported higher leveis of depressive mood (Chapter 5) while males reported higher levels of risk behaviour (Chapter 5). A substantial body of evidence has shown the co-variation of smoking with depression (Choi et al., 1997; Escobedo et al., 1998; Horn et al., 2004; Rojas et al., 1998; Zhu et al., 1999). There is also evidence that a genetic predisposition towards the rewarding effects of nicotine and a resultant vulnerability to depressive symptoms may act synergistically in the progression of adolescent smoking (Audrain McGovern et al, 2004). Interventions that increase the quantity and quality of rewarding activities may have the dual benefit of improving mood and reducing the progression of cigarette smoking (Audrain McGovern et al, 2004).

Several studies have also reported on the co-variation of and gateway effect of tobacco use with deviance prone behaviour such as alcohol and marijuana use (Chen et al., 2002a; Everett et al., 1998; Jessor, 1991; Proimos et al., 1998; Rigotti et al., 2000; Siqueira and Brook, 2003; USDHHS, 1994; Wetzels et al, 2003). In the US, adolescents who engage in antisocial behaviour such as physical fighting and stealing were more likely to smoke, drink alcohol, use illicit drugs, experience academic failure and commit up to $60 \%$ of general crime and $80 \%$ of violent offences (Backinger et al., 2003a). In 2002, homicide dominated the non-natural causes of death among young people in SA (Crime, 2003) and there are also indications that violence is the predominant cause of non-fatal injury in this group (Peden, 2000). SA regards the youth as one of its strategic asset to lift itself out of the social and economic decimation of apartheid. Further understanding of the relationship between factors such as depressive mood and risk behaviour and smoking onset and cessation will be invaluable in informing the decision for comprehensive rather than singular behavioural programmes.

In sum, our results denonstrate the relative importance and influence of distal factors such as depressive mood and risk behaviours in smoking onset and continuation for the subgroups studied in this thesis and lend support to the argument for multi-faceted rather than vertical programmes.

\section{Access point analysis}

While several studies have concentrated on the motivational determinants of smoking onset and smoking cessation, little direct attention has been paid to other components that may influence the programmes' impact such as the provider, setting, delivery methods and programme context (Best et al., 1988). The I-Plan Model (De Vries, 1998) much like Social Marketing (Lefebvre and Rochlin, 1997; Walsh et al., 1993) distinguishes the need for documenting the target groups" preferences for the channels of programme delivery, known as an Access Point Analysis. This is especially relevant in a multi-cultural society where the nature of the interventions may need to be culturally specific even though the educational 
objectives of tobacco control programmes are the same (De Vries, 1998).

Our study showed that methods to access adolescents for smoking prevention and cessation programmes were largely similar (see Chapter 6) supporting the fact that prevention and cessation respond to stages along the same smoking continum. These similarities minimise the financial and infrastructural investment required to integrate tobacco control programmes into the school curriculum and diffuse them across the education system. Additionally, the finding in Chapter 6 that tobacco control programmes can be jointly presented to boys and girls further enables the delivery of programmes in co-education schools. However, the functional meaning of smoking can be different for boys and girls (Lambert $e t$ al., 2001-2002) and our results did suggest the need for some gender-sensitive sessions which can be accommodated in co-education schools through participatory delivery formats such as small group discussions.

In Chapter 6 , the school was regarded as the primary setting for tobacco control programmes as it offers access to large groups of adolescents for a sustained period. The South African Schools Act of 1996 made schooling compulsory for all children between 7-14 years of age and school attendance has grown substantially. Participants, however, rejected the disciplinary stance adopted by the school and their parents towards smoking. As far back as 1986, the Ottawa Charter recommended enabling or supportive environments to facilitate an improvement in health (WHO, 1986). Orienting school smoking policies away from a disciplinary stance to a non-judgemental and supportive approach may increase the receptivity to and active participation in tobacco control programmes. In fact, the National Drug Policy for schools in SA recommends an enabling and supportive environment to assist adolescents who are entangled in the web of drug abuse (National Drug Policy, 2002).

In the same vein, trust and empathy were regarded as essential characteristics of the programme provider (see Chapter 6). Even though motivational interviewing requires rigorously trained personnel (Lawendowski, 1998; Resnicow et al, 2002) which may be beyond the scope of school-based programmes, lessons can be learnt from this technique as to how to engender trust and empathy. The sustainability of school-based tobacco control programmes in practice is dependent on teachers as primary programme providers. Their credibility as programme providers would be improved if opportunities were created for them to quit smoking. Considering the kingpin role that teachers are expected to play in school-based programmes, further research is required in SA on their capacity to deliver tobacco control programmes especially in light of the transitional education environment and several competing health priorities such as HIV/AIDS being addressed through schools. Participants were also in favour of peer leaders as programme providers as long as they were elected by their classmates. There is evidence to show the effectiveness of teacherled programmes supported by peer-leaders (Glynn, 1989; Mellanby et al, 2000). Although participants expressed a need for ex-smokers to share their experiences of coping with an addictive behaviour, caution must be exercised as the use of fear appeals have been shown to be ineffective (USDHHS, 1994). 
In keeping with the importance of the social context of smoking behaviour, participants believed that school-based tobacco control programmes should be supplemented with out-of-school activities preferably held over weekends and vacations when more cigarettes are smoked (see Chapter 6). Out-of-school activities such as posters displayed at venues where adolescents spend their free time have been effectively used in the ESFA smoking prevention study (De Vries et al., 2003b) as well as other school-based tobacco control programmes (Ausems et al., 2002; Perry et al., 1992).

Adolescents preferred school-based participatory delivery formats such as small group discussions that allow for the sharing of experiences as well as moral support from friends (see Chapter 6). They were also in favour of innovative mass media approaches. The effects of mass media approaches combined with school-based tobacco control programmes are durable (Flynn et al., 1994; Vartiainen et al., 1998) as long as they are based on sound marketing principles, are theoretically driven, and use messages that are based on the needs and interest of the target group (Lantz et al., 2000). Our findings support the use of school-based participatory delivery formats supplemented with community-based mass media approaches.

In conclusion our findings demonstrate the importance of conducting an Access Point Analysis with the target group as a distinct objective of health promotion planning models. Additionally, Table 7.1 provides a cogent summary of the channels through which adolescents can be accessed for tobacco control programmes in SA.

Table 7.1 Summary of components for tobacco control programmes among adolescents in South Africa

\begin{tabular}{|c|c|}
\hline Programme Components & Recommendations \\
\hline Programme setting & $\begin{array}{l}\text { Primarily at the school } \\
\text { Out-of-school settings where adolescents spend their time }\end{array}$ \\
\hline Programme timing & $\begin{array}{l}\text { Primianily school hours } \\
\text { Out-of-school activities over weekends and holidays }\end{array}$ \\
\hline Programme providers & $\begin{array}{l}\text { Non-judgementall and empathetic teachers and peers } \\
\text { Ex-smokers who have experience in smoking }\end{array}$ \\
\hline Programme dellvery format & $\begin{array}{l}\text { School-based participatory approaches such as small group } \\
\text { discussions, role plays and dramas } \\
\text { Community-based mass media interventions such as televisions } \\
\text { programmes and posters }\end{array}$ \\
\hline Key elements of the programme & $\begin{array}{l}\text { Recruitment: exciting, fun-filled actiwities } \\
\text { Sustainability: integrate the programme into daily lives } \\
\text { Comprehensive approaches with community and policy level } \\
\text { interventions to suppont school-based programmes }\end{array}$ \\
\hline Subgroups within the programmes & $\begin{array}{l}\text { Joint programmes } \\
\text { Some gender-sensitive sessions } \\
\text { Sensitivity to the socio-economic status of the community }\end{array}$ \\
\hline
\end{tabular}




\section{Methodological limitations}

The cross-sectional nature of the study did not allow for an estimation of or the direction of causality and at best could identify associations or correlates of smoking onset and smoking cessation. In order to identify determinants of smoking onset and smoking cessation, the findings of the study must be replicated in longitudinal studies.

The study area was confined to one health region in the Western Cape Province due to financial constraints. Even though the study captured a cross section of the three main population groups in SA, to generalise the study findings, nationally representative samples may be required.

Smoking onset and smoking cessation are two distinct behaviours with distinet motivational determinants that are optimally measured with different sub-groups (never smokers vs triers for onset and regular smokers vs quitters for cessation), hence with separate samples. The cross-sectional survey, the results of which are described in Chapters 3,4 and 5 , was initially designed with the intention of measuring the factors related to smoking cessation. However, the identification of sufficient numbers of smokers for the three ethnic groups, with widely varying prevalence, in a school setting meant that many more non-smokers had to also complete the questionnaire. Furthermore, financial constraints and the need to protect the smoking status of the students meant that only one questionnaire was feasible for both groups. The questionnaire had to be adapted such that meaningful information could be gathered from both these groups. Hence, the associates of non-smoking behaviour were measured which placed the study in the unusual position of being able to assess the factors assoclated with smoking onset and smoking cessation. The explained variance in the regression analyses for both these behaviours was in fact satisfactory.

One of the primary aims of the quantitative study was to investigate ethnic differences in the motivational factors related to smoking and smoking cessation. This could have been optimally achieved through a comparison of Black African, Coloured and White students on the ASE factors across the smoking continuum (never smokers vs. triers vs. monthly smokers vs. regular smokers vs. non-smoking deciders vs. quitters). However, the low smoking rates among Black African students and the lower participation among White students limited the power of the study to conduct ethnic comparisons for each of the phases in the smoking continuum. The smaller cell sizes in these two ethnic groups also prevented a study of ethnic differences in dependence and withdrawal symptoms. Furthermore, the multiple interactions observed between smoking status and ethnic groups for the individual items studied, resulted in tables that were complex to present in coherent results and discussion sections. While initially we ran the analysis using multiple interaction terms, these specific outcomes are not outlined. As a compromise, the decision was taken to present the quantitative data in three separate papers (Chapters 3,4 and 5) and to conduct group specific analyses.

The power of the quantitative study to detect differences between smoking 
categories within the ethnic groups was low. Furthermore, the sample size also precluded a study of gender differences within the ethnic groups on the motivational factors related to smoking onset and smoking cessation. It is strongly recommended that where ethnic differences are to be investigated, alternative strategies must be identified to stratify by ethnicity as the increasing racial integration of schools makes stratification at the school level tenuous.

The low smoking rate among Black African females as well as the social taboo towards smoking in this group possibly hampered the identification of Black African females for the qualitative phase of the study. Thus the cultural beliefs of smoking were not adequately elaborated among Black Arican females.

Factors such as low socio-economic status, poverty, and low educational attainment, that are related to smoking, tend to cluster in certain ethnic groups (Tyas and Pederson, 1998). The study attempted to include robust measures of socio-economic status and poverty due to its importance and relevance to the SA context. However, focus group discussions with adolescents during pilot testing of the questionnaire showed that socio-economic indicators such as parental income and education were not viable and questions on the availability of household goods/services (e.g., water, electricity, television, telephone services etc.) were not differentiating for the group studied. The question "How often would you say that the people living in your house don't have food to eat?" was included in the questionnaire as an indicator of poverty. Due to problems experienced with the Afrikaans translation, the question could not be included in the analyses. Instead ethnicity, which is closely related to socio-economic status in SA, was used as a proxy for these set of factors.

Self-reports of smoking and nicotine dependence were not biologically validated due to logistical and financial constraints. However, when anonymity is assured, self-reports of smoking have been shown to be reliable and in agreement with biochemical markers (Dolcini et al., 1.996). Furthermore, other studies have shown agreement between self-reported nicotine dependence and biochemical markers (Prokliorov et al., 2000; Rojas et al., 1998). Several measures were adopted to ensure the anonymity and confidentiality of students during survey administration. Students were Informed both verbally and in writing that their answers would be kept confidential and were requested not to write their names on the questionnaire. The questionnaire was administered by trained research assistants simulating 'examination-like' conditions to prevent peers from viewing their responses. Teachers were also asked to leave the classroom during survey administration. By nature focus group discussions cannot provide individual confidentiality. However, the importance of maintaining group confidentiality was stressed to the participants in writing as well as at the outset and closure of each focus group discussion.

The use of the Fagerstrom Tolerance Questionnaire (FTQ) to measure nicotine dependence among adolescents has been criticised. It is purported that it measures behavioural dependence rather than physiological dependence and that it does not measure a unidimensional construct of dependence (Colby et al., 2000b). The low internal consistency of the FTQ has been reported in several studies (Chen et al., 
2002 b; Horn et al., 2003) as was seen in our study. It has been also labelled as inappropriate for measuring the early onset of dependence among adolescents (Colby et al., 2000; DiFranza et al., 2002a) suggesting the need for adolescentspecific measures of nicotine dependence.

The Diagnostics and Statistical Manual of Mental Disorders' (DSMIV) (American Psychiatric Association, 1994) criteria for measuring nicotine dependence has been also criticised for not being theory-based, applicable to all populations, evaluated among adolescents and for suggesting that dependence only begins with prolonged and heavy use when data exists to show that dependence develops even among non-daily users (Colby et al., 2000a; Difranza et al., 2000; Difranza et al., 2002a; DiFranza, et al., 2002b) as was reported in our study.

However, in the absence of theoretical consensus on the number and actual dimensions of nicotine dependence, researchers have adapted existing scales such as the FTQ and DSM IV criteria to provide an indication of nicotine dependence and withdrawal symptoms among adolescents.

Our qualitative findings (Chapter 2 and 6) as well as the findings from the SA Global Youth Tobacco Survey (Swart et al, 2004), highlighted the importance and relevance of addressing environmental factors such as access to cigarettes and marketing and advertising that are known to influence smoking among adolescents. These socio cultural factors are distinguished in the I-Change Model as predisposing factors together with behavioural, psychological and biological predisposing factors. However, due to the length of the questionnaire that primarily focused on the proxinal factors, for which data was unavailable in SA, these socio-cultural factors could not be addressed in the quantitative study (Chapters 3 and 4).

\section{Recommendations for tobacco control programmes in South Africa}

In summary, the findings of the study lend themselves to the following recommendations for tobacco control programmes among adolescents in South Africa:

- Tobacco control programmes must convince smokers of the benefits of nonsmoking and provide them viable alternatives for the positive functions that smoking fulfils such as calming the nerves or accessing peer groups, teach them skills to resist the influences of smoking peers and increase their self-efficacy to resist smoking in stressful, social and routine situations.

- The social cognitive approach of the I-Change Model provides a satisfactory explanatory framework to achieve these educational objectives in the South African context. However, further elaboration of attitudinal beliefs, cultural and distal factors that motivate smoking is required among Black African adolescents.

- The development of refusal skills in stressful, routime and social situation would benefit students from all ethnic groups. White adolescents, in particular, would benefit from coping skills to resist smoking in social situations.

- The participation of the social environment, through social norms of important others and modelling particularly among best friends, is an essential feature of 
smoking among Coloured adolescents. Community-based programmes would do well to recognise the differing importance and influence of the social environment in addressing tobacco use.

- Cognitive-behavioural tobacco control programmes for adolescents must be augmented with skills to cope with both psychological and physiological dependence even for experimental smokers. Pharmacotherapy may be also required for highly dependent adolescent smokers.

- Smoking prevention and smoking cessation cannot be viewed as mutually exclusive processes at opposing ends of the smoking continuum as the early appearance of dependence showed otherwise. As adolescents progress along the smoking continuum, tobacco control programmes that adjust their programme content to include both prevention and cessation strategies are advocated.

- Multi-faceted approaches that address factors such as depression and risk behaviour would enhance the efficacy of tobacco control programmes.

- The long-term effectiveness of school-based tobacco control programmes is dependent on the extent to which it is supported by interventions at the meso (community) and macro (policy) levels. At the meso level, these may include programmes to help teachers and parents stop smoking while at the macro level this may involve enforcement of the ban on the sale of cigarettes to minors.

- Access Point Analyses should become definitive objectives of health promotion planning models as adolescents have distinct preferences for the channels through which they can be accessed for tobacco control programmes.

- School smoking policies should be geared towards creating a non-judgemental and supportive environment. Educational strategies rather than disciplinary strategies must be adopted to address smoking behaviour.

- School-based tobacco control programmes must be augmented with out-ofschool activities held over weekends and vacations.

- Non-judgemental, empathetic and trusting teachers supported by peer leaders can serve as programme providers. Ex-smokers should be invited periodically to share their experience of coping with an addictive behaviour.

- School-based participatory delivery formats such as small group discussions should be augmented with community-based mass media approaches.

- Tobacco control programmes can be jointly presented to boys and girls with some gender-sensitive sessions.

- Even though the findings of this thesis showed that the relative weight of the motivational factors may be different for the ethnic groups, the history of racial segregation and discrimination in SA makes recommendations for ethnic-specific school-based programmes undesirable. Thus, the direct translation of the ethnic factors related to smoking onset and smoking cessation into programme objectives would be an over-simplification of the determinants of ethnic differences. However, further understanding of the link between other factors such as low socio-econonic status, poverty and low educational attainment that tend to aggregate in certain ethnic groups, will allow for tobacco control programmes to be tailored to the motivational determinants of these subgroups. 
- Programme development must also factor in the influence of the cultural climate on tobacco use. Tobacco control programmes in SA will benefit from a framework of poverty alleviation and social uplifment that promote greater future prospects and perhaps more health promoting choices.

\section{Recommendations for future research}

The cross sectional nature of the study coupled with the transitory nature of the period of adolescence, where experimentation is normative and the peer group fluid, necessitates longitudinal studies on the determinants of adolescent tobacco use.

Specifically, longitudinal studies on the ethnic and gender-specific proximal and distal predictors of smoking (comparing never smokers and triers) and smoking cessation (comparing regular smokers and quitters) are needed.

Further understanding of factors such as socio-economic status, poverty and low educational attainment that come to aggregate in certain ethnic groups are required to tailor tobacco control programmes to the motivational determinants of these subgroups.

Exploratory studies are required among Black African students to elaborate attitudinal beliefs, cultural and distal factors that motivate tobacco use. Furthermore, an investigation of the resilience or protective factors that keep smoking rates low among Black African females is required.

To facilitate smoking cessation before adolescents become dependent, research is required on the early course of onset and progression of both psychological and physiological dependence across the smoking continuum.

Intervention studies are also required to test the efficacy of both cognitive behavioural programmes and pharmacotherapy on adolescent cessation.

Further studies are also required to disentangle the motivational determinants of those who try smoking and stop (non-smoking deciders) compared to ex-regular smokers or quitters.

In view of the importance of the social environment in smoking behaviour, an understanding of the influence of factors such as parenting styles and practices and smoking among teachers (as the primary programme providers in the school setting) at the meso level as well as advertising and marketing of the tobacco industry at the macro level, which were essentially beyond the scope of this study, would provide a more comprehensive picture of the determinants of smoking among adolescents. 


\section{References}

Adelman, W. P. (2004). Nicotine replacement therapy for teenagers: about time or a waste of nme? Arthives of Pediatrics and Adolescent Medicine, 158(3), 205-206.

Arhihenbuwa, C. O. and Obregon, R. (2000). A critical assessment of theories/models used in health communication for HIV/AIDS. Joumal of Health Communication, 5 Suppl, 5-15.

Ajzen, 1. The theory of planned behaviour. (1991). Organisational Behaviour and Human Decision Processes, 50, 179-2 $\mathbb{L}$.

American Association of Physical Anthropology. (1996). AAPA statement on biological aspects of race. American fournal of Physical Anthropology, 101, 569-570.

Amerlcan Psychiatric Association. (1994). Diagnostic and Statistical Manual of Mertal Disorders (4th ed.). Author, Washington.

Arisa, C. $A$ and Nebot, M. A. (2002). Factors associated with smoking progresslon among Spanish adolescents. Health Education Research, 17(6),750-760.

Audrain McGovern, J., Lerman, C., Wileyto, E. P., Rodiriguez, D. and Shields, P. G. (2004). Interacting effects of genetic predispositton and depression on adolescent smoking progression. American Journal of Psychlatry, 161(7), 1224-1230.

Ausems, M. Mesters, I., Van Breukelen, G. and De Vries, H. (2002). Short-term effects of a randomized computer-based out-of-school smoking prevention trial aimed at elementary schoolchildren. Preventive Mediche, 34(6), 581-589.

Backinger, C. In. Fagan, P., Matthews, E. and Grana, R. (2003a). Adolescent and young adult tobacco prevention and cessation: current status and future directions. Tobacco Control, 12 Suppl 4, Iv46-Iv53.

Backinger, C. L. McDonald, P., Ossip Klein, D. J., Colby, S. M., Maule, C. O., Fagan, P., Husten, C. and Colwell, B. (2003b). Improving the future of youth smoking cessation. Amertcan Journal of Health behaviour, 27 Suppl 2, S170-184.

Balch, G. 1. (1998). Exploring perceptions of smoking cessation among high school smokers: Input and feedback from focus groups. Preventive Medicine, 27(5 Pt 3), A55-63.

Bandura, A. (1986). Social Foundations of Thought and Action: A Soctal Cognitive Theory. Prentice Hall, New York.

Bandura, A. (1977), Soclal Learning Theory, Prentice Hall, New York.

Bandura, A. (1962). Soclal Learning through Imitation. In Iones, M. R. (ed.), Nebraska Symposium on Motivation. University of Nebraska Press "Lincoln.

Batumind, D. (1966). Effects of authortative parental control on child behaviour. Child Development. $37(4), 887-907$.

Bennett, D. L. and Tonkin, R. S. (2003). International developments in adolescent health care: a story of advocacy and achievement. Joumal of Adolescent Heath , 33(4), 240-251.

Best, I. A., Thomson, S., Sant, S. Smith, E. and Brown, K. (1988). Preventing cigarette smoking among sehool children. Annual Review of Public Health, $9,161-201$.

Biglan, A. Ary, D. V., Smolkowski, K., Duncan, T. and Black, C. (2000). A randomised controlled trial of a community intervention to prevent adolescent tobacco use. Tobacco Control, $9(1), 24-32$.

Black, D. R., Loftus, E. A., Chatterjee, R., Tffany, S. and Babrow, A. S. (1993). Smoking cessation interventions for university students: recruitment and program design considerations based on social marketing theory. Preventive Medicine 22(3), 388-399.

Bonaguro, I. A. and Bonaguro, E. (1987). Self-concept, stress symptomatology, and tobacco use Journal of School Health, 57(2), 56-58.

Botwn, G. J., Baker, E., Dusenbury, L., Botvin, E. M. Diaz, T., Johnson, C. A., Pentz, M. A., Weber, M. D., Dwyer, ], H., Baer, N., Mackinnon, D. P. Hansen, W. B. and Flay, B. R. (1995). Long-term followup results of a randomized drug abuse prevention trial in at wite middle-class population. Journal of the American Medical Association, 273(14), 1106-1112.

Botvin, G. J., Eng, A. and Willams, C. (1980). Preventing the onset of cigarette smoking through life skills training. preventive Medicine, $9(1), 135-143$. 
Bracht, N. (1990). Health Promotion at the Community Level (1st ed) Sage Publications, Callorrita.

Bracht, N. (1999). Health Promotion at the Communty Level: New Advances (2nd ad). Sage Publications, California.

Bracht, N., Kingsbury, L. and Rissel, C. (1999). A Five-Stage Community Organisation Model for Heatth Promotion. Empowernent and Partnership Strategies. In Bracht, N. (ed.). Health Promotion at the Communty Level. New Advances (2nd ed.). Sage Publications, California.

Bradshaw, D. Groenewald, P., Laubscher, R., Namnan, N., Nojilana, B, Norman, P., Pleterse, D and Schneider, M. (2003). Initial Burden of Disease Estimates for South Africa, 2000. South African Medicall Research Council, Cape Town.

Braverman, M. T. and Aaro, L. E. (2004). Adolescent smoking and exposure to tobacco narketing under a tobacco advertising ban: findings from 2 Nonwegian national samples. American Joumal of Public Health, 94(7), 1230-1238.

Breslau, N. and Peterson, E. L. (1996). Smoking cessation in young adults: age at initiation of cigarette smoking and other suspected influences. American Jourral of Public Health, 86(2), 214-220.

Brownson, R. C., DiLorenzo, T. M., Van Tuinen, M. and Finger. W. W. (1990). Patterns of cigarette and smokeless tobacco use among children and adolescents. Preventive Mediche, 19(2), 170-180.

Buchanan, D. R., Reddy, S. and Hossain, Z. (1994). Social marketing: a critical appraisal. Wealth Promotion International, $9(1)$.

Bullock, A. D., De Vries, H., Lopez, M. L. and Thomas, H. (1996). Smoking preventlon and young people: Using research to identify out-of-school intervention sites in three countries. Educational Review. $48(2), 143-152$.

Burt, R. D. and Peterson, A. V. (1998). Smoking cessation among high school seniors. Preventive Medicine, 27(3), 319-327.

Chassin, L., Presson, C. C. and Sheman, S. I. (1984). Cigarette smoking and adolescent psychosocial development. Basic and Applied Social Psychology, 5(4), 295-315.

Chassin, L., Presson, C. C. and Sherman, S. (1985). Cognitive and social influence factors in adolescent. smoking cessation. Addictive Behaviors, 9, 383-390.

Chen, H. S., Horner, S. D. and Percy, M. S. (2003). Cross-cultural validation of the stages of the tobacco acquisition questionnaire and the decisional balance scale. Research in Nursing and Health, 26(3), 233-243.

Chen, X., Unger, I. B., Palmer, P., Weiher, M. D., Johnson, C., A., Wong, M. M. and Austin, G. (2002a). Prior cigarette smoking initiation predicting current alcohol use: evidence for a gateway drug effect: among Callifornia adolescents from eleven ethnic groups. Addictive Behoviors, 27(5), 799-817.

Chen, X., Zheng, H., Steve, S., Gong. 1., Stacy, A., Xla, 1., Gallaher, P., Dent, C., Azen, S., Shan, J., Unger, J. B. and Johnson. C. A. (2002b). Ulse of the Fagerstrom tolerance questionnaire foi measuring nicotine dependence among adolescent smokers in China: a pllot test. Psychology of Addictive Behaviors, 16(3), $260-263$.

Choi, W. S., Ahluwalia, J. S. Harris, K. J. and Okuyemi, K. (2002). Progression to established smoking: the influence of tobacco marketing. American Joumal of Preventive Medicine, 22(4), 228-233.

Chol, W. S. Plerce, I. P., Gilpin, E. A., Farkas, A. J. and Berry, C. C. (1997). Which adolescent experimenters progress to established smoking in the United States. American Journal of Preventive Mediche, 13(5), 385-391.

Colby, S. M., Tiffany, S. T., Shiffman, S. and Niaura. R. S. (2000a). Are adolescent smokers dependent on nicotine? A review of the evidence. Drug and Alcohol Dependence, 59 Suppl 1, S83-95.

Colby, S. M., Tiffany, S. T., Shifrman, S. and Niaura, R. S. (2000b). Measuring nicotine dependence among youth: A review of available approaches and instruments. Drug and Alcohol Dependence, 59 Suppl 1, S2.3-39.

Conrad, K. M., Flay. B. R. and Hill; D. (1992). Why children start smoking cigarettes: predictors of onset. British Joumal of Addiction, $87(12)$ 1711-1724.

Crime, V. (2003). National Injury Mortality Survellance System 2002. Medical Research Council. University of South Africa, Cape Town. 
Dappen, A. Schwartz, R. H. and Oo Donnell, R. (1996). A survey of adolescent smoking pattems. Jowmal of the American Board of Family Pracice, $9(1), 7-13$.

Darling, $\mathrm{N}$. and Steinberg, L. (1993). Parenting style as context: An integrative model. Psychological Bulletin. $113(3): 487-496$.

Davis, R. M. (1986). Promotion of cigarettes in developing countries. Journal of the American Medical Assoclation, 255(8), 993 .

Department of Health and Medical Research Council. (1998). South Africa Demographic and Health Survey. Preliminary Report. Authors, Pretoria.

Department of Health, Medical Research Council and Measure DHS. (2002). South Africa Demographic and Health Survey 1998. Full Report. Authors, Pretoria.

De Vries, H. (1998). Planning and Evaluating Health Promotion. In Scott, D. and Weston, R. (eds.), Evaluating Health Promotion. Stanley Thornes, Cheltenham.

De Vries, H. (1995). Socio-economic differences in smoking: Dutch adolescents' beliefs and behaviours. Social Sclence and Mediche, 41(3), 419-424.

De Vries, H., Backbier, E., Kok, G. and Dijkstra, M. (1995). The impact of social influences in the context of attitude, self-efficacy, intention and previous behaviour as predictors of smoking onset. Journal of Applied Social Psychology, 25, 237-257.

De Vries, H., Backbier, E., Dijkstra, M., Van Breukelen, G., Parcel, G. and Kok, G. (1994). A Dutch social influence smoking prevention approach for vocational school students. Health Education Research, 9(3), 365-374.

De Vries, H., Dijkstra, M. and Kuhman, P. (1988). Self-efficacy: The third factor besides attitude and subjective norm as a predictor of behavioural intentions. Health Education Research, 3(3), 273-282.

De Vries, H., Engels, R., Kremers, S., Wetzels, In and Mudde, A. (2003a). Parents" and friends' smoking status as predictors of smoking onset: Findings from six European countries. Health Education Research. $18(5), 627-636$.

De Vrles, H. and Mudde, A. N. (1998). Predicting stage transitions for smoking cessation applying the Attitude-Social influence-Efficacy model. Psychology and Health, 13(2), 369-385.

De Vries, H., Mudde, A., Kremers, S., Wetzels, I. Uiters, E., Ariza, C., Vitoria, P. D., Fielder, A., Holm, K. Janssen, K., Lehtuvuori, R. and Candel, M. (2003b). The European Smoking Prevention Framework Approach (ESFA): Short-term effects. Health Education Research, 18(6), 649-663.

De Vries, H., Mudde, A., Leijs, L., Charlton, A., Vartiainen, E., Buijs, G., Clement, M. P., Storm, H., Gonzalez Navarro, $A_{n}$, Nebot, M., Ptins, T. and Kremers, $S$. (2003c). The European Smoking Prevention Framework Approach (EFSA): An example of integral prevention. Health Education Research, 18(5). $611-626$.

Difranza, J. R., Rigottl, N. A., McNeill, A. D., Ockene, J. K., Savageau, J. A., St Cyr, D. and Coleman, M. (2000). Inttal symptoms of nicotine dependence in adolescents. Tobacco Control, $9(3), 313-319$.

Difranza, J, R, Savageau, J. A., Fletcher, K, Ockene, J. K, Rigotti, N. A., McNeill, A. D., Coleman, M. and Wood, $C$. (2002at). Measuring the loss of autonomy over nicotine use in adolescents: the DANDY (Develojment and Assessment of Nicotine Dependence in Youths) study. Archives of Pediatrics and Adolescent Medicine, 156(4), 397-403.

Difranza, J. R., Savageau, J, A., Rigotti, N. A., Fletcher, K., Ockene, J. K., McNeill, A. D., Coleman, M. and Wood, $C$. (2002b). Development of symptoms of tobacco dependence in youths: 30 month follow up datat from the DANDY study. Tobacco Control, 11(3), 228-235.

Dijkstra, M., Mesters, I., De Vries, H. Van Breukelen, G., and Parcel, G. S. (1999). Elfectiveness of a social influence approach and boosters to smoking prevention. Health Educotion Research, 14(6). 791-802.

Distefan, 1. M., Pierce, J. P. and Gilpin, E. A. (2004). Do favorite movie stars influence adolescent smoking initiation? American Joumal of Public Health, 94(7), 1239-1244.

Dolcini, M. M., Adler, N. E. and Ginsberg, D. (1996). Factors influencing agreement between self-reports and biological measures of smoking among adolescents. Journal of Research on Adolescence, 6(4), $515-542$. 


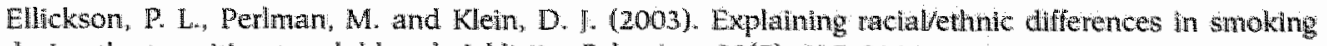
during the transition to adulthood. Addicture Behaviors, $28(5), 915-931$.

Engels, R. C.. Knibbe, R. A. De Vries, H. and Drop, M. I. (1998). Antecedervis of smoking oessation among adolescents: Who is motivated to change? Preventive Mediche, $27(3), 348-357$.

Epstein, I. A., Botvin, G. I. and Diaz, T. (1998). Ethnic and gender differences in smoking prevalenes among a longitudinal sample of inner-city adolescents. Joumal of Adolescent Heath, 23(3), 160-166.

Erhard, R. (1999). Peer-led and adult-led programs-student peroptions Journal of Drug Edwation, $29(4), 295-308$.

Ershler, I., Leventhal, H. Fleming, R. and Glym, K. (1989). The quitting experience for smokers in sixh through welth grades. Addictive Behaviors, 14(4), 365-378.

Escobedo, L. G. Reddy, M. and Giovino, G. A. (1998). The relationship between depressive symptoms and cigarette smoking in US adolescents. Addiction, $93(3), 433-440$.

Evans, R. I. (1976). Smoking in children: Developing a social psychological strategy of deterrence. Preventive Medicine, $5(1), 122-127$.

Evars, M. G. (1991). The problem of analyzing multiplicative composites. Anerican Psyehologist, 46 (1), $6-15$.

Everett, S. A. Giowino, G. A., Warren, C. W., Crossett, L. and Kant, L. (1998). Other substance use among high school students who use tobacco. Joumal of Adolescent Health, 23(5), $289-296$.

Fagerstrom, K. O and Schneider. N. (1989). Measuring nicotine dependence: A revitew of the Fagerstron Tolerance Questionnaire Joumai of Behavioural Medicine, $12(2), 159-182$.

Fishbein, M. and Ajzen, I. (1975). Belief, Attitude, Intention and behovtour: An Introductor to Theory and Research. Reading Mass, Addison Wesley.

Flay, B. (1993). Youth tobacco use: risks, patterns, and control. In Slade, J. and Orleans, C. T. (eds. Nicotine Addiction: Principles and Manggement. Oxford University Press, New York.

Flymn, B. S., Worder, J. K., Secker Walker, R. H., Pirle, P. L., Badger, G. J., Carpenter, I. M. and Geller, B. M. (1994). Mass media and solyool interventions for cigarette smoking prevention: effects 2 years after completion. American Joumal of Public Health, 84(7), 1148-1150.

Fothergill, K. and Ballard, E. (1998). The school-linked health center: a promising model of conmumitybased care for adolescents. Joumal of Adolescen Health, 23(1), 29-38.

Foulds J. (1999). Smoking cessation in young people. Should we do more to help young smolkers quit? Seminar conducted by the Health Education Authority.

Freeman, H. P. (2003). Commentary on the meaning of race in science and society. Cancer Epidemiology, Bomorkers and Prevention, $12(3), 2325-236 \mathrm{~s}$.

Futteman, D. C. Peralta, L, Rudy, B. J., Wolson, S., Gutmachet, s. and Rogers, A. S. (2001). The ACCESS (Adolescents Connected to Care, Evalwation, and Special Services) project social markethe to promote HIV testing to adolescents, methods and first year results from a six city campatgn. Joumal of Adolescent Health, $29(3$ Suppl), $19-29$.

Gillespie, A., Stanton, W. Lowe, J. B. and Hunter, B. (1995). Feawbllity of school-based smoking cessation programs. The houmal of School Health, 65(10), 432-437.

Glym, T. I. (1989). Essential elements of school-based smoking prevention programs. Joumal of School Health, $59(5), 181-188$.

Green, L., Poland, B. D. and Rooman, I. (2000). The Settings Approach to Health Promothon. In Poland, B.D. Green, L. and Rootmary, 1. (eds.), Sethngs for Health Pronotion. Linkng Theory and Practice. Sage Publication, California.

Green, L. W. and Kreuter. M. W. (1991). Health Promotion Planming: An Educational and Enwtronmentat Approach. Mayfield Publishing Company, Palo Alto.

Griesler, P. C. and Kandel, D. B. (1998). Ethnic differences in correlates of adolescent clgaretre smoking. Journal of Adolescent Health, 23(3), 167-180.

Griesler, P. C. Kandel, D. B. and Davies, M. (2002). Ethuic differences in predictors of initiation and persistence of adolescent cigarette smoking in the National Longltudinal Survey of Youth. Nicolne and Tobacco Research, $4(1), 79-93$. 
Gupta, $R$, Gurm, H. and Barholomew; I. R. (2004). Smokeless tobacco and cardiovascular risk. Archive of Interthal Medictie, 164(27). 1845-1849.

Hamilton, G. Cross, D., Lower, T., Resnicow, $K_{\text {. }}$ and Willams, P. (2003). School policy: what helps to reduce teenage smoking? Nicoline and Tobacco Research, 5(4), 507-513.

Hanewinkel, R. and Asshauer, M. (2004). Fifteen-month follow-up results of a school-based life-skills approacli to smoking prewention. Health Education Research, 19(2), 125-137.

Hernandez, M. and lyengar, S. S. (2001). What drives whom? A cultural perspective on human agency. Social Cognttion, 19(3), 269-294.

HIII, D. White, V. and Segan, K. (1995). Cigarette smoking in secondlary school students in 1993. Australion Joumal of Public Health, 19, 445-449.

Holm, Ka, Kremers, S. P. and De Viries, H. (2003). Why do Danish adolescents take up smoking? European Joumal of Public Heatth, 13(1), 67-74.

Honjo, $K$, and Kawachl, I. (2000). Effects of market liberalisation on smoking in Japan. Tobacco Control. $9(2), 193-200$.

Horn, K., Dine, G., Kalsekar, I., Massey, C. J., Manzo Tennant, K. and McGloin, T. (2004). Exploring the relationship between mental health and smoking cessation: a study of rural teens. Prevention Science, $5(2), 113-126$

Horn, K. Fernandes, A., Dino, G., Massey, C. J. \& Kalsekar, L. (2003). Adolescent nicotine dependence and smoking cessation outcomes. Addictive Behaviors, 28(4), 769-776.

Hurt, R. D., Croghan, G. A., Beede, S. D., Wolter, T. D., Croghan, I. T. and Patten, C. A. (2000), Nicotine patch therapy in 101 adolescent smokers: efficacy: withdrawal symptom relief, and carbon monoxide and plasma cotinine lewels. Archives of Pediatrics and Adolescent Medicine, 154(1), 31-37.

Hurt, R. D., Sachs, D. P., Glover, E. D., Offord, K. P., Johnston, J. A., Dale, L. C., Khayrallah, M. A., Schroeder, D. R., Glover, P. N., Sullivan, C. R., Croghan, I. T. and Sulivan, P. M. (1997). A comparison of sustained-release buproplon and placebo for smoking cessation. New England Journal of Medicine, $337(17), 1195-1202$.

Iyengar, S. S, and Lepper, M. R. (1999). Rethinking the value of choice: A cultural perspective on intrinsic motivation. Journal of Personality and Social Psychology, 76(3), 349-366.

Jessor, R. (1991). Risk behaviour in adolescence: a psychosocial framework for understanding and action. Journal of Adolescent Health, 12(8), 597-605.

Kandel, D. B. and Chen, K. (2000). Extent of smoking and nicotine dependence in the United States: 1991-1993. Nicotine and Tobacco Research, 2(3), 263-274.

Kande1, D., Chen, K., Warner, L. A., Kessler, R. C. and Grant, B. (1997). Prevalence and demographic correlates of symptoms of last year dependence on alcohol, nicotine, marijuana and cocaine in the U.S. population. Drug and Alcohol Dependence, 44(1), $11-29$.

Randel; D. B. and Davies; M. (1982). Epidemiology of depressive mood in adolescents. Archives of Pediatites and Adolescent Medicine, 39, 1205-1212.

Kandel D, B. Kiros, G. E., Sehaffran, C. and Hu, M. C. (2004). Racial/ethnic differences in cigarette smoking initation and progression to datly smoking: a multilevel analysis. American Journal of Public Health, 94(1), 128-135.

Kelder, S. H., Prokhorov, A., Barroso, C. S., Murray N., Orpinas, P. and McComick, L. (2003). Smoking differences among African Anerican, Hispanic, and White middle school students in an urban setting. Addretve Behaviors, 28(3), 513-522.

Kennedy, M. G. Mlzuno, Y., Seals, B. F. Myllyluoma, I. and Weeks Norton, K. (2000). Increasing condom use among adolescents with coalition-based social marketing. AIDS, 14(12), 1809-1818.

Kessler, D. A. (1995). Nicotine addiction in young people. New England Joumal of Mediche, 333(3). $186-189$.

Killen, J. D., Robinson, T. N., Ammerman, S., Hayward, C, Rogers, J., Stone, C., Samuels, D., Levin, S. K., Green, S. and Schatzberg, A. F. (2004). Randomized clinical trial of the efficacy of bupropion combined with nicotine patch in the treatment of adolescent smokers. Journal of Consulting and Clinical Psychology, 72(4), 729-735. 
King, G., Flisher, A. I. Mallett, R, Graham, 1., Lombard, C., Rawson, I, Morojele, N. K and Miller, M. (2003). Smoking in Cape Town: community influences on adolescent tobacco use, Preventtwe Medicine. $36(1) .114-123$.

Klepp, K. L, Masatu, M. C., Setel, P. W. and Lie, G. T. (1999). Maintaining Preventive Health Effons in Sub-Saharan Arica. AIDS in Tanzania. In Bracht. N. (ed.), Health Promotion at the Community Level (2nd ed.). Sage Publications, Califonia.

Klepp, K. I., Tell, G. and Vellar, O. D. (1993). Ten-year follow-up of the Oslo youth study smoking prevention program. Preventive Medicine, 22(4), 453-462.

Kok, G. and De Vries, H. (1989). Primary prevention of cancers: The need for heolth education and intersectoral health promotion: University of Limburg, Maastricht.

Komro, K. A., Perry, C. L., Murray, D. M., Veblen, M. S., Williams, C. L. and Anstine. P. S. (1996). Peer planned social activities for preventing alcohol use among young adolescents. The lournal of School Health, 66(9), 328-334.

Kremers, K. Mudde, A. and De Vries, H. (2004). Development and longitudinal test of an instrument to measure behavioral stages of smoking intiation. Substance Use and Misuse, 39(2), 225-252.

Kremers, S. P., Mudde. A. N. and De Vries, H. (2001a). "Kleking the mitiation": Do adolescent exsmokers differ from other groups within the initiation continuum? Preventive Medicine, 33(5), 392-401.

Kremers, S. P., Mudde, A. N. and De Vries, H. (2001b). Subtypes within the precontemplation stage of adolescent smoking acquisition. Addictive Behaviors, 26(2), 237-251.

Lambert, M. Hublet, A., Verduyckt, P., Maes, L. and Van den Broucke, S. (2001-2002). Report on the Gender Differences in Smoking in Young People. The Flenish Institute for Health Pronotion, Belgim.

Lamkin, L., Davis, B. and Kamen, A. (1998). Rationale for tobacco cessation interwentions for youth. Preventive Medicine, 27:3-8.

Lancaster, T, Stead, L., Silagy, C. and Sowden A. (2000). Effectiveness of interventions to help people stop smoking: findings from the Cochrane Library. British Medical Journal, 321, 355-8.

Lantz, P. M., Jacobson, P. D., Warner, K. E., Wasserman, I., Pollack, H. A., Berson, I. and Ahlstrom, A. (2000). Investing in youth Tobacco Control: a review of smoking prevention and control strategies. Tobacco Control, 9(1), 47-63.

Lawendowski, L. A. (1998). A motivational intervention for adolescent smokers. Preventive Medicine, $27(5 \mathrm{Pt} 3), \mathrm{A} 39-46$.

Lawrance, L. (1998). Validation of a self-efficacy scale to predict adolescent smoking. Health Education Research, 4(3), 351-360.

Lefebwre, R. C. and Rochlin, L. (1997). Social Marketing. In Glanz, K., Lewis, F. M. and Rimer, B. K. (eds.), Health Behaviour and Health Education. Theory, Research and Practice (2nd ed.). Jossey-Bass, Sath Franscisco.

Lovato, C., Linn, G., Stead, L. F. and Best, A. (2003). Impact of tobacco advertising and promotion on increasing adolescent smoking behavours. Cochrone Database of Systematic Reviews Online Update Software(4), Cd003439.

Maccoby, E. E. and Martin, 1. A. (1983). Socialization in the Context of the Family: Parent-child Interaction. In Hetherington, E. M (ed.), Handbook of Child Psychology. Wiley, New York, p. 1-101.

Mackay, 1. (1997). Smoking in China: "the limits of space". Tobacco Conitrol, 6(2), 77-79.

Mackay, I. L. (1994). The fight aganst tobacco in developing countries. Tubercle and Lung Disease. $75(1), 8-24$.

Markham, W. A., Aveyard, P., Thomas, H., Charlton, A, Lopex, M. L. and De Vries, H. (2004). What determines future smoking intentions of 12- to 13-year-old UK Africari-Caribbean. Indian, Pakistani and white young people? Health Education Research, 19, 15-28.

Mbeki, P. T. (2004). State of the Nation Address of the President of South Africa. Retricved November 25, 2004, from http://info.gov.za/speeches/2004/04020610561002.htm

McDonald, P., Colwell, B. Backinger, C. L., Husten, C. and Maule, C. O. (2003). Better practices for youth tobacco cessation: evidence of review panel. American Journal of Health behaviour, 27 Suppl 2, S144-158. 
Mehtar, S. (1999). South Cape / Karoo Region Annual Report 1999. Public Health Progranme and Health Information Programime: South Cape / Karoo Regional Office, George.

Mellanby, A. R., Rees, J. B. and Thipp: II. H. (2000). Peer-Jed and adult-led school health education: a critlcal review of avallable comparative research. Heallh Education Research, 15(5), 533-545.

Meyer Weytz, A., Reddy, P., Van den Borne, H. W., Kok, G. and Pietersen, I. (2000a). The determinants of health care seeking behaviour of adolescents attending STD clinics in South Africa. Joumal of Adolescence, $23(6), 741-752$.

Meyer Weitz, A. Reddy, P., Welyts, W. Van Den Bome, B. and Kok, G. (1999). STD-related knowledge, beliefs and attitudes of Xhosa-speaking patients attending STD primary health-care elinics in South Arical. Intemaltonal Joumal of STD and AIDS, 10(6), 392-400.

Meyer Weitz, A, Reddy, S. P. and Levin, J. (2000b). The impact of South Africa's first Tobacco Control legislation on adults' smoking status: February 1995 to November 1998: Unpublished manuscript.

Michaud, P. A. (2003). Prevention and health promotion in school and community settings: a commentary on the international perspective loumal of Adolescent Health, 33(4), 219-225.

Morbidity and Mortality Weekly Report. (2004). Cigarette use among high school students - United States, 1991-2003. Morbidity and Mortallty Weekly Report, 53(23), 499-502.

Morbidity and Mortality Weekly Report. (1994). Reasons for tobacco use and symptoms of nicotine withdrawal among adolescent and young aduit tobacco users-Linited States, 1993. Morbidity and Mortality Weekly Report, 43(41), 745-750.

Morbidity and Mortality Weekly Report. (1998). Selected cigarette smoking initiation and quitting behaviors among high school students-United States, 1997. Morbidity and Mortality Weekly Report. $47(19), 386-389$.

Mudde, A. N. (1994). The development and evaluation of a community and mass media approach to smoking cessation (Doctoral dissertation, University of Limburg, 1994).

Murray, C. J. and Lopez, A. D. (1997). Alternative projections of mortality and disability by cause 1990-2020: Global Burden of Disease Study. Lancet, 349(9064), 1498-1504.

O'Loughlin, J., Difranza, J., Tyndale, R. F., Meshefedjian, G., McMillan Davey, E, Clarke, P. B., Hanley, J. and Paradis, G. (2003). Nicotine dependence symptoms are associated with smoking frequency in adolescents. American Joumal of Preventwe Medicine, 25(3), 219-225.

Oppenheimer, G. M. (2001). Paradigm llost: race, ethnicity, and the search for a new population taxonomy. American journal of Public Health, 91(7), 1049-1055.

Pasick, R. I. (1997). Socioeconomic and Cultural Factors in the Development and use of Theory. In Glanz, K., Lewis, F. M. and Rimer, B. K. (eds.), Health Behaviour and Health Education. Theory, Research and Practloe (2nd ed,). Jossey Basss, Califorma.

Panday, S., Reddy, S. P. and Bergstrom, E. (2003). A qualitative study on the determinants of smoking behaviour among adolescents in South Africa. Scandinavion Journal of Public Health, 31(3), 204-210.

Panday, S, Reddy, S. P., Kuiter, R. A. C., Bergstrom, E. and De Vres, H. (2004a). Nicotine dependence and withdrowal symptoms among adolescents in South Africa. Manuscript submitted for publication.

Panday, S., Reddy, S. P., Ruiter, R. A. C., Bergstrom, E. and De Vries, H. (2004b). The deterninants of smoking anong adolescents in South Africa. Manuscript submitted for publication.

Panday, S., Reddy, S. P. Ruiter, R. A. C., Bergstrom, E. and Vries, H. (in press). The determinants of smoking cessation among adolescents in South Africa. Health Education Research.

Parcel, G., Kelder, S. H. and Basen-Engquist, K. (2000). The School as a Setting for Health Promotion. In Poland, B.D., Green, L. W. and Rootman, 1. (eds.), Settings for Health Promotion. Linking Theory and practice. Sage Publications, Callfornia.

Peden, M. (2000). Non-fatal violence. Some results from the pilot national surveillance system. Trauma Review, 8(2).

Perry C. L., Eriksen, M. P. and Glovino G. (1994). Tobacco use: a pediatric epidemic. Tobocco Control, 3, 97-98.

Perry, C. L.. Griffim, G. and Murray, D. M. (1985). Assessing needs for youth health promotion. Preventive Medicine, 14(3), 379-393. 
Perry, C. L, Kelder, S. H., Murray, D. M. and Klepp. K. I. (2992). Communitynide smoking prevention: Long-term outcomes of the Minnesota Heart Health Program and the Class of 1989 Study. American Joumal of Public Health, 82(9), 1210-1216.

Perry, C. L., Klepp, K. I. and Sillers, C. (1989), Community-wode strategies for cardiovascular health: The Minnesota Heart Health Program youth program. Health Education Research, 4(1), 87-101.

Perry, C. L., Willians, C. L., Forster, I. L., Wollson, M., Wagenaar, A. C., Finnegan, ). R., MeCovern, P. G., Veblen-Mortenson, S., Komro, K. A. and Anstine, P. S. (1993). Background, conceptualization and design of a community-wide research progran on adolescent alcohol use: Project Northlathd. Heolth Education Research, 8(1), 125-136.

Peto, R. Lopez, A. D., Boreham, J., Thun, M. and Heath, C. (1994). Mortality from Smoking in Developed Countries 1950-2000. Oxford Uniwersity Press, Oxford.

Peto, R., Lopez, A. D., Boreham. J. Thun, M. and Heath, C. (1992). Mortality from tobacco in developed countries: indirect estimation from national vital statistics. Lancet, 339(8804), 1268-1278.

Pierce, J. P. and Gilpin, E. A. (1995). A historical analysis of tobacco marketing and the uptake of snoking by youth in the United States: 1890-1977. Health Psychology, 14(6), 500-508.

Plano Clark, V. L., Miller, D. L., Creswell, I. W. McVea, K, MCEntarffer, R., Harter, L. M. and Mickelson, W. T. (2002). In conversation: high school students talk to students about tobaceo use and prevention strategies. Qualitative Health Research, 12(9), 1264-1283.

Prochaska, J. O. (1984). Systems of Psychotherapy: A Transtheoretical Analysis. (2nd ed.), Brooks-Cole, California.

Prochaska, J. O. and DiClemente, C. C. (1983). Stages and processes of self-change of smoking: Toward an integrative model of change. Journal of Consulting and Clmical Psychology, 51(3), 390-395.

Prochaska, I. O., Norcross, I. and DiClemente, C. (1994). Changing for Good. Willam Morrow and Company, New York.

Prokhorov, A. V., De Moor, C., Pallonen, LI. E., Hudmon, K. S., Koehly, L. and Hu, S. (2000). Validation of the modified Fagerstrom tolerance questionnaire with salvary cotinine among, adolescents. Addictive Behaviors, 25(3), 429-433.

Prokhorov, A. V. Hudmon, K. S., de Moor, C. A., Kelder, S. H., Conroy, J. L. and Ordway, N. (2001). Nicotine dependence, withdrawal symptoms, and adolescents' readiness to quit smoking. Nicotine and Tobacco Research, 3(2), 151-155.

Prokhorov, A. V. Pallonen, U. E., Fava, J. L., Ding, L. and Niatra, R. (1996). Measuring nicotine dependence among high-risk adolescent smokers. Addictive Behavfors, 21(1), 117-127.

Promos, J., DuRant, R. H., Pierce, J. D. and Goodman, E. (1998). Gambling and other risk behaviors among 8 th- to 12 th-grade students. Pediatrics, 102(2), e23.

Promugation of nattonal policy on the managenent of drug abuse by learners in publie and indeperident schools and further education and training instittutions. (2002). Government Gazette. No. 2412, Vol. 3427.

Reacling, R. (1997). Poverty and the health of children and adolescents. Archives of Disease in Childhood, $76,463-467$.

Reddy, P., Meyer Weitz, A., van den Borne, B. and Kok, G. (2000). Determinants of condom-tise behaviour among STD clinic attenders in South Africa. International joumal of STD and AIDS, 11(B), $521-530$.

Reddy. P., Meyer Weitz, A. and Yath, D. (1996). Smoking status, knowledge of health effects and attitudes towards Tobacco Control in South Africa. South African Medical Joumal, 86(1.1), 1389-1393.

Reddy, S. P. (1997). Selling deception and disease: The tobacco industries global marketing practices. Paper presented at the the 4 th International Conference on Preventive Cardiology, Montreal, Canada.

Reddy, S. P. (1999a). Tobacco Control as a model of health promotion in South Africa. American Joumal of Health Promotion, 2(5), 6-8.

Reddy, S. P. (19996). Tobacco legislation: The South African experience. Paper presented at the International Conference on Heart Health in Developing Countries, New Delhi, India.

Reddy, S. P. (2001). Tobacco Control in South Africa: From Research to Legislation. Paper presented at the The Emerging Center for Research on Health Disparities, Atlanta, USA. 
Reddy, S. P. Meyer Weitz, A. and Levine J. (1998). Smoking prevalence among adults in South Africa. Unpublished manuseript South African Medical Research Council.

Reddy, S. P., and Panday, S. (1999). Smoking cessation progrommes for adolescents. Paper presented att the International Consultation of Tobacco and Youth, Singapore.

Reddy, S. P., Panday, S., Swart, D. Jinabhai, C. C., Amosun, S. L., James, S., Monyeki, K. D., Stewens, G. Morojele, N., Kambaran, N. S. Omardien, R. G. and Van den Borne, H. W. (2003). Umthenthe Uhlaba Usamla - The South African Youth Risk Behaviour Survey 2002. South African Medical Research Councll, Cape Town.

Redmond, W. H. (2002). Smoking reduetion among high school seniors: a test of selected indicators. Journal of Adolescent Heath, 31(5), 417-424.

Resnicow, K. Dilorio; C., Soet, J. E., Ernst, D., Borrelli, B. and Hecht, J. (2002). Motivational interviewing in health promotion: it sounds like something is changing. Health Psychology, 21(5), $444-451$.

Ribisl, K. M. Williams, R. S. and Kim, A. E. (2003). Internet sales of cigarettes to minors. Joumal of the American Medical Association, 290(10), 1356-1359.

Riectel, B. W. Robinson, L. A. Klesges, R. C. and McLain Allen, B. (2002). Characteristics of adolescents caught with cigarettes at school: implications for developing smoking cessation programs. Nicotine and Tobacco Research, 4(3), 351-354.

Riedel, B. W. Robinson, L. A., Klesges, R. C. and McLain Allen, B. (2003). Ethnic differences in smoking withdrawal effects among adolescents. Addictive Behaviors, 28(1), 129-140.

Rigotti, N. A., Lee, I. E. and Wechsler, H. (2000). US college students' use of tobacco products: results of a national survey. The Joumal of the American Medical Association, 284(6), 699-705.

Rissel, C. and Bracht, N. (1999). Assessing Community Needs, Resources, and Readiness. Building on Strengths. In Bracht, N. (ed.), Health Promotion at the Community Level (2nd ed.). Sage Publications, Callifornia.

Rogers, E. M. (1983). Diffuston of Innowalions. Collier Macmillan Publishers, New York.

Rojas, N. L., Killen, J. D., Haydel, K. F. and Robinson, N. (1998). Nicotine dependence among adolescent smokers. Archives of Pediatrics and Adolescent Medicine, 152, 151-156.

Rooney, B. L. and Murray, D. M. (1996). A meta-analysis of smoking prevention programs after adjustment for errors in the unit of analysis. Health Education Quarterly, 23(1), 48-64.

Sallis, I. F. and Owen, N. (1997). Ecological Models. In Glanz, K., Lewis, F. M. and Rimer, B. K. (eds.), Health Behaviour and Health Education. Theory, Research and Practice (2nd ed.). Jossey-Bass, San Francisco.

Sargent, I. D., Mott, L. A. and Stevens "M. (1998). Predictors of smoking cessation in adolescents. Archives of Pediatics and Adolescent Medicine, 152(4), 388-393.

Shadlel, W. G., Shiffman, S., Niaura, R. Nichter, M. and Abrams, D. B. (2000), Current models of nlcotine dependence: what is known and what is needed to advance understanding of tobacco etiology among youth. Drug and Alcohol Dependence, 59 Suppl 1, S9-22.

Silagy, C., Lancaster, T., Stead, L., Mant, D. and Fowler, G. (2004). Nicotine replacement therapy for smoking cessation. Cochrane Database of Systematic Reviews Online Update Software(3), Cdo00146.

Siqueira, L. M., Rolnitzky, L. M. and Rickert, V. I. (2001). Smoking cessation in adolescents: the role of nicotine dependence, stress, and coping methods. Archives of Pediatrics and Adolescent Medicine, 155(4), $489-495$.

Siqueira, L. M. and Brook, J. S. (2003). Tobacco use as a predictor of lllicit drug use and drug-related problems in Colonbian youth. Joumal of Adolescent Health, 32(1), 50-57.

Sttas, F, Urban, M., Bradshaw, D., Kielkowski, D., Bah, S. and Peto, R. (2004). Tobacco attributable deaths in South Africa. Tobacco Control, 13,396-399.

Skara, S. and Sussman, S. (2003). A review of 25 longterm adolescent tobacco and other drug use prevention program evaluations. Preventive Medicine, 37(5), 451-474.

Snith, T. A., House, R. F. Croghan, I. T., Gauvin, T. R., Colligan, R. C., Offord, K. P., Gomez Dahl, L. C. and Hurt, R. D. (1996). Nicotine patch therapy in adolescent smokers. Pediatrics "98(4 Pt 1), 659-667. 
South African National Department of Education. (2001a). Brochure for the 2000 School Register of Needs Report. Author, Pretoria.

South African National Department of Education. (2001b). Education in South Africa: Achirivements since 1994. Author, Pretoria.

Stanton, W. R. (1995). DSM-III-R tobacco dependence and quitting during late adolescence. Addictre Behaviars, 20(5), 595-603.

Stanton, W. R., Lowe J. B., Fisher, K. J. Gillespie, A. M. and Rose, I. M. (1999). Bellefs about smoking cessation among out-of-school youth. Drug and Alcohol Dependence, 54(3), 251-258.

Stanton, W., Gillespie, A and Lowe, J. B. (1995) Students' attitudes to quitting. In Slama, K, (cd.), Tobacco or Health. Plenum Press, New York.

Stanton, W. R., Lowe, J. B. and Gillespie, A. M. (1996). Adolescents' experiences of smoking cessation. Drug and Alcohol Dependence, $43(1-2), 63-70$.

Statistics South Africa. (2003). General Household Survey. July 2003. Author, Pretoria.

Statistics South Africa. (2004a). Labour Force Survey March 2004. Author, Pretoria.

Statistics South Africa. (2004b). Mid-year Population Estimates, South Africa 2004. Author, Pretoria.

Statisties South Africa, and Census 2001. (2003). Investigation into appropriate definitions into urban and rural areas for South Africa discussion document. Author, Pretoria.

Story, M., Lytle, L. A., Birnbaum, A. S. and Perry, C. L. (2002). Peer-led, school-based nutrition education for young adolescents: feasibility and process evaluation of the TEENS study. Jourrid of School Health, 72(3), 121-127.

Sussman, S. (2002). Effects of sixty six adolescent tobacco use cessation trials and seventeen prospective studies of self-initiated quitting. Tobacco Induced Diseases, 1(1), 35-81.

Sussman, S., Dent, C. W., Flay, B. R., Hansen, W. B. and Johnson, C. A. (1987). Psychosocial predictors of cigarette smoking onset by white, black. Hispanic, and Asian adolescents in Southern Callfornia. Morbidity and Mortality Weekly Report, 36 Suppl 4, 11s-16s.

Sussman, S., Dent, C. W., Severson, H., Burton, D. and Flay, B. R. (1998). Self-initlated quitting annong adolescent smokers. Preventive Medicine, 27(5 Pt 3), A19-28.

Swart, D. and Panday, S. (2003). The Surveillance and Monitoring of Tobacco Control in South Africa. In Tools for Adwancing Tobacco Control in the XXVIst century: Success stories and lessons leaned. World Health Organisation, Geneva.

Swart, D. and Reddy, P. (2000). Global Youth Tobacco Survey in South Africa. Overview and Progress Report (Draft). Medical Research Council, Cape Town.

Swart, D. and Reddy. S. P. (1998). Strengthening comprehenshe Tobacco Control policy development in South Africa using political mapping. South African Medical Research Council, Cape Town.

Swart, D., Reddy, P. Panday, S., Philip, J., Naidoo, N. and Ngobent, N. (2004). The 2002 Global Youth Tobacco Survey (GYTS): The 2nd GYTS in South Africa (SA) - A compartson between GYTS (SA) 1999 and GYTS (SA) 2002. South Arican Medical Research Council. Cape Town.

Swart, D., Reddy, P. Ruiter, R. A. C. and de Vries, H. (2003). Cigarette use among nale and female grade 8-10 students of different ethnicity in South African schools. Tobacco Control, 12(1), EL.

Taylor, M., Dlamini, S. B., Kagoro, H. Jinabhai, C. C. and de Vries, H. (2003). Uinderstanding high school students' risk beliawiors to help reduce the HIV/AIDS epidemic in KwaZUUlu-Natal, Soulli Africa. Journal of School Health, 73(3), 97-100.

Telch, M. I., Miller, L. M., Killen, I. D., Cooke, S. and Maccoby, N. (1990). Social influences approach to smoking prevention: the effects of videotape delivery with and without same-age peer leader participation. Addictive Behaviors, 15(1), 21-28.

The Global Youth Tobacco Survey Collaborative Group. (2002). Tobacco use among youth: a cross country comparison. Tobacco Control, $11(3): 252-70$.

Thomas, $\mathrm{R}$. (2004). School-based programmes for preventing smoking. In The Cohrane Library (Vol. 1). John Wiley \& Sons, Chicester.

Tobacco Products Amendment Act, 1999 Regulations. (1999). Government Gazette, Regulation Gazette No. 6689 , Vol. 414 . 
Tobacco Praducts Amendment Axt No 12. (1999). Retrieved 13 October 2002, from http:/196.36.153.56/doh/docs/legislation/acts/1999/act 12.html

Tobacco Products Control Act No 83.(1993). Govenment Gazelte, No. 14916, Vol. 337.

Tobacco Products Control Amendment Bill. (2003). Government Gazette. No. 25601.

Tobler, N. S., Roona, M. R., Ochghom, P., Marshall, D. G., Streke, A. V. and Stackpole, K. M. (2000). School-based adolescent drug prevention programs: 1998 meta-analysis. Joumal of Primary Prevention. 20(4). $275-336$.

Tones, K. and Tilford; S. (1994). Healh education: Effectiveness, Efficiency and Equily. Chapman \& Hall, Londion.

Torres, R. R. M. and Fernandez. F.P. (1995). Self esteem and value of health as determinants of adolescent heat th behaviour. Joumal of Adolescent Health, 16(60), 60-63.

Triandis, $H_{.}$C. (1995). Individualism and Collectwism. Westwiew Press, Colorado.

Tyats, S. L. and Pederson, L. L. (1998). Psychosocial factors related to adolescent smoking: A critical review of the literature. Tobacco Control, $7(4), 409-420$.

Unger, J. B., Rohrbach, L. A., Cruz, T. B., Baezconde Garbanati, L., Howard, K. A., Palmer, P. H. and Johnson, $C . A .(2001)$. Ethnic variation in peer influences on adolescent smoking. Nicotine and Tobacco Research, 3(2), 167-176.

Unger, I. B., Yan, L., Shakib, S., Rohrbach, L. A., Chen, X, Qlan, G., Chou, C. P., Jianguo, S., Azen, S.,

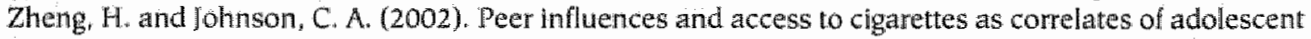
smoking: a cross-cultural comparison of Whatn, China, and California, Preventive Medicine, 34(4). $476-484$.

United Nations Population Development South Africa. (2003). South Africa Human Development Repart 2003. The Challenge of sustamable development in South Africa: Unlocking People's Creativity. Oxford University Press, Cape Town.

U.S. Department of Health and Human Services. (1994). Preventing Tobacco Use among Young People: A Report of the Surgeon General. Author, Atlanta.

U.S. Department of Health and Human Services. (1998). Tobacco Use among US Racial/Ethnic Minority Groups. A Report of the Surgeon General. Author, Atlanta.

UI.S. Department of Health and Human Services. (2000). Reducing tobacco use. A report of the Surgeon General - Executive Summary. Author, Atlanta.

U.S. Department of Health and Human Services. (2004). The Health Consequences of Smoking. A Report of the Surgeon General. Author, Atlanta.

van Walbeek, C. (2002). Recent trends in smoking prevatlence in South Africa-some evidence from AMPS data. South African Medical Journal, 92(6), 468-472.

van Walbeek, C. (2003). Tobacco Excise Taxation in South Africa. In Tools for Advancing Tobacco Control in the XXVIst century: Success storles and lessons learned. World Health Organisation, Geneva.

Vartatimen, E., Patuola, $M_{*}$, McAlister, A. and Puska, P. (1998). Fifteen-year follow-up of smoking prevention effects in the North Karelia youth project. American Joumal of Public Health, $88(1), 81-85$.

Wakefteld, M., and Chaloupka, E. (2000). Effectiveness of comprehensive Tobacco Control progranmes in reducing teenage smoking in the USA. Tobacco Control, 9(2), 177-186.

Walsh, D. C., Rudd, R. E., Moeykens, B. A. and Moloney, T. W. (1993). Social marketing for public health. Health Affarts, 12(2), 104-119.

Warren, C. W. Riley, I., Asma, S., Eriksen, M. P., Green, L., Blanton, C., Loo, C., Batchelor, S. and Yach, D. (2000). Tobacco use by youth: a surveillance report from the Global Youth Tobacco Survey project. Bulletin of the World Health Organization, $78(7), 868-876$.

Wetzels, J. J., Kremers S. P. Viroria P. D. and De Vries, H. (2003). The alcohol-tobacco relationship: A prospective study among adolescents in six European countries. Addiction, 98(12), 1755-63.

Williams, C. L., Perry; C. L., Farbakhsh, K. and Veblen-Mortenson, S. (1999). Project Northland: comprehensive alcohol use prevention for young adolescents, their parents, schools, peers and 
communities. Journal of Studies on Alcohol. Supplement, $13,112-124$.

World Health Organisation. (1986). Ottowo Charter. Paper presented at the First Intemational Conference on Health Promotion, Ottawa Canada.

World Health Organisation. (2002). The World Health Report 2002. Reducing Risks, Promoting Healthy Lipe. Author, Geneva.

World Health Organisation. (2004). Tobacco and poverty. A vicious circle. Tobacco Free Initative. Author, Geneva.

World Health Organisation. (2003). WHO Framework Convention on Tobacco Control. Fifty sidth World Health Assembly. Author, Geneva.

World Health Organisation. (1998): World No-Tobacco Day. 31 May 1998 (Advisory Kit). Author, Geneva.

Worden, I. K., Flynn, B. S., Geller, B. M. Cohen, M., Shelton, L. G., Secker Walker, R. H., Solomon, D. S., Solomon, L. J., Couchey, S. and Constanza, M. C. (1988). Development of a smoking prevention mass media program using diagnostic and formative research. Prewentive Medicine, 17(5), 531-558.

World Bank. (1999). Curbing the Epidemic: Government and the Economics of Tobaco Control. Author, Washington DC.

Yach, D. (1986). The impact of smoking in deweloping countries with special reference to Africa. International foumal of Heaith Services Planning Administration, Evaluation, 16(2), 279-292.

Yach, D. (1995). Tobacco Control in the new South Arrica: new government, same industry tactics. Promotion and Education, 2(1), 18-22, 58.

Yach, D. and Bettcher, D. (2000). Globalisation of tobacco industry influence and new global responses. Tobacco Control, $9(2), 206-216$.

Yach, D. and Ferguson, B. J. (1999). Can we stop children and adolescents from smoking? Social Science and Medicine, 48(6), 757-758.

Yee, A. H., Fairchild, H. H., Weizmann, E. and Wyatt, G. E. (1993). Addressing psychology's problems with race. American Psychologist, 48(11), 1132-1140.

Zhu, S. H., Sun, J., Billings, S. C., Choi, W: S. and Malarcher, A. (1999). Predictors of smoking cessation in U.S. adolescents. American Journal of Preventive Medicine, 16(3), 202-207. 
Tobaceo Products Amendment Act No 12. (1999). Retrieved 13 October 2002, from http://196.36.153.56/doh/docs/legislation/acts/1999/act 12.htrin

Tobacco Products Control Act No 83.(1993). Government Gozette, No. 14916, Vol. 337.

Tobacco Producis Conitrol Amendment Bill. (2003). Govemment Gazette, No. 25601.

Jobler, N. S., Roona, M. R., Ochshom, P., Marshall, D. G., Streke, A. V. and Stackpole, K. M. (2000). School-based adolescent drug prevention programs: 1998 meta-analysis. Journal of Primary Prevention, $20(4), 275-336$.

Tones, K and Tilford, S. (1994). Health education: Effectweness, Efficiency and Equly. Chapman \& Hall, London.

Torres, R. R. M. and Fernandez, F.P. (1995). Self esteem and value of health as determinants of adolescent health behaviour. Joumal of Adolescent Health, 16(60), 60-63.

Triandis, H. C. (1995). Individualism and Collectivism. Westwiew Press, Colorado.

Tyas, S. L. and Pederson, L. L. (1998). Psychosocial factors related to adolescent smoking: A critical review of the literature. Tobacco Control, $7(4), 409-420$.

Unger, I. B., Rohrbach, L. A., Cruz, T. B., Baezconde Garbanati, L., Howard, K. A., Palmer, P. H. and Johnson, C. A. (2001). Ethnic variation in peer Inlluences on adolescent smoking. Nicotine and Tobacco Research, 3(2), 167-176.

Unger, I. B., Yan, L., Shakib, S., Rohrbach, L. A., Chen, X., Qian, G., Chou, C. P., Jianguo, S., Azen, S., Zheng. H. and Johnson, C. A. (2002). Peer influences and access to cigarettes as correlates of adolescent smoking: cross-cultural comparison of Wuhan, China, and California. Preventive Medicine, 34(4), $476-484$.

United Nations Population Development South Africa. (2003). South Africa Human Development Report 2003. The Challenge of sustainable development in South Africa: Unlocking People's Creativity. Oxford University Press, Cape Town.

U.S. Department of Health and Human Services. (1994). Preventing Tobacco Use among Young People: A Report of the Surgeon General: Author. Atlanta.

U.S. Department of Health and Human Services. (1998). Tobacco Use among US Racial/Ethnic Minority Groups. A Report of the Surgeon General. Author, Atlanta.

U.S. Department of Health and Human Services. (2000). Reducing tobacco use. A report of the Surgeon General - Execulive Summary. Author, Atlanta.

U.S. Department of Health and Human Services. (2004). The Health Consequences of Smoking. A Report of the Surgeon General. Author, Atlanta.

wan Walbeek, C. (2002). Recent trends in smoking prevalence in South Africa-some evidence from AMPS data. South African Medical Joumal, $92(6), 468-472$.

van Wabeek, C. (2003). Tobacco Excise Tinxation in South Arica. In Tools for Advancing Tobacco Control th the XXVIst century: Success stories and lessons leaned. World Health Organisation, Geneva.

Vartainen, E., Paavola, M., MeAlster, A, and Puska, P. (1998). Fifteen-year follow-up of smoking preventlon effects in the North Karelik youth project. American Journal of Public Health, 88(1), 81-85.

Wakefield, M., and Chaloupka, F. (2000). Effectiveness of comprehensive Tobacco Control programmes in reducing teenage smoking in the USA. Tobacco Control, $9(2), 177-186$.

Walsh, D. C., Rudd, R. E., Moeykens, B. A. and Moloney, T. W. (1993). Soclal marketing for public health. Health Affars, 12(2), 104-119.

Warren, C. W. Riley, L., Asma, S., Eriksen, M. P., Green, L., Blanton, C., Loo, C., Batchelor, S. and Yach, D. (2000). Tobacco use by youth: a surveillance report from the Global Youth Tobacco Survey project. Bulletin of the World Health Organization, 78(7), 868-876.

Wetzels, I. I, Kremers S. P., Vitoria P. D. and De Vries, H. (2003). The alcohol-tobacco relationship: A prospective study among adolescents in six European countries. Addiction, 98(12), 1755-63.

Willians, C. L., Perry, C. L., Farbakhsh, K. and Veblen-Mortenson, S. (1999). Project Northland: comprehensive alcohol use prevention for young adolescents, their parents, schools, peers and 
communities. Journal of Studies on Alcohol Supplement, 13,112-124.

World Health Organisation. (1986). Ottawa Charter Paper presented at the First International Conference on Health Promotion, Ottawa, Canada.

World Health Organisation. (2002). The World Health Report 2002. Reducing Risks, Promoting Healthy Life. Author Geneva.

World Health Organisation. (2004). Tobacco and poverb. A vicious circle. Tobatco Free Initiative. Author, Geneva.

World Health Organisation. (2003). WHO Framework Convention on Tobacco Control: Fifty sixth World Health Assembly. Author. Geneva.

World Health Organisation. (1998). World No-Tobacco Day. 31 May 1998 (Advisory Kit). Author, Geneva.

Worden, J. K., Flynn, B. S., Geller, B. M., Cohen, M., Shelton, L. G., Secker Walker, R. H., Solomon, D. S., Solomon, L. J., Couchey, S. and Constanza, M. C. (1988). Development of a smoking prevention mass media program using diagnostic and formative research Prevertive Medicine, 17(5), 531-558.

World Bank. (1999). Curbing the Epidemic: Government and the Economics of Tobacco Control. Author. Washington $\mathrm{DC}$.

Yach, D. (1986). The impact of smoking in developing countries with special reference to Africa. Intemational Journal of Health Services Pianning. Administration, Evaluation, 16(2), 279-292.

Yach, D. (1995). Tobacco Control in the new South Africa: new government, same industry tactics. Promotion and Education, 2(1), 18-22, 58.

Yach, D. and Bettcher, D. (2000). Globalisation of tobacco industry influence and new global responses. Tobacco Control, $9(2), 206-216$.

Yach, D. and Ferguson, B. J. (1999). Can we stop children and adolescents from snoking Social Sclence and Medicine, $48(6), 757-758$.

Yee, A. H., Fairchild, H. H., Weizmann, F. and Wyatt, G. E. (1993). Addressing psychology's problems with race. American Psychologist, 48(11), 1132-1140.

Zhu, S. H., Sun, J., Billings, S. C., Choi, W. S. and Malarcher, A. (1999), Predictors of smoking cessation in U.S. adolescents. American Journal of Preventive Medicine, 16(3), 202-207. 


\section{Summary}

In the last decade, South Africa has taken significant legislative strides to protect its people from the harm of tobacco use. Subsequently, smoking rates have decreased significantly among both the adult and adolescent population. However, cardiovascular disease, lung cancer and several other tobacco-related illnesses still feature as the predominant causes of premature morbidity and mortality. It is anticipated that further strengthening of tobacco control legislation to ratify the Framework Convention on Tobacco Control will grow adolescents' interest in quitting. In order to sustain declining smoking rates and to pre-empt premature morbidity and mortality, evidence-based tobacco control programmes are required for adolescents.

The Health Promotion Matrix and the I-Plan Model, two complementary planning models that adopt comprehensive approaches, underpin programme development. The I-Change Model provided the theoretical framework for the study of the motivational determinants of smoking prevention and cessation as well as the channels through which adolescents can be accessed for Tobacco Control programmes. In this thesis, ethnic differences in the motivational determinants of smoking onset and cessation were investigated with a view to develop culturally sensitive programmes. Nine focus group discussions were conducted among grade 8-9 smokers and ex-smokers in the Southern Cape-Karoo Region, Western Cape Province. This was followed by a cross-sectional survey among 4768 grade $9-11$ students.

Chapter 1 provides an overview of South Africa including the morbidity and mortality profile, a global perspective on tobacco use, the history of Tobacco Control legislation in SA and a description of the smoking epidemic among adolescents. It also outlines the theoretical models used in the study and concludes with an outline of the study context and the research project. Chapter 2 of the thesis discusses a qualitative assessment of the determinants of smoking behaviour among Grade 8 and 9 smokers and ex-smokers. Chapter 3 outlines the ethnic determinants of smoking, depressive mood and risk behaviour in a sample of Grade 9-11 monthly and non-monthly smokers. Chapter 4 discusses the ethnic determinants of smoking cessation among Grade 9-11 monthly smokers and former smokers. Chapter 5 reports on the prevalence and gender differences in nicotine dependence, withdrawal symptoms, depressive mood and risk behaviour between weekly and monthly smokers. Chapter 6 describes adolescent preferences for the channels through which they can be accessed for Tobacco Control programmes. Key elements of Tobacco Control programmes are also discussed. Chapter 7 summarises and discusses the main findings, methodological limitations, and makes recommendations for Tobacco Control programmes among adolescents in $\mathrm{SA}$ as well as for future research.

The findings of Chapters 2,3 and 4 suggest that Tobacco Control programmes must convince smokers of the benefits of non-smoking and provide them viable alternatives for the positive functions that smoking fulfils, teach them skills to resist 
peer influences and increase their self-efficacy to refrain from smoking in stressful. sociall and routine situations. Social cognitive approaches such as the I-Change Model provide an adequate explanatory framework to achieve these educational objectives for all South African adolescents.

Chapters 2, 3 and 4, however, also demonstrate that the relative weight of the motivational determinants of smoking onset and cessation were different for the ethnic groups. In-depth research is required on the extent to which cultural beliefs and distal factors motivate smoking among Black African adolescents. Even though self-efficacy was the most consistent determinant of smoking onset and cessation across the ethnic groups, White adolescents, in particular, would benefit from coping skills to resist smoking in social situations. Furthermore, the participation of the social environment, through social norms of important others and modelling, particularly among best friends, is an essential feature of smoking among Coloured adolescents. The translation of ethnic differences into programme objectives, against a backdrop of racial inequalities in $\mathrm{SA}$, requires further understanding of the extent to which these differences can be explained by factors such as socioeconomic status and poverty.

The investigation of nicotine dependence and withdrawal symptoms in Chapters 2 and 5 demonstrate that substantial percentages of adolescent smokers, even experimental smokers, experience dependence. Cognitive-behavioural approaches must be supported with skills to cope with physiological and psychological dependence. Additionally, pharmacotherapy may be also necessary for highly dependent adolescent smokers. The early appearance of signs of dependence indicates that smoking prevention and cessation cannot be viewed as mutually exclusive processes. As adolescents progress along the smoking continuum, Tobacco Control programmes must adjust their programme content to include both prevention and cessation strategies.

Chapter 6 demonstrates that adolescents have distinct preferences for the channels through which they can be accessed for Tobacco Control programmes. School-based tobacco control programmes delivered through participatory delivery formats must be augmented with out-of-school activities including communitybased mass media approaches. School smoking policies should be geared towards creating a supportive environment using educational rather than disciplinary strategies. Non-judgmental, empathetic and trusting teachers supported by peer leaders can serve as programme providers. Tobacco Control programmes can be jointly presented to boys and girls provided that some gender-sensitive sessions are held.

Chapters 2 and 6 also showed that the long-term effectiveness of school-based tobacco control programmes is dependent on the extent to which it is supported by interventions at the community and policy levels and embedded within a framework of poverty alleviation and social upliftment. Furthermore, Chapters 3,4 and 5 indicate that multi-faceted programmes addressing factors such as depression and risk behaviour may be required. 


\section{Samenvatting}

Zuid-Afrika heeft het laatste decennium belangrijke wettelijke stappen ondernomen om haar inwoners te beschermen tegen de schadelijke effecten van het gebruik van tabak. Als gevolg daarvan is het aantal rokers, zowel onder volwassenen als onder jongeren, significant afgenomen. Echter, hart- en vaatziekte, longkanker en verschillende andere tabaksgerelateerde ziekten zijn nog steeds de belangrijkste oorzaken van vroegtijdige ziekte en sterfe. Verwacht wordt dat het verder aanscherpen van de tabakswetgeving, ter bekrachtiging van de Framework Convention on Tobacco Control, zal leiden tot een groeiende interesse onder jongeren om te stoppen met roken. Om de afname van het aantal rokers voort te zetten en om vroegtijdige ziekte en sterfte te verminderen, zijn rookpreventieprogramma's, die gebaseerd zijn op wetenschappelijk onderzoek, voor jongeren noodzakelijk.

De Health Promotion Matrix en het I-Plan Modiel, twee complementaire planningsmodellen die meerdere invalshoeken toepassen, vormen een basis voor interventieontwikkeling. Het I-Change Model biedt het theoretische kader voor de studie naar motivationele determinanten van rookpreventie en stoppen met roken alsook de kanalen waarcloor jongeren benaderd kunnen worden voor rookpreventieprogramma's. In dit proefschrift worden de etnische verschillen in motivationele determinanten van het beginnen en stoppen met roken onderzocht, met als doel programma's te ontwikkelen waarbij rekening wordt gehouden met cullturele verschillen. Negen focusgroep interviews zijn uitgevoerd bij 13- en 14-jarige (grade 8-9) rokers en ex-rokers uit de zuidelijke Kaap-Karoo regio, provincie West Kaap. gevolgd door een cross-sectioneel onderzoek onder 4768 studenten (grade 9-11; 15 en 16 jaar).

Hoofdstuk 1 geeft een overzicht van Zuid-Afrika met betrekking tot ziekte- en sterftekenmerken, een mondiaal overzicht van tabaksgebruik, de geschiedenis van de tabakswetgeving in Zuid-Afrika en een beschrijving van het rookgedrag onder adolescenten. Verder geeft Hoofdstuk $\downarrow$ een beschrijving van de theoretische modellen die gebruikt zijn in het onderzoek en wordt afgesloten met een samenvatting van het project en de context waarin het onderzoek heeft plaatsgevonden. Hoofdstuk 2 van dit proefschrift bespreekt een kwalitatief onderzoek naar de determinanten van rookgedrag onder 13-en 14-jarige rokers en ex-rokers. Hoofdstuk 3 geeft een overzicht van de etnische determinanten van roken, depressiviteit en risicogedrag in een groep van maandelifkse en nietmaandelijkse rokers (grade 9-11). Hoofdstuk 4 behandelt de etnische determinanten van het stoppen met roken onder maandelijkse rokers en ex-rokers (grade 9-11). Hoofdstuk 5 beschrijft de prevalentie van en geslachtsverschillen met betrekking tot nicotineafhankelijkheid, ontwenningsverschijnselen, depressiviteit en risicogedrag tussen wekelijkse en maandelijkse rokers. Hoofdstuk 6 geeft een beschrijving van de voorkeuren die jongeren hebben voor de kanalen via welke zij. benaderd kunnen worden voor rookpreventieprogramma's. Tevens worden de belangrijkste elementen van rookpreventieprogramma's besproken. Hoofdstuk 7 geeft een samenvatting en 
bespreekt de belangrijkste bevindingen, methodologische beperkingen, en geeft zowel aanbevelingen voor rookpreventieprogramma's onder adolescenten in ZuidAfrika als aanbevelingen voor toekomstig onderzoek.

De resultaten van Hoofdstuk 2, 3 en 4 suggereren dat rookpreventieprogramma's rokers moeten overtuigen van de voordelen van het niet roken en hen uitvoerbare alternatieven dienen te geven voor de positieve effecten van roken die zij ervaren. Verder moeten deze programma's rokers vaardigheden aanleren on invloeden van leeftijdsgenoten te weerstaan en de eigen-effectiviteit verhogen om niet te roken in stressvolle, sociale en routinematige situaties. Sociaal-cognitieve benaderingen, zoals het I-Change Model, verschaffen een geschikt kader om deze voorlichtingsdoelen voor Zuid-Afrikaanse adolescenten te bereiken.

Hoofdstuk 2, 3 en 4 laten daamaast ook zien dat het relatieve belang van de motivationele determinanten van beginnen en stoppen met roken verschillend zijn voor de etnische groepen. Verder onderzoek is nodig naar de mate waarin culturele opvattingen en distale factoren roken beïnvloeden bij zwarte Afrikaanse adolescenten. Hoewel eigen-effectiviteit bij alle etnische groepen de meest consistente determinant van beginnen en stoppen met roken is, hebben blanke. adolescenten meer profijt van coping vaardigheden om niet te roken in sociale situaties. Verder speelt bij adolescenten van gemengde rassen de sociale omgeving, middels sociale normen en modeling (in het bijzonder tussen goede vrienden) een essentieel rol bij roken. In het kader van de rassenongelijkheid in Zuid-Afrika vereist de vertaling van etnische verschillen naar programmadoelen verder onderzoek naar de mate waarin deze verschillen verklaard kunnen worden door factoren zoals socio-economische status en armoede.

Het onderzoek naar nicotineafhankelijkheid en ontwenningsverschijnselen in Hoofdstuk 2 en 5 toont aan dat een aanzienlijk percentage van de adolescente rokers, zelfs experimentele rokers, afhankelijkheid ervaart. Cognitief-gedragsmatige benaderingen moeten ondersteund worden met vaardigheden die jongeren leren omgaan met lichamelijke en psychologische afhankelijkheid. Daarnaast kan voor zeer afhankelijke adolescente rokers farmacotherapie noodzakelijk zijn. Hèt vroegtijdig optreden van afhankelijkheidssymptomen toont aan dat rookpreventie en stoppen met roken niet gezien kunnen worden als onverenigbare processen. Aangezien adolescenten zich steeds in een andere fase van het rookcontinuüm bevinden, is het belangrijk dat rookpreventie-interventies hun programma-inhoud aanpassen en zowel preventiestrategieën als strategieën voor het stoppen met roken bevatten.

Hoofdstuk 6 laat zien dat adolescenten verschillende voorkeuren hebben met betrekking tot de kanalen via welke zij benaderd kunnen worden voor rookpreventieprogramma's. Rookpreventieprogramma's op scholen, waarbij de nadruk ligt op actieve participatie, moeten aangevuld worden met buitenschoolse activiteiten zoals community-based massamediale benaderingen. Het rookbeleid op scholen moet gericht zijn op het creëren van een ondersteunende omgeving waarbij gebruik wordt gemaakt van educatieve in plaats van disciplinaire strategieèn. Docenten die niet-veroordelend, empathisch en vertrouwend zijn, en daamaast ondersteund 
worden door een groepsleider uit de klas, kunnen gezien worden als degenen die het programma ten uitvoer brengen. Rookpreventieprogramma's kunnen aan jongens en meisjes gezamenlijk worden aangeboden, mits enkele seksespecifieke lessen gegewen worden.

Hoofdstuk 2 en 6 laten tevens zien dat de lange termijn effecten van rookpreventieprogramma's op scholen afhankelijk zijn van de mate waarin zij ondersteund worden door interventies op gemeenschappelijk en beleidsniveau en de mate waarin de programma's zijn ingebed in een kader van armoedevermindering en sociale verbetering. Verder tonen Hoofdstukken 3,4 en 5 aan dat programma's met meerdere componenten, gericht op factoren als depressiviteit en risicogedrag, noodzakelijk kunnen zijn. 


\section{Acknowledgements}

Many people and institutions have contributed to the completion of this thesis. I offer my sincere gratitude and appreciation to each and every one of them:

I thank my supervisors, Hein de Vries, Priscilla Reddy and Erik Bergstrom for so skillfully steering the completion of this project and for their insightful commentary. Hein, it has been an honour and a privilege to work under your expert guidance. You are a true inspiration to young scientists! Priscilla, I thank you for identifying me as a Ph.D. student and facilitating my development as a researcher. Without this, this thesis would not have been possible. Erik, silence is indeed the greater part of valour! Thank you for your vision and for your support.

I am deeply indebted to the Medical Research Council, South Africa for supporting my development as a researcher. In particular, I would like to thank the following two programmes:

1) National Health Promotion Research and Development Group for identifying me at a capacity development workshop, for supporting my scholarship application to Umea University to complete my Masters degree, for affording me the opportunity and funding to train as a research intern and for funding the research (Prof Reddy as the Director and Principal Investigator) that has culminated in this dissertation.

2) Research Development Programme for funding me through the research internship programme, for providing me with a pre-doctoral scholarship to finalise my dissertation at Maastricht University and for their financial contribution towards my travel expenses to attend the graduation ceremony.

I am grateful to Maastricht University for their financial support and their warm hospitality in hosting me at the university during the six months that I spent completing my dissertation as well as for the financial assistance to print the dissertation.

I extend my gratitude to Umea University, where my PhD was initiated, for their continued support, financial assistance and vision to bring this project to completion. I thank the Swedish International Development Cooperation Agency for funding my international travel expenses during the data analysis phases of the project and for assisting me in purchasing a laptop to write up my thesis.

I thank Child, Youth and Family Development, Human Sciences Research Council for their financial contribution towards the printing of my dissertation and for allowing me the time and space to finalise my PhD.

I am also grateful to the Study Fund Foundation for South African Students in the Netherlands for their financial assistance to attend the graduation ceremony.

I wish to acknowledge the many schools and students in South Africa who so willingly participated in the studies. I am also indebted to the research assistants who so adeptly assisted with data collection. I offer special thanks to Dr Marshall and the team of school nurses at the Department of Health in the Southern Cape-Karoo Region who facilitated access to the schools and students and assisted with data collection.

To my co-author, Rob Ruiter. You represent to me all the good that humanity can 
offer. You have been an insightful colleague and mentor and above all a wonderful friend. I have few words to express my gratitude to you.

To my co-author, Dehran Swart. We've shared many cups of tea, travelling this journey as colleagues and as PhD students. Thank you for your continued support and your faith in me over the years. I have come away with a lifelong friend.

To my paranimfen, Astrid Reubsaet and Liesbeth Osch. I am deeply indebted to you for facilitating the road to the graduation ceremony and for your support, kindness and your friendship.

To Prof. Mbewu and Prof. Stig Wall. I offer many thanks to you for your guidance and support especially during the initial phases of this project. Your invisible hands in the background have not gone unnoticed.

Muhdni Grimwood, thank you for your genius in turning my wad of pages into this $\mathbb{P}$ hD dissertation, as always under the tightest deadline!

I am indebted to the many, many colleagues and friends at the Medical Research Council, South Africa, Maastricht University, The Netherlands and Umea University, Sweden who have inspired me, offered me friendship and in one way or another supported me during the completion of this thesis. Romilla and Carol, you mentorship and your guidance have been invaluable to me. Jané, Sharon, Marshia and Fred, you made working a joy! Miranda, thank you for a home away from home. Mohammed, thank you for your friendship through the rainy days in Maastricht. Marja, you have been a star in opening up the channels to bring this thesis to completion!

To my parents, my family and my friends: There are no words to express my gratitude to you for your unconditional support and belief in me throughout this endeavour. I have been an absent daughter, sister, aunt and friend for the last few years and I appreciate your tolerance and your patience. This is as much your achievement as it is mine.

And finally to my maker, $I$ offer reverence to you for giving me the strength of character and the wisdom to bring this task to completion. 


\section{Curriculum Vitae}

Saadhna Panday was born on the 12th of April 1975 in Durban, South Africa. She matriculated from Wingen Heights Secondary School in Durban. In 1996, she obtained a Bachelor of Pharmacy Degree (cum laude) from the University of Durban-Westville, South Africa. She served her pharmacist internship at R. K. Khan Hospital in Durban. In 1999, she went on to complete a Masters Degree in Public Health at Umeå University, Sweden. From 1999 to 2003, she trained as a research intern and served as a scientist at the South African Medical Research Council. During this time she collected the data for her thesis. In 2002, she served as the project director for the first National Youth Risk Behaviour Survey in South Africa and as a co-investigator on the second Global Youth Tobacco Survey. In April 2003, she joined Afrox Healthcare as the Pharmacy Legal and Professional Specialist. Saadhna then spent six months (\|une - November 2004) at Maastricht University completing her $\mathrm{PhD}$ dissertation. She is currently employed as a researcher at the Human Sciences Research Council in South Africa. 